\title{
A Fluorescent and Switchable Rotaxane Dual Organocatalyst
}

\author{
Chak-Shing Kwan, ${ }^{a}$ Albert S. C. Chan, ${ }^{b}$ and Ken Cham-Fai Leung*a,c \\ a Department of Chemistry and Institute of Creativity, The Hong Kong Baptist University, Kowloon \\ Tong, Kowloon, Hong Kong SAR \\ ${ }^{\mathrm{b}}$ School of Pharmaceutical Sciences, Sun Yat-sen University, Guangzhou, P. R. China \\ ${ }^{\mathrm{c}}$ Institute of Molecular Functional Materials, University Grants Committee, Hong Kong SAR \\ *E-mail: cfleung@hkbu.edu.hk
}

\section{Supporting Information}




\section{Table of Contents}

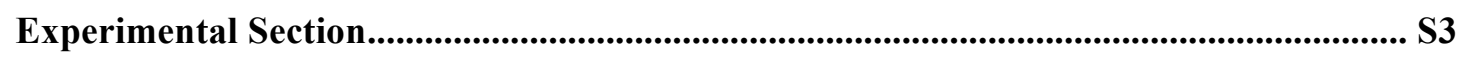

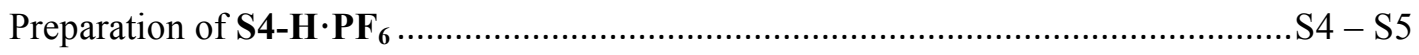

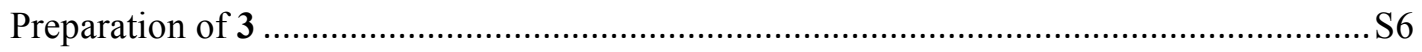

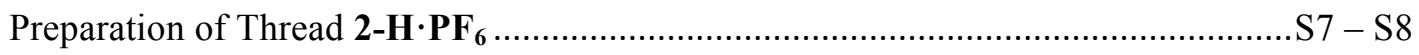



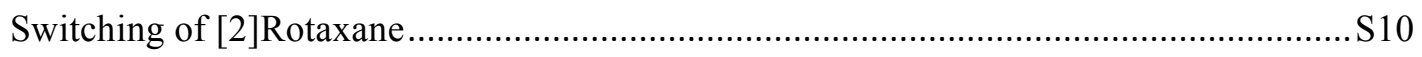

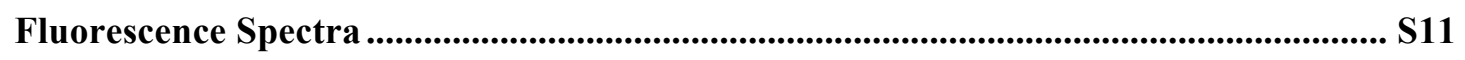

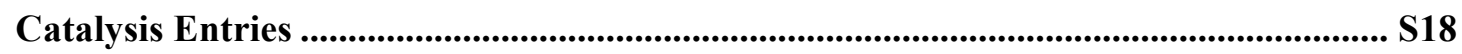

Reaction mechanism of two catalytic reactions ........................................................... 19

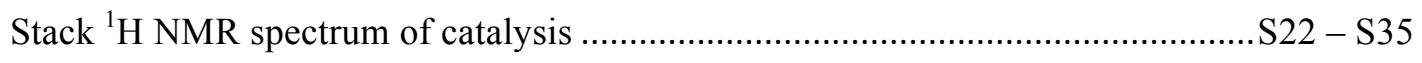

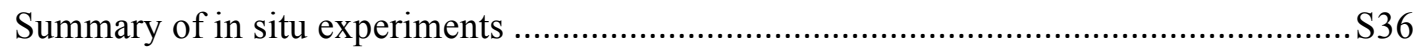

Kinetics study of selected organocatalysis .....................................................

NMR Spectra of selected compounds..........................................................................S43

Mass Spectra of selected compounds ...........................................................................S50

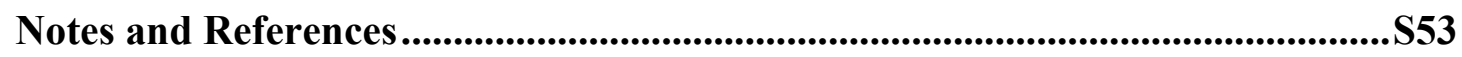




\section{Experimental Section}

\section{General Methods}

Unless otherwise noted, all the chemicals were purchased from Sigma-Aldrich and solvents were purchased commercially and used without further purification. All the reactions were conducted under anhydrous, high purity $\mathrm{N}_{2}$ atmosphere protection. Thin-layer chromatography (TLC) was performed on aluminum plate, and the plates were visualized by UV light, staining with phosphomolybdic acid or ninhydrin with heating. Column chromatography purification was performed on silica gel $\left(\mathrm{SiO}_{2}\right) 60 \mathrm{~F}$ (Merck 9385, 0.040-0.063 mm). ${ }^{1} \mathrm{H}$ NMR and ${ }^{13} \mathrm{C}$ NMR spectra characterization were recorded at $298 \mathrm{~K}$ with a spectrometer Bruker Avance-III $\left({ }^{1} \mathrm{H}: 400 \mathrm{MHz}\right.$ and ${ }^{13} \mathrm{C}$ : $101 \mathrm{MHz})$. Chemical shifts of solvent $\left(\mathrm{CDCl}_{3}, \mathrm{CD}_{3} \mathrm{CN}\right)$ were calibrated reference to the solvent residue peak $\left(\mathrm{CDCl}_{3}=7.26 \mathrm{ppm}, \mathrm{CD}_{3} \mathrm{CN}=1.94 \mathrm{ppm}\right)$. Coupling constants $(J)$ were reported in hertz $(\mathrm{Hz})$, with standard abbreviations indicating the multiplicity of the peaks $(\mathrm{s}=$ singlet, $\mathrm{d}=$ doublet, $\mathrm{t}=$ triplet, $\mathrm{q}=$ quartet, quin $=$ quintet, $\mathrm{m}=$ multiplet, $\mathrm{br}=$ broad). Melting points of the compounds were collected by Electrothermal 9100 digital melting point apparatus. High-resolution mass spectrometry was performed with Bruker Autoflex spectrometer (MALDI-TOF-MS), and Thermofinnigan MAT 95 XL spectrometer (ESI-MS). Fluorescence was measured by Perkin Elmer LS55B Luminescence Spectrometer. 


\section{Synthesis Overview}

\section{Preparation of $\mathrm{S} 4-\mathrm{H} \cdot \mathrm{PF}_{6}$}

(1)

s1

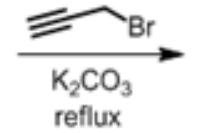

reflux<smiles>C#CCOc1ccc(C#N)cc1</smiles>

S2

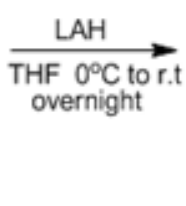

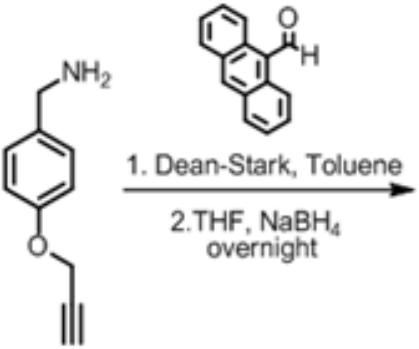

S3
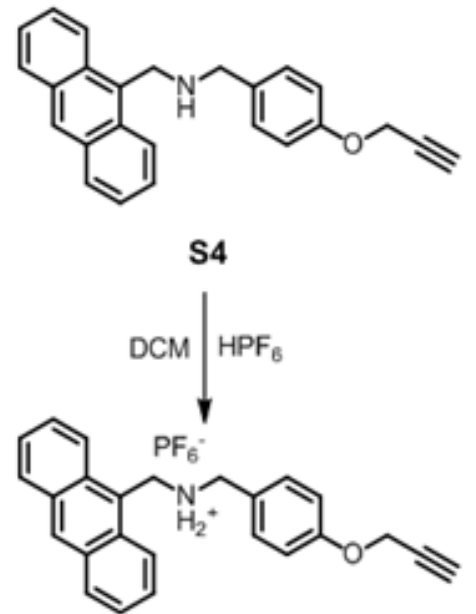

$\mathrm{S} 4-\mathrm{H} \cdot \mathrm{PF}_{6}$

\section{Scheme S1: Synthesis of S4-H·PF 6 .}

$\mathbf{S 1}$ to $\mathbf{S 3}$ were prepared according to the literature reported procedures. ${ }^{\mathrm{S} 1}$

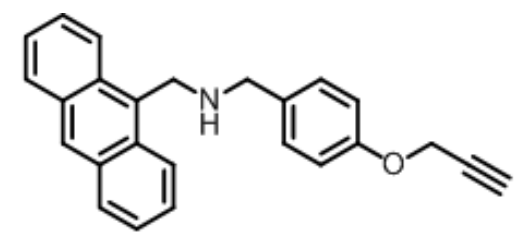

S4

\section{Synthesis of S4}

S3 (3.00 g, $18.0 \mathrm{mmol}$ ), and 9-anthracenecarboxaldehyde (3.80 g, $18.0 \mathrm{mmol})$, were dissolved in $\mathrm{MeOH}$ and refluxed overnight. Upon cooling to room temperature, yellow solid was filtered and redissolved in $\mathrm{MeOH}$. $\mathrm{NaBH}_{4}(2.80 \mathrm{~g}, 72.0 \mathrm{mmol})$ was added portionwise at $0{ }^{\circ} \mathrm{C}$, and warm to room temperature. The reaction mixture was stirred overnight. $\mathrm{H}_{2} \mathrm{O}(30 \mathrm{~mL})$ was added to quench the excess $\mathrm{NaBH}_{4}$ and the solvent was removed under reduced pressure. The suspension was extracted with DCM (3 x $100 \mathrm{~mL})$ and water. The combined organic layers were dried over anhydrous $\mathrm{MgSO}_{4}$ and concentrated under reduced pressure. The yellow solid was purified by column chromatography $\left(\mathrm{SiO}_{2} ; \mathrm{DCM}\right)$ yielding a pale yellow solid (4.23 g, 65\%). M.p. $=99{ }^{\circ} \mathrm{C} .{ }^{1} \mathrm{H}$ NMR $\left(400 \mathrm{MHz}, \mathrm{CDCl}_{3}\right) \delta 8.40(\mathrm{~s}, 1 \mathrm{H}), 8.27-8.18(\mathrm{~m}, 2 \mathrm{H})$, $8.01(\mathrm{dd}, J=8.3,1.6 \mathrm{~Hz}, 2 \mathrm{H}), 7.53-7.45(\mathrm{~m}, 4 \mathrm{H}), 7.38(\mathrm{~d}, J=8.6 \mathrm{~Hz}, 2 \mathrm{H}), 7.01(\mathrm{~d}, J$ $=8.7 \mathrm{~Hz}, 2 \mathrm{H}), 4.73(\mathrm{~d}, J=2.4 \mathrm{~Hz}, 2 \mathrm{H}), 4.68(\mathrm{~s}, 2 \mathrm{H}), 3.99(\mathrm{~s}, 2 \mathrm{H}), 2.55(\mathrm{t}, J=2.4 \mathrm{~Hz}$, 
1H). ${ }^{13} \mathrm{C}$ NMR (101 MHz, $\left.\mathrm{CDCl}_{3}\right) \delta 156.7,133.5,131.6,131.6,130.3,129.6,129.1$, 127.2, 126.1, 124.9, 124.2, 114.9, 78.7, 75.6, 55.9, 53.7, 44.8. HRMS (MALDI-TOF): $\mathrm{C}_{25} \mathrm{H}_{21} \mathrm{NO}: \mathrm{m} / z=351.1590[\mathrm{M}]^{+}$(calcd. 351.1618).

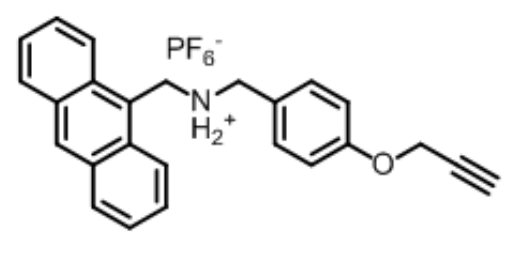

$$
\text { 1-H.PF } 6
$$

\section{Synthesis of $\mathbf{S} 4-\mathrm{H}_{\mathbf{H}} \cdot \mathrm{PF}_{\mathbf{6}}$}

S4 $(1.00 \mathrm{~g}, 2.80 \mathrm{mmol})$ was dissolved in DCM $(10 \mathrm{~mL})$, hexafluorophosphoric acid $(1.50 \mathrm{~mL})$ was added and the reaction mixture was stirred for $30 \mathrm{~min}$. Then, $\mathrm{H}_{2} \mathrm{O}(20$ $\mathrm{mL})$ was added, and the aqueous layer was extracted with DCM $(3 \times 50 \mathrm{~mL})$. The combined organic layers were dried over anhydrous $\mathrm{MgSO}_{4}$ and concentrated under reduced pressure, yielding a yellow glassy solid $(0.80 \mathrm{~g}, 57 \%)$, and was pure enough to use without further purification. ${ }^{1} \mathrm{H}$ NMR $\left(400 \mathrm{MHz}, \mathrm{CD}_{3} \mathrm{CN}\right) \delta 8.61(\mathrm{~s}, 1 \mathrm{H})$, $8.14-8.08(\mathrm{~m}, 4 \mathrm{H}), 7.62-7.51(\mathrm{~m}, 4 \mathrm{H}), 7.45(\mathrm{~d}, J=8.7 \mathrm{~Hz}, 2 \mathrm{H}), 7.05(\mathrm{~d}, J=8.7 \mathrm{~Hz}$, 2H), 4.97 (s, 2H), 4.78 (d, $J=2.4 \mathrm{~Hz}, 2 \mathrm{H}), 4.24$ (s, 2H), 2.84 (t, $J=2.4 \mathrm{~Hz}, 1 \mathrm{H})$. 


\section{Preparation of 3}

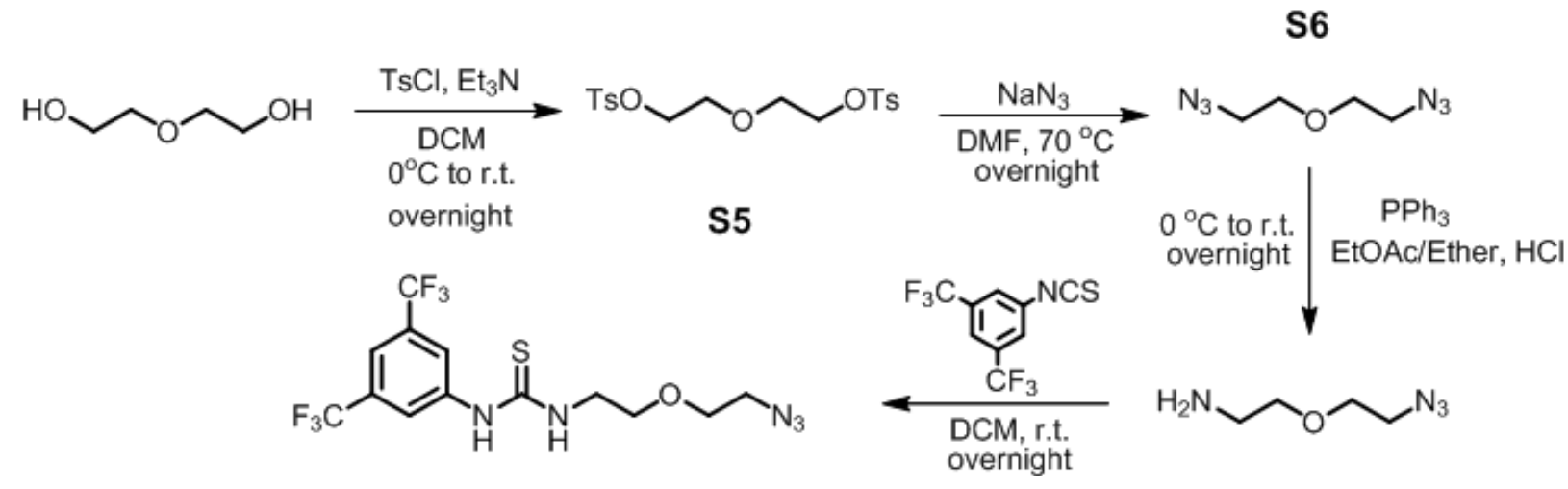

3

S7

Scheme S2: Synthesis of 3

$\mathbf{S 5}$ to $\mathbf{S 7}$ were prepared according to the literature reported procedures. ${ }^{\text {S2 }}$<smiles>N#CCOCCNC(=S)Nc1cc(C(F)(F)F)cc(C(F)(F)F)c1</smiles>

3

\section{Synthesis of 3}

S7 (5.00 g, $38.4 \mathrm{mmol}$ ) was dissolved in DCM, and 3,5-bis(trifluoromethyl)phenyl isothiocyanate $(7.00 \mathrm{~mL}, 38.4 \mathrm{mmol})$ was added dropwise and stirred at ambient temperature overnight. The solvent was removed by reduced pressure, yielding a pale yellow solid (14.2 g, $92 \%$ ), and was pure enough without further purification. M.p. = $81{ }^{\circ} \mathrm{C} .{ }^{1} \mathrm{H}$ NMR $\left(400 \mathrm{MHz}, \mathrm{CD}_{3} \mathrm{CN}\right) \delta 8.54$ (br, 1H), 8.11 (s, 2H), 7.73 (s, 1H), 7.05 (br, 1H), 3.75 (br, 2H), $3.76-3.51(\mathrm{~m}, 4 \mathrm{H}), 3.40(\mathrm{~s}, 2 \mathrm{H}) .{ }^{13} \mathrm{C} \mathrm{NMR}\left(101 \mathrm{MHz}, \mathrm{CDCl}_{3}\right)$ $\delta 181.4,140.8,130.8\left(\mathrm{q}, J_{\mathrm{CF}}=32.3 \mathrm{~Hz}\right.$ ), 124.4, 123.2, 121.7, 69.1, 50.2, 43.9. HRMS (MALDI-TOF): $\mathrm{C}_{13} \mathrm{H}_{13} \mathrm{~F}_{6} \mathrm{~N}_{5} \mathrm{OS}: m / z=402.0823[\mathrm{M}]^{+}$(calcd. 402.0818). 


\section{Preparation of Thread $2-\mathrm{H} \cdot \mathbf{P F}_{6}$}

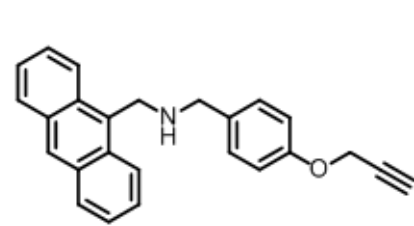

S4

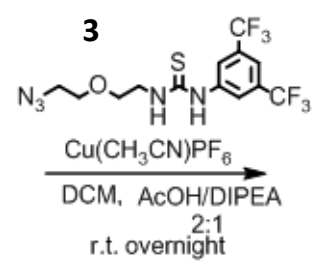

r.t. overnight

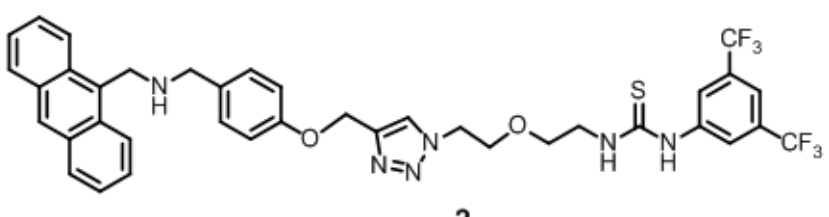

2

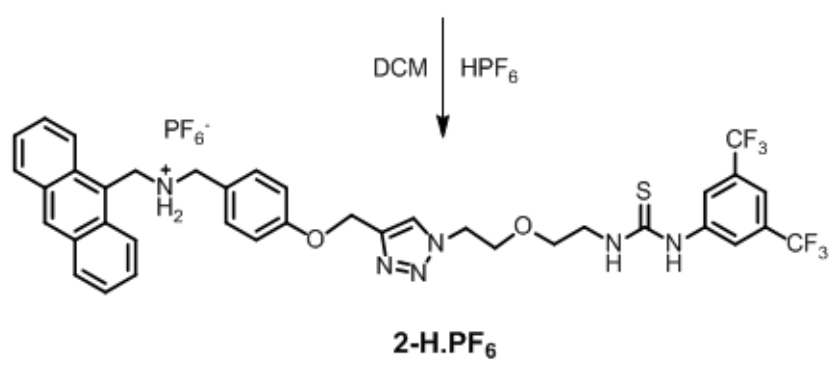

Scheme S3: Synthesis of Thread 2-H·PF 6<smiles>FC(F)(F)c1cc(NC(=S)NCCOCCn2cc(COc3ccc(CNCc4c5ccccc5cc5ccccc45)cc3)nn2)cc(C(F)(F)F)c1</smiles>

\section{Synthesis of Thread 2}

S4 (300 $\mathrm{mg}, 0.85 \mathrm{mmol})$ and 3 (350 $\mathrm{mg}, 0.85 \mathrm{mmol})$ was dissolved in degassed DCM $(5 \mathrm{~mL}), \mathrm{Cu}\left(\mathrm{CH}_{3} \mathrm{CN}\right)_{4} \mathrm{PF}_{6}(320 \mathrm{mg}, 0.85 \mathrm{mmol})$ and DIPEA $(140 \mu \mathrm{L}, 0.85 \mathrm{mmol})$, were added to the reaction mixture, and stirred overnight at ambient temperature. After that, DCM was added to dilute the reaction mixture, and was washed with $\mathrm{NaCN}$ solution. The aqueous layer was extracted with DCM twice. The combined organic layers were dried over anhydrous $\mathrm{MgSO}_{4}$ were concentrated under reduced pressure. The residue was purified by column chromatography $\left(\mathrm{SiO}_{2} ; \mathrm{EtOAc}\right)$ yielding a yellow solid (300 mg, 47\%). M.p. $=93{ }^{\circ} \mathrm{C} .{ }^{1} \mathrm{H} \mathrm{NMR}\left(400 \mathrm{MHz}, \mathrm{CD}_{3} \mathrm{CN}\right) \delta$ $8.45(\mathrm{~s}, 1 \mathrm{H}), 8.31-8.23(\mathrm{~m}, 2 \mathrm{H}), 8.14(\mathrm{~s}, 2 \mathrm{H}), 8.02$ (dd, $J=6.7,2.8 \mathrm{~Hz}, 2 \mathrm{H}), 7.93$ (s, 1H), 7.69 (s, 1H), $7.53-7.43(\mathrm{~m}, 4 \mathrm{H}), 7.32$ (d, $J=8.5 \mathrm{~Hz}, 2 \mathrm{H}), 7.13(\mathrm{~s}, 1 \mathrm{H}), 6.96$ (d, $J=8.6 \mathrm{~Hz}, 2 \mathrm{H}), 5.14(\mathrm{~s}, 2 \mathrm{H}), 4.59(\mathrm{~s}, 2 \mathrm{H}), 4.56-4.50(\mathrm{~m}, 2 \mathrm{H}), 3.92(\mathrm{~s}, 2 \mathrm{H}), 3.89-$ $3.81(\mathrm{~m}, 2 \mathrm{H}), 3.64(\mathrm{br}, 2 \mathrm{H}), 3.59(\mathrm{t}, \mathrm{J}=4.5 \mathrm{~Hz}, 2 \mathrm{H})$ (missing of one thiourea proton peak). ${ }^{13} \mathrm{C}$ NMR (101 MHz, $\left.\mathrm{CD}_{3} \mathrm{CN}\right) \delta 181.1,157.0,143.3,141.0,133.3,131.9$, $131.2,130.9,130.5,129.9,129.2,128.5,126.5,125.5,124.7,124.4,124.3,122.8$, $121.7,114.3,68.5,61.1,52.8,49.6,44.3,43.6$ (1 peak is missing/overlapping). HRMS (ESI): $\mathrm{C}_{38} \mathrm{H}_{34} \mathrm{~F}_{6} \mathrm{~N}_{6} \mathrm{O}_{2} \mathrm{~S}: m / z=753.2440[\mathrm{M}+\mathrm{H}]^{+}$(calcd. 753.2368). 


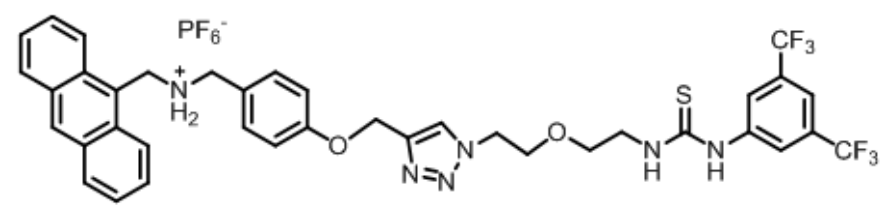

2-H.PF 6

\section{Synthesis of Thread $2-\mathrm{H} \cdot \mathbf{P F}_{6}$}

Thread 2 (100 mg, $0.13 \mathrm{mmol})$ was dissolved in DCM $(8 \mathrm{~mL})$, hexafluorophosphoric acid $(1 \mathrm{~mL})$ was added and the reaction mixture was stirred for 30 mins. Then, $\mathrm{H}_{2} \mathrm{O}$ $(20 \mathrm{~mL})$ was added, and the aqueous layer was extracted with DCM $(3 \times 50 \mathrm{~mL})$. The combined organic layers were dried over anhydrous $\mathrm{MgSO}_{4}$ and concentrated under reduced pressure, yielding a yellow glassy solid, and was pure enough without further purification (70 mg, $60 \%$ ). ${ }^{1} \mathrm{H}$ NMR (400 MHz, $\left.\mathrm{CD}_{3} \mathrm{CN}\right) \delta 8.72(\mathrm{~s}, 1 \mathrm{H}), 8.62(\mathrm{~s}, 1 \mathrm{H})$, $8.14(\mathrm{~d}, \mathrm{~J}=7.2 \mathrm{~Hz}, 4 \mathrm{H}), 8.08$ (d, J = 8.7 Hz, 2H), 7.97 (s, 1H), 7.70 (s, 1H), $7.66-$ 7.55 (m, 4H), 7.47 (d, J = 8.6 Hz, 2H), 7.08 (d, J = 8.7 Hz, 2H), 5.20 (s, 2H), 5.18 (s, $2 \mathrm{H}), 4.57-4.52(\mathrm{~m}, 2 \mathrm{H}), 4.43(\mathrm{~s}, 2 \mathrm{H}), 3.90-3.82(\mathrm{~m}, 2 \mathrm{H}), 3.65(\mathrm{~s}, 2 \mathrm{H}), 3.61(\mathrm{~d}, \mathrm{~J}=$ $4.3 \mathrm{~Hz}, 2 \mathrm{H})$. (missing one thiourea proton peak). 


\section{Preparation of Rotaxane $\mathbf{1 - H} \cdot \mathbf{P F}_{6}$}
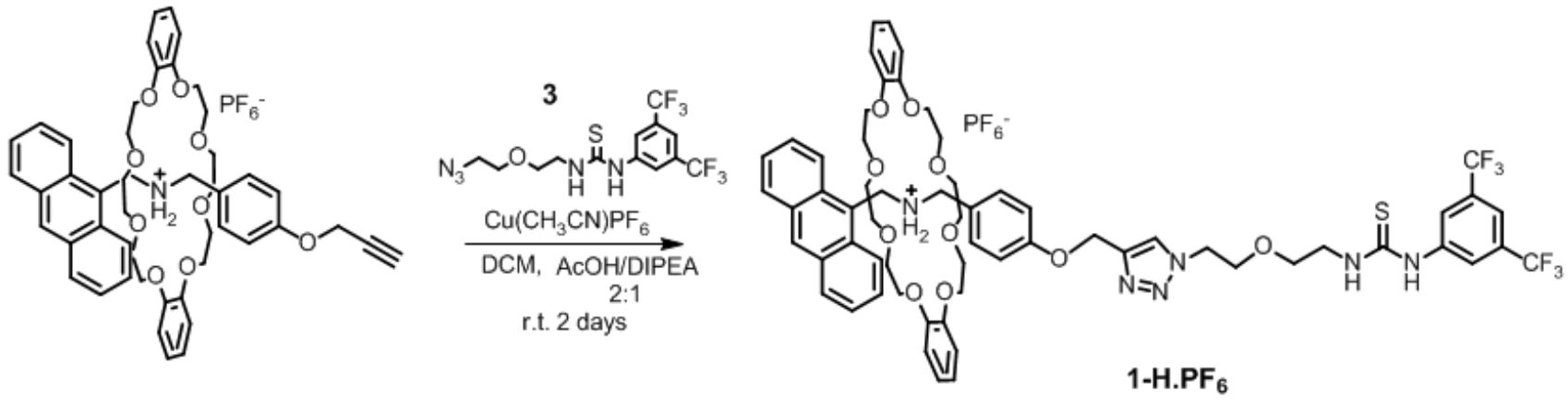

Scheme S4: Synthesis of Rotaxane 1-H·PF 6

\section{Synthesis of Rotaxane $1-H_{1} \cdot \mathbf{P F}_{6}$}

S4-H·PF 6 (500 mg, $1.0 \mathrm{mmol})$ and DB24C8 (450 mg, $1.0 \mathrm{mmol})$ were dissolved in degassed DCM ( $8 \mathrm{~mL}$ ), and stirred for 1 hour at ambient temperature. 3 (400 mg, 1.0 mmol), $\mathrm{Cu}\left(\mathrm{CH}_{3} \mathrm{CN}\right)_{4} \mathrm{PF}_{6}(370 \mathrm{mg}, 1.0 \mathrm{mmol})$, premixed $\mathrm{AcOH}(70 \mu \mathrm{L}, 1.22 \mathrm{mmol})$ and DIPEA $(106 \mu \mathrm{L}, 0.61 \mathrm{mmol})$ in DCM $(0.5 \mathrm{~mL})$ were added to the reaction mixture, and stirred for 2 days at ambient temperature. After that, DCM (30 mL) was added to dilute the reaction mixture, and was washed with $\mathrm{NaCN}$ solution. Then, the reaction mixture was reprotonated by $\mathrm{AcOH}(2 \mathrm{~mL})$, and final washed with $\mathrm{NH}_{4} \mathrm{PF}_{6}$ solution $(20 \mathrm{~mL}, 2 \mathrm{M})$. The combined organic layers were dried over anhydrous $\mathrm{MgSO}_{4}$ and concentrated under reduced pressure. The residue was purified by column chromatography $\left(\mathrm{SiO}_{2}\right.$; EtOAc, then Acetone, then to Acetone with $\mathrm{NH}_{4} \mathrm{PF}_{6}(0.30$ $\left.\mathrm{gL}^{-1}\right)$ ) yielding a pale yellow glassy solid (800 mg, 59\%). M.p. $=122{ }^{\circ} \mathrm{C} .{ }^{1} \mathrm{H} \mathrm{NMR}$ $\left(400 \mathrm{MHz}, \mathrm{CD}_{3} \mathrm{CN}\right) \delta 8.62(\mathrm{~s}, 1 \mathrm{H}), 8.47(\mathrm{~d}, J=8.9 \mathrm{~Hz}, 2 \mathrm{H}), 8.15(\mathrm{~d}, J=11.4 \mathrm{~Hz}, 3 \mathrm{H})$, 7.95 (s, 1H), 7.86 (d, $J=8.4 \mathrm{~Hz}, 2 \mathrm{H}), 7.70$ (s, 1H), 7.59 (ddd, $J=8.8,5.0,1.1 \mathrm{~Hz}$, 2H), $7.49-7.42(\mathrm{~m}, 4 \mathrm{H}), 6.95(\mathrm{~d}, J=8.8 \mathrm{~Hz}, 2 \mathrm{H}), 6.64-6.60(\mathrm{~m}, 4 \mathrm{H}), 6.37-6.32$ (m, 4H), $5.55(\mathrm{t}, J=6.8 \mathrm{~Hz}, 2 \mathrm{H}), 5.21(\mathrm{t}, J=7.2 \mathrm{~Hz}, 2 \mathrm{H}), 5.09(\mathrm{~s}, 2 \mathrm{H}), 4.55(\mathrm{br}, 2 \mathrm{H})$, $3.87(\mathrm{~s}, 2 \mathrm{H}), 3.84-3.77(\mathrm{~m}, 6 \mathrm{H}), 3.77-3.70(\mathrm{~m}, 6 \mathrm{H}), 3.68-3.63(\mathrm{~m}, 11 \mathrm{H}), 3.46-$ $3.38(\mathrm{~m}, 4 \mathrm{H})$ (missing of one thiourea proton peak). ${ }^{13} \mathrm{C} \mathrm{NMR}\left(101 \mathrm{MHz}, \mathrm{CD}_{3} \mathrm{CN}\right) \delta$ $181.1,173.1,157.9,153.9,146.3,142.7,141.2$, 130.4, 130.2, 129.0, 128.5, 126.8, $125.4,124.7,124.4,124.2,123.6,122.7,122.4,121.2,120.7,114.4,111.5,70.5,69.9$, 68.4, 67.5, 61.1, 51.9, 49.6, 44.8, 43.7 (a peak is missing/overlapping). HRMS (ESI): $\mathrm{C}_{62} \mathrm{H}_{67} \mathrm{~F}_{6} \mathrm{~N}_{6} \mathrm{O}_{10} \mathrm{~S}^{+}: \mathrm{m} / \mathrm{z}=1201.4571\left[\mathrm{M}-\mathrm{PF}_{6}\right]^{+}$(calcd. 1201.4538). 


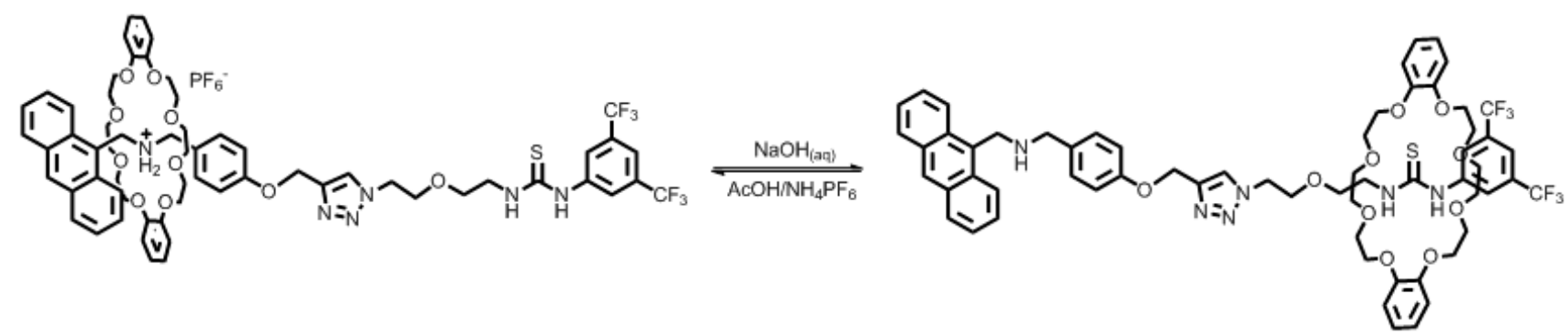

Scheme S5: Acid-base switching of Rotaxane 1-H·PF 6 and Rotaxane 1

Deprotonation: $\mathbf{1}-\mathbf{H} \cdot \mathbf{P F}_{\mathbf{6}}(50 \mathrm{mg}, 0.37 \mathrm{mmol})$ was dissolved in DCM $(5 \mathrm{~mL}), \mathrm{NaOH}$ solution $(2 \mathrm{M}, 5 \mathrm{~mL})$ was then added to the reaction mixture and was stirred for one hour at ambient temperature. Two layers were separated, and the aqueous layer was extracted with DCM twice. The combined organic layer were dried over anhydrous $\mathrm{MgSO}_{4}$ and concentrated under reduced pressure, yielding a pale yellow glassy solid. (40 mg, quantitative).

Reprotonation: 1 (40 mg, $0.33 \mathrm{mmol})$ was dissolved in DCM (5.00 mL), glacial $\mathrm{AcOH}(2.00 \mathrm{~mL})$ was added to the reaction mixture and was stirred for one hour at ambient temperature. After that, water and $\mathrm{NH}_{4} \mathrm{PF}_{6}(0.10 \mathrm{~g})$ was added, the reaction mixture was stirred for 30 minutes. Two layers were separated, and the aqueous layer was extracted with DCM twice. The combined organic layer were dried over anhydrous $\mathrm{MgSO}_{4}$ and concentrated under reduced pressure, yielding a pale yellow glassy solid. (40 mg, quantitative). 


\section{Fluorescence Spectra}

The measurement of fluorescence was performed in quartz cells using acetonitrile $(\mathrm{MeCN})$ as solvent. Concentration of the analyte was $1 \times 10^{-6} \mathrm{M}$, and the excitation wavelength was $368 \mathrm{~nm}$.

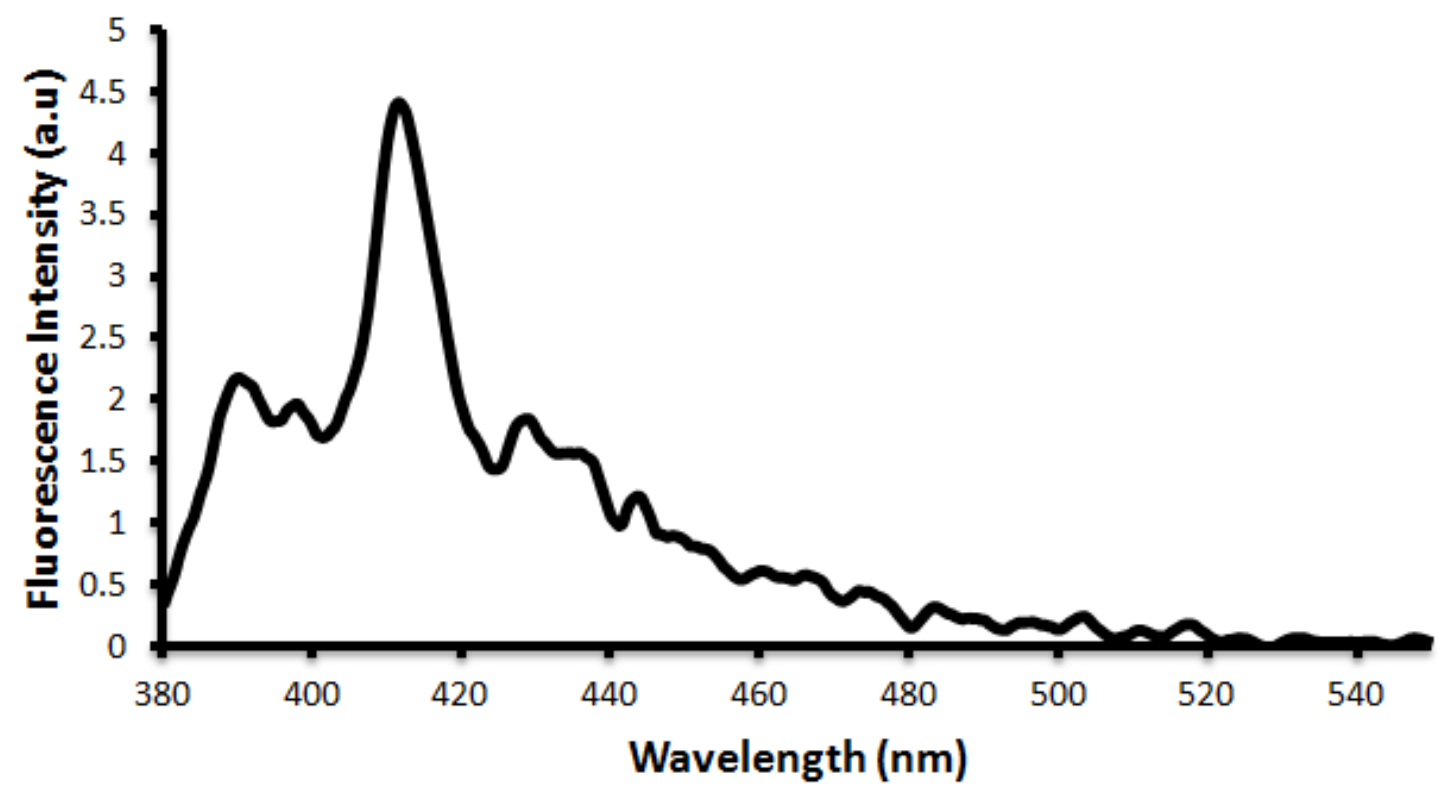

Figure S1 Fluorescence spectrum of rotaxane $1-\mathrm{H} \cdot \mathrm{PF}_{6}$ dissolving only in absolute TEA.

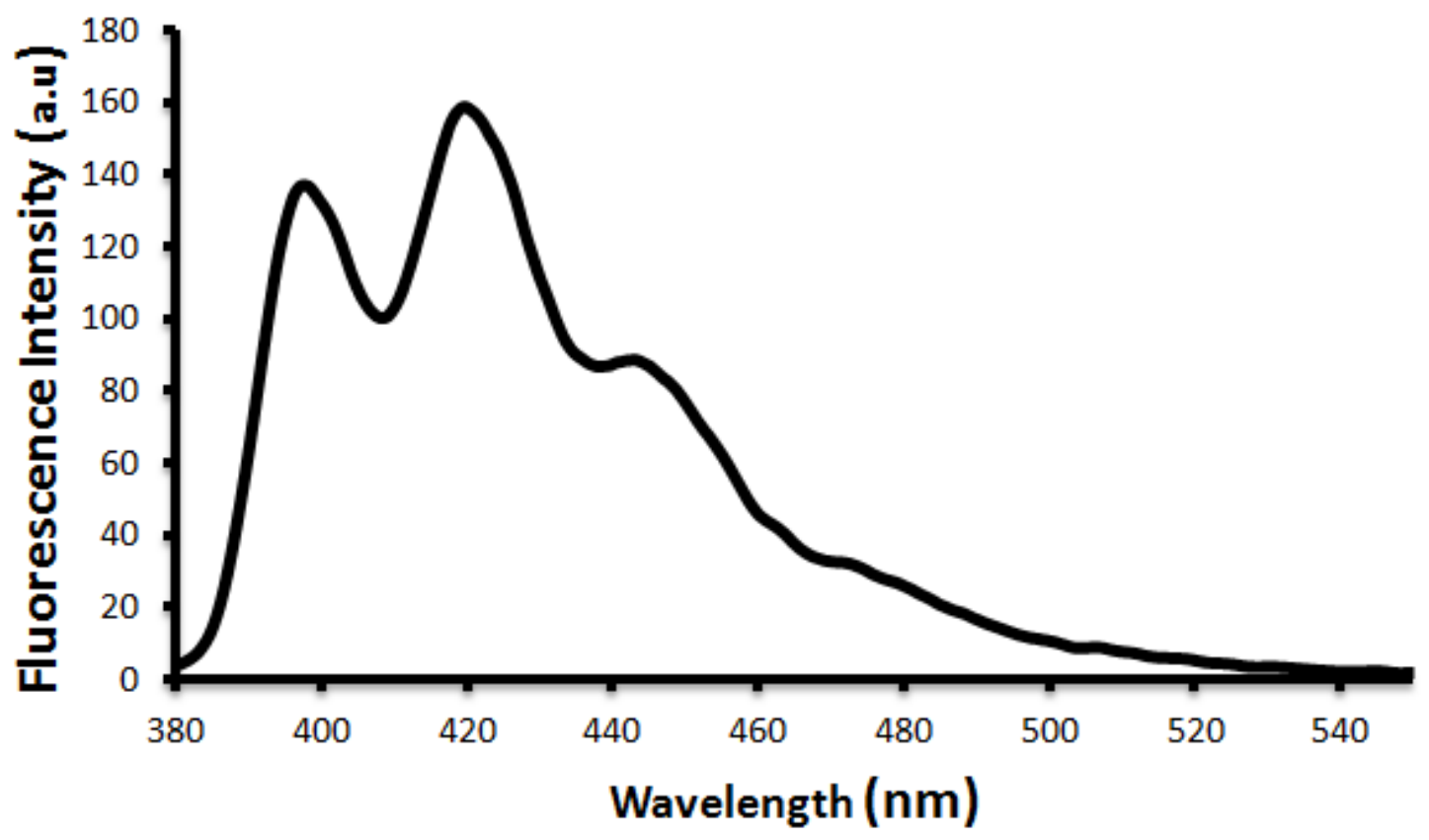

Figure S2 Fluorescence spectrum of rotaxane $\mathbf{1}$ dissolving only in absolute AcOH. 


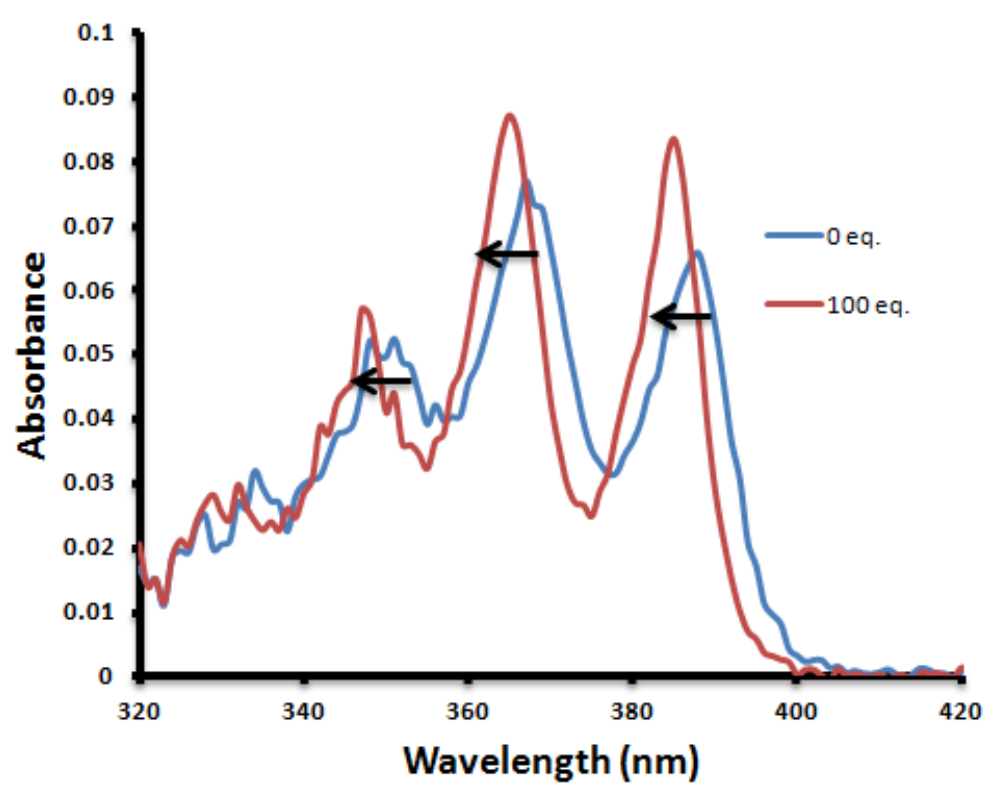

Figure $\boldsymbol{S 3} \mathrm{UV} / \mathrm{Vis}$ spectrum of rotaxane $\mathbf{1}-\mathrm{H} \cdot \mathrm{PF}_{6}$ in $\mathrm{CH}_{3} \mathrm{CN}$ with addition of 100 eq. of TEA. A blue shift was observed.

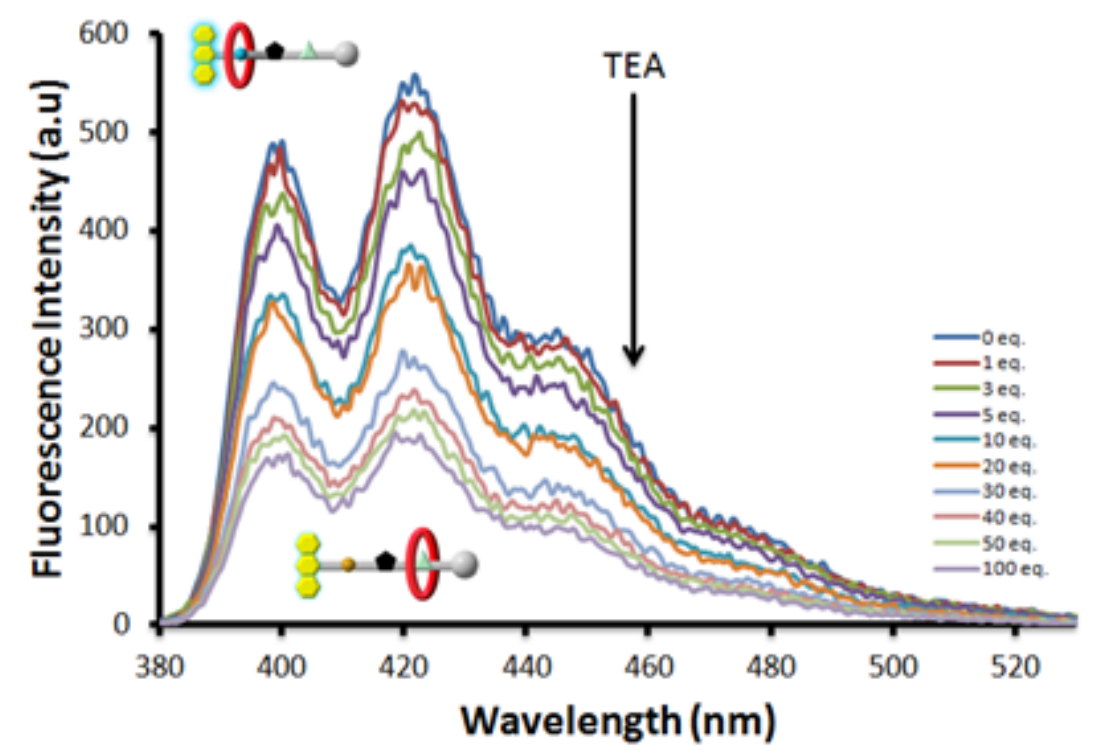

Figure $S 4$ Fluorescence spectrum of rotaxane $1-\mathrm{H} \cdot \mathrm{PF}_{6}\left(\lambda_{\mathrm{exc}}=368 \mathrm{~nm}, 1 \times 10^{-6} \mathrm{M}\right)$ in $\mathrm{CH}_{3} \mathrm{CN}$ with addition of various equivalents TEA ( 0 to 100 equiv). 


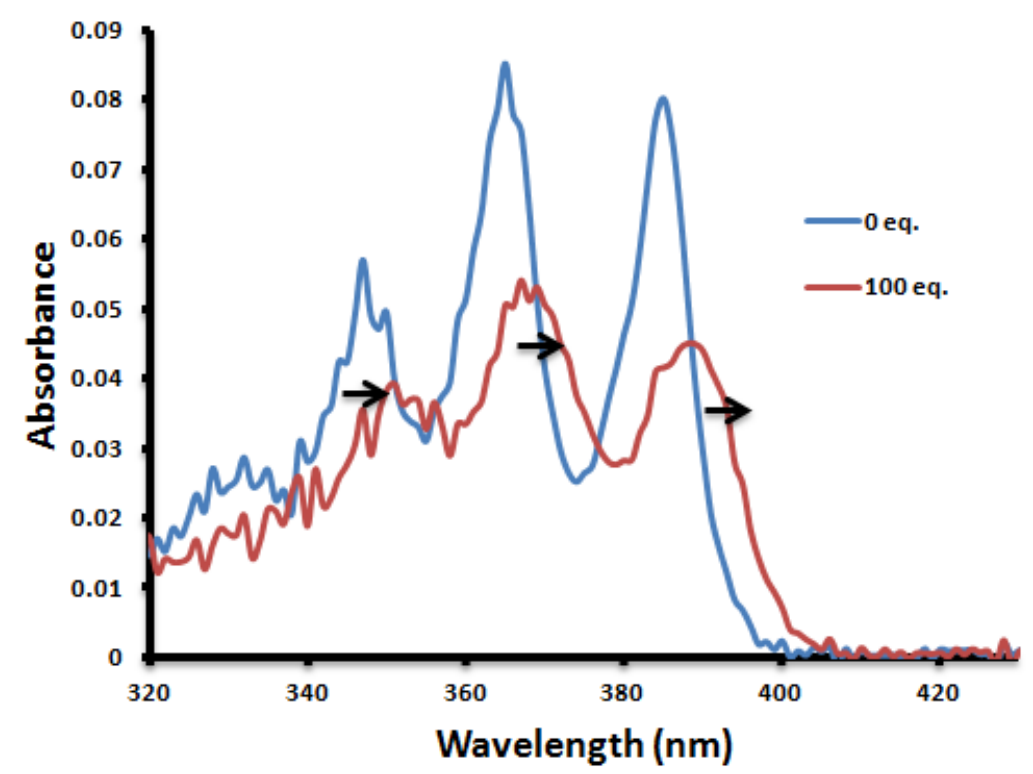

Figure S5 UV/Vis spectrum of rotaxane 1 in $\mathrm{CH}_{3} \mathrm{CN}$ with addition of 100 eq. of AcOH. A red shift was observed.

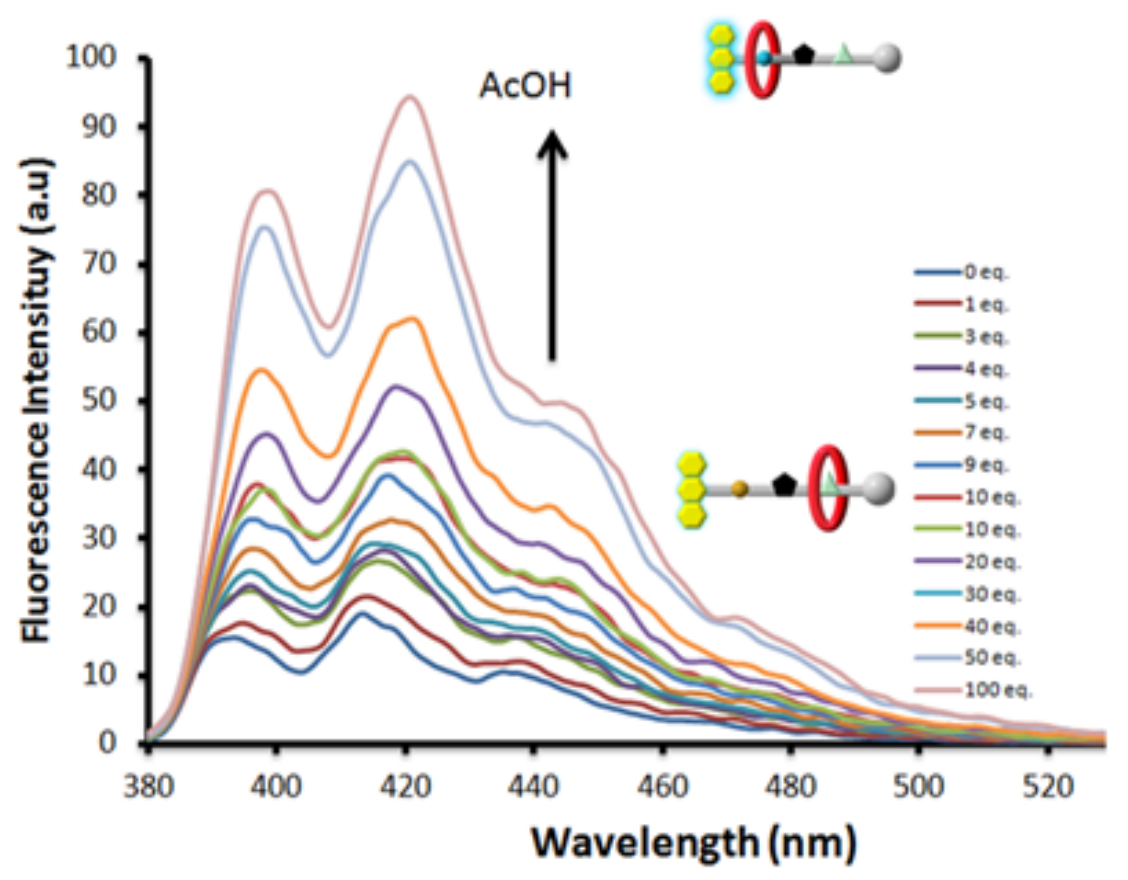

Figure S6 Fluorescence spectrum of rotaxane $1\left(\lambda_{\mathrm{exc}}=368 \mathrm{~nm}, 1 \times 10^{-6} \mathrm{M}\right)$ in $\mathrm{CH}_{3} \mathrm{CN}$ with addition of various equivalents $\mathrm{AcOH}$ ( 0 to 100 equiv). 


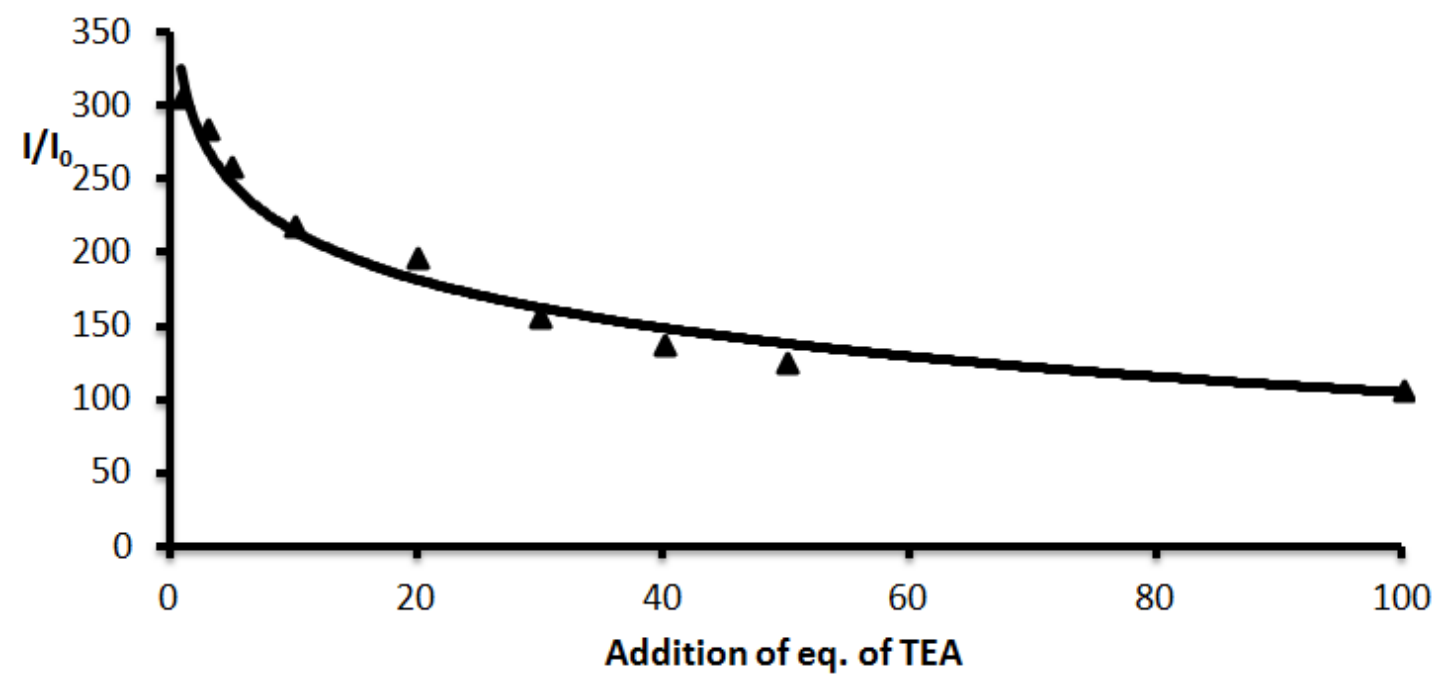

Figure $\boldsymbol{S} 7$ The plot of the relative fluorescence intensity $\mathrm{I} / \mathrm{I}_{\mathrm{o}}$ at $421 \mathrm{~nm}$ after the addition of TEA to $1-\mathrm{H} \cdot \mathrm{PF}_{6}$.

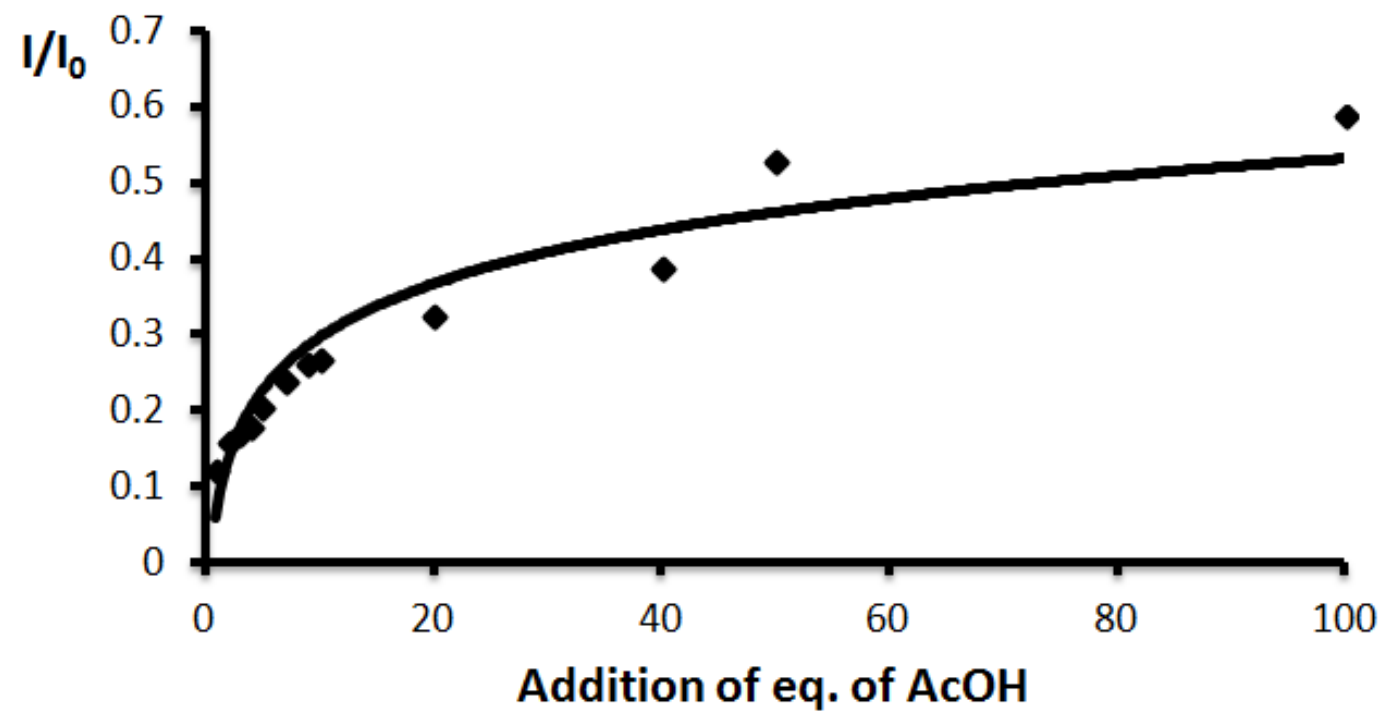

Figure $\boldsymbol{S 8}$ The plot of the relative fluorescence intensity $\mathrm{I} / \mathrm{I}_{\mathrm{o}}$ at $421 \mathrm{~nm}$ after the addition of $\mathrm{AcOH}$ to 1. 


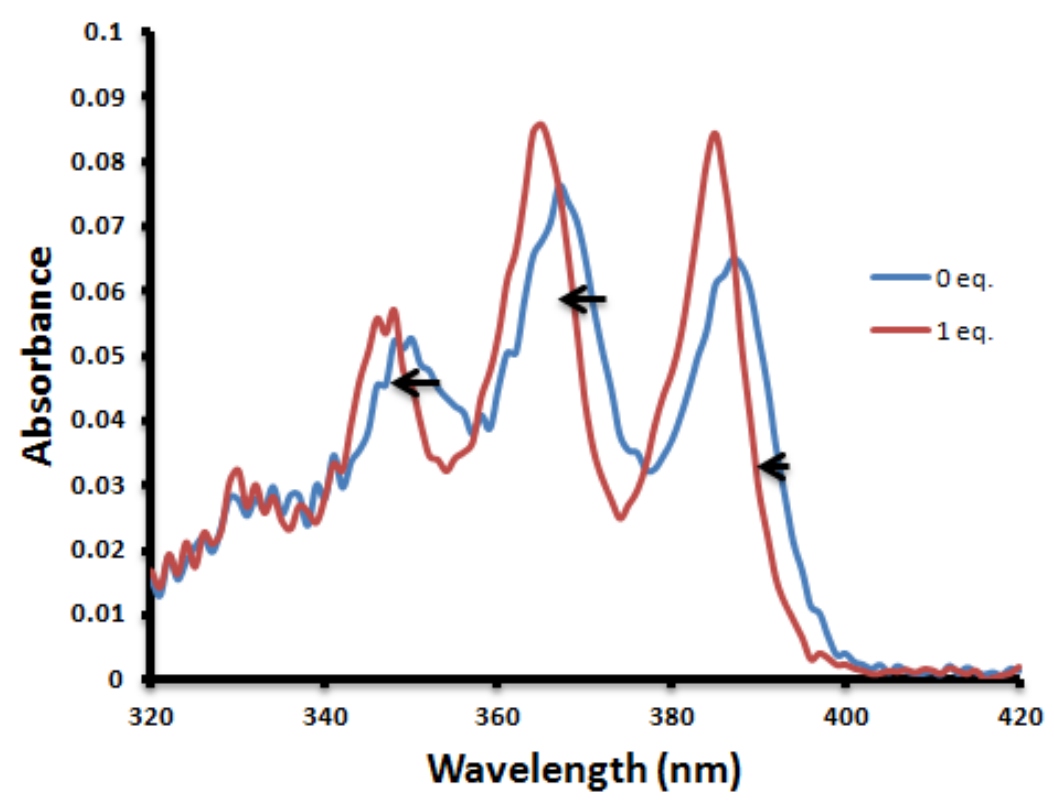

Figure $\mathbf{S 9} \mathrm{UV} / \mathrm{Vis}$ spectrum of thread $2-\mathrm{H} \cdot \mathrm{PF}_{6}$ in $\mathrm{CH}_{3} \mathrm{CN}$ with addition of 1 eq. of TEA. A blue shift was observed.

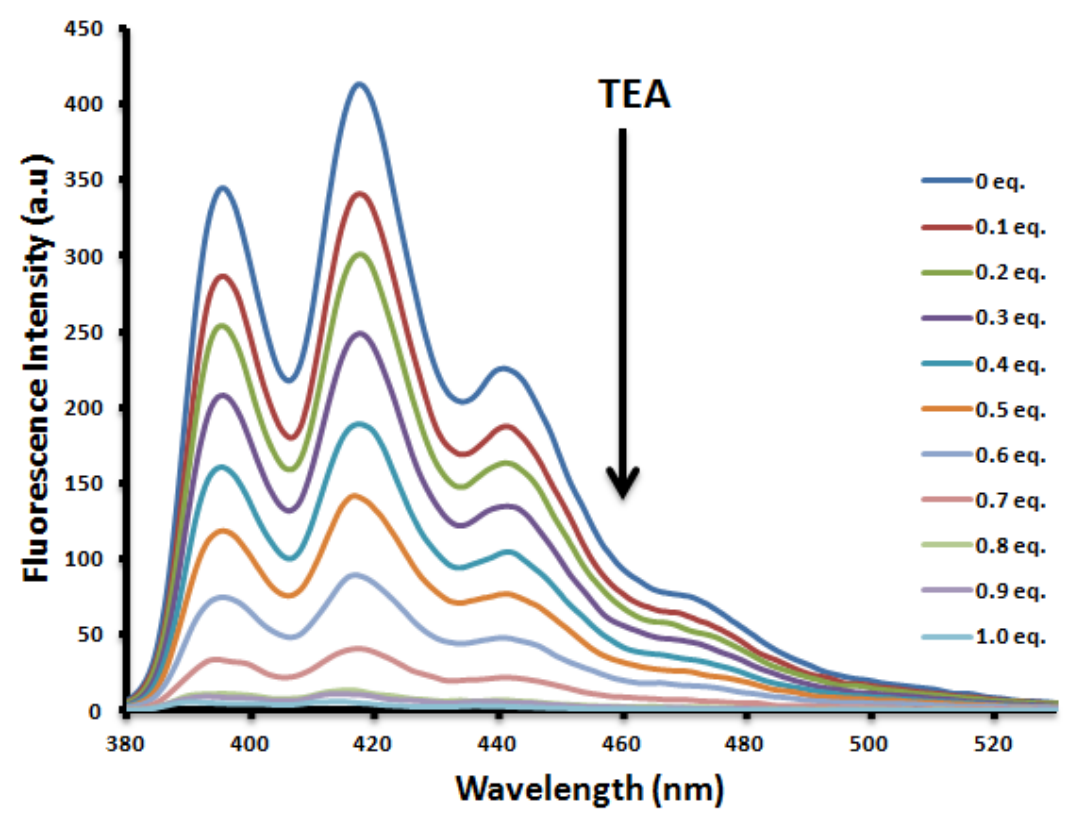

Figure S10 Fluorescence spectrum of thread $2-\mathrm{H} \cdot \mathrm{PF}_{6}\left(\lambda_{\mathrm{exc}}=368 \mathrm{~nm}, 1 \times 10^{-5} \mathrm{M}\right)$ in $\mathrm{CH}_{3} \mathrm{CN}$ with addition of various equivalents TEA ( 0 to 1 equiv). 


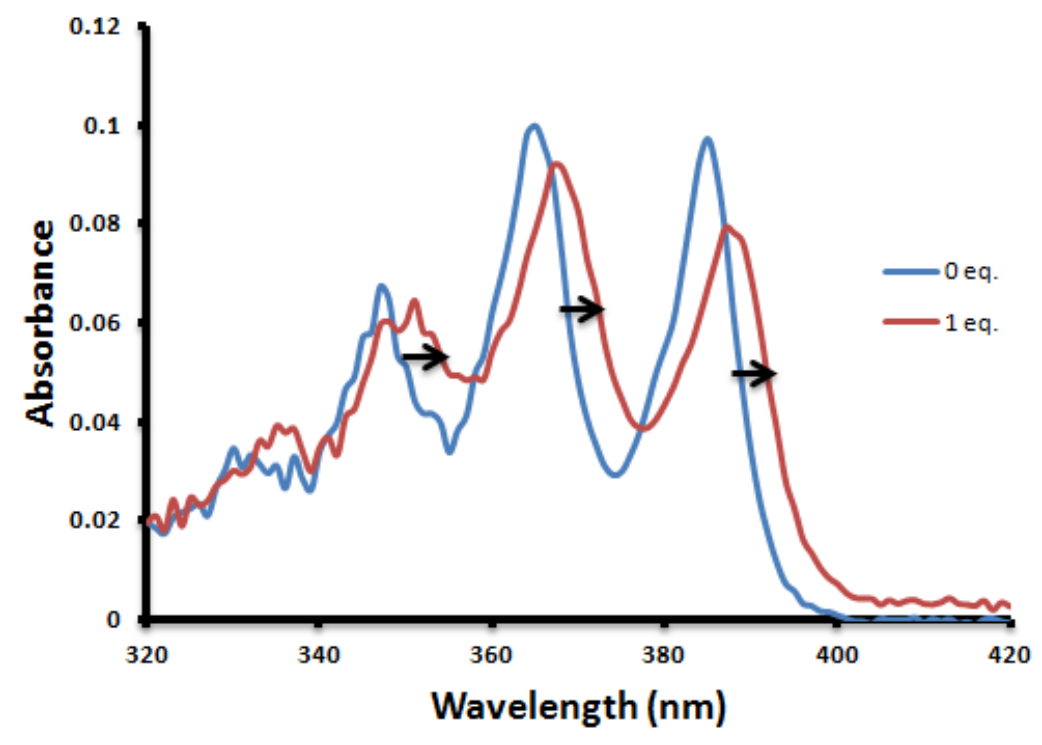

Figure S11 UV/Vis spectrum of thread 2 in $\mathrm{CH}_{3} \mathrm{CN}$ with addition of 1 eq. of TFA. A red shift was observed.

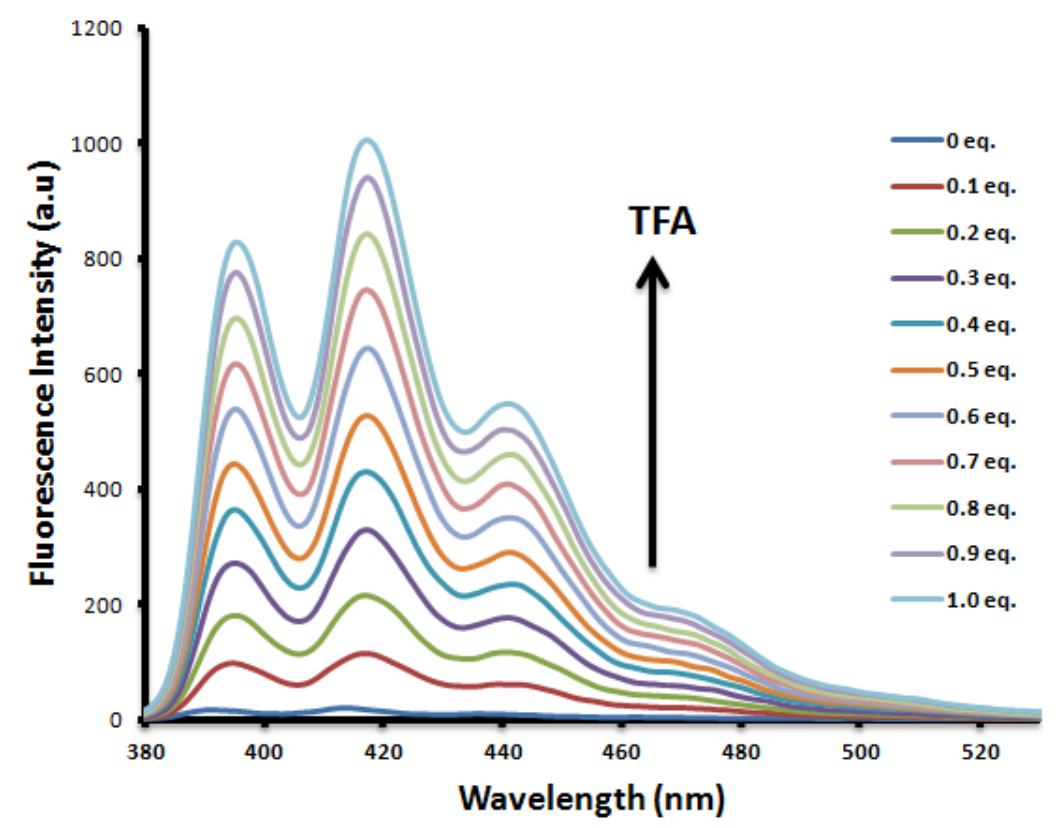

Figure S12 Fluorescence spectrum of thread $2\left(\lambda_{\text {exc }}=368 \mathrm{~nm}, 1 \times 10^{-5} \mathrm{M}\right)$ in $\mathrm{CH}_{3} \mathrm{CN}$ with addition of various equivalents TFA ( 0 to 1 equiv).

The red-shift of anthracene bands of rotaxane $\mathbf{1}$ and thread $\mathbf{2}$ in UV-Vis upon addition of acid, and the blue-shift of rotaxane $1-\mathrm{H} \cdot \mathrm{PF}_{6}$ and thread $2-\mathrm{H} \cdot \mathrm{PF}_{6}$ upon addition of base were in agreement with the literature report. ${ }^{\mathrm{S} 7}$ 


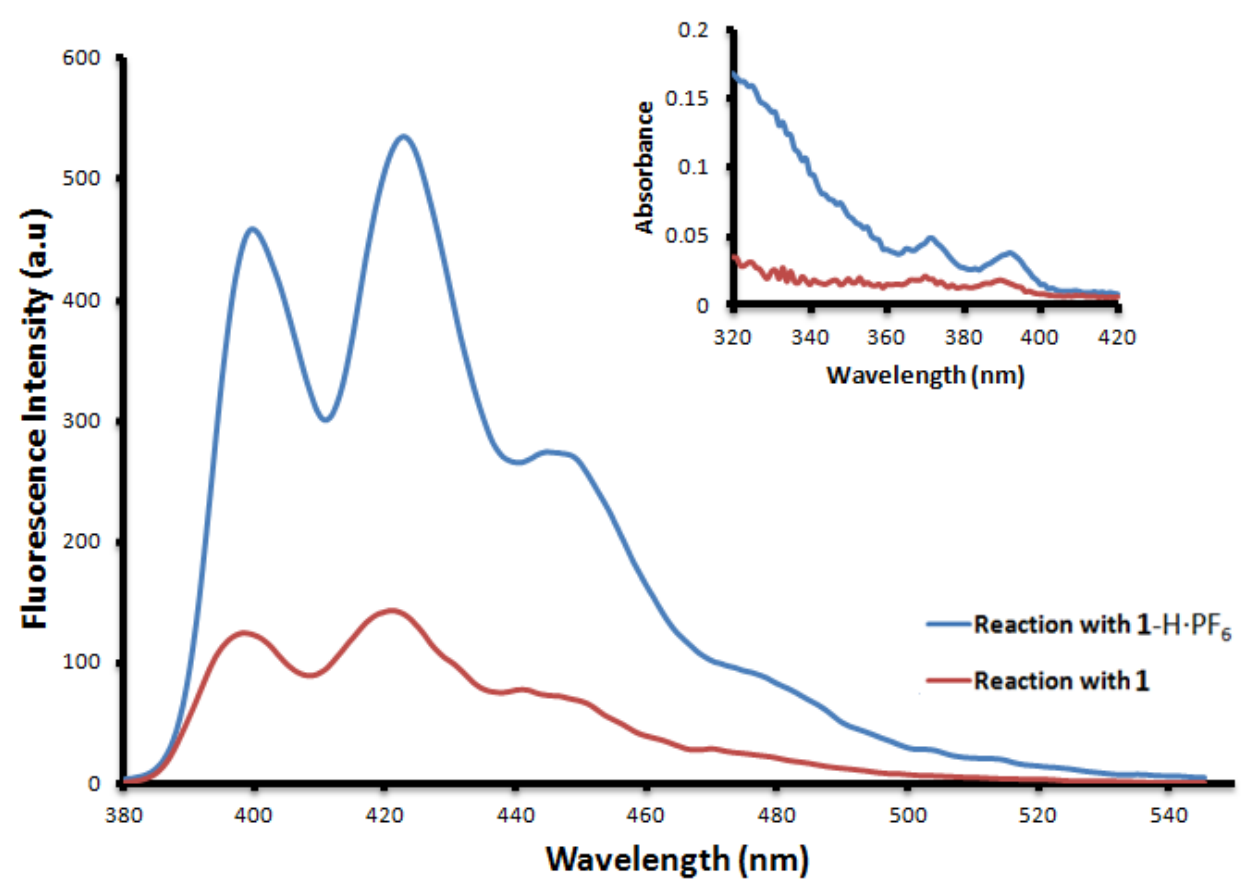

Figure S13 Fluorescence spectrum of $1-\mathrm{H} \cdot \mathrm{PF}_{6}$ and 1 in the catalytic reaction entry 5 and $6\left(\lambda_{\text {exc }}=368 \mathrm{~nm}, 1 \times 10^{-5} \mathrm{M}\right)$ in $\mathrm{CH}_{2} \mathrm{Cl}_{2}$. Insert: $\mathrm{UV} / \mathrm{V}$ is spectrum of $1-\mathrm{H} \cdot \mathrm{PF}_{6}$ and 1 in the reaction entry 5 and 6 . 


\section{Catalysis Entries}

\section{General procedure for catalytic entry}

Catalyst (1, $\mathbf{1}-\mathrm{H} \cdot \mathrm{PF}_{6}$ or $\mathbf{2}-\mathrm{H} \cdot \mathrm{PF}_{6}(15 \mu \mathrm{mol}, 0.15$ equiv. $\left.)\right)$, acetylacetone (A)/ dibenzoylmethane (B) $(0.1 \mathrm{mmol}, 2$ equiv.), trans- $\beta$-nitrostyrene (C) $(0.05 \mathrm{mmol}, 1$ equiv.), (E)-crotonaldehyde (D) $(0.1 \mathrm{mmol}, 2$ equiv.) and $\mathrm{NaOAc}(20 \mu \mathrm{mol}, 0.2$ equiv.) were dissolved in $125 \mu \mathrm{L}$ of $\mathrm{CH}_{2} \mathrm{Cl}_{2}$, stirring for 5 days at ambient temperature in an ordinary vial. Sodium acetate is a weak base to activate the 1,3-diketone derivative $\mathbf{A}$ or B. The reaction progress of was monitored and analyzed by ${ }^{1} \mathrm{H}$ NMR spectroscopy, by taking out $1 \mu \mathrm{L}$ of the reaction mixture, diluting with $600 \mu \mathrm{L}$ of $\mathrm{CDCl}_{3}$. 

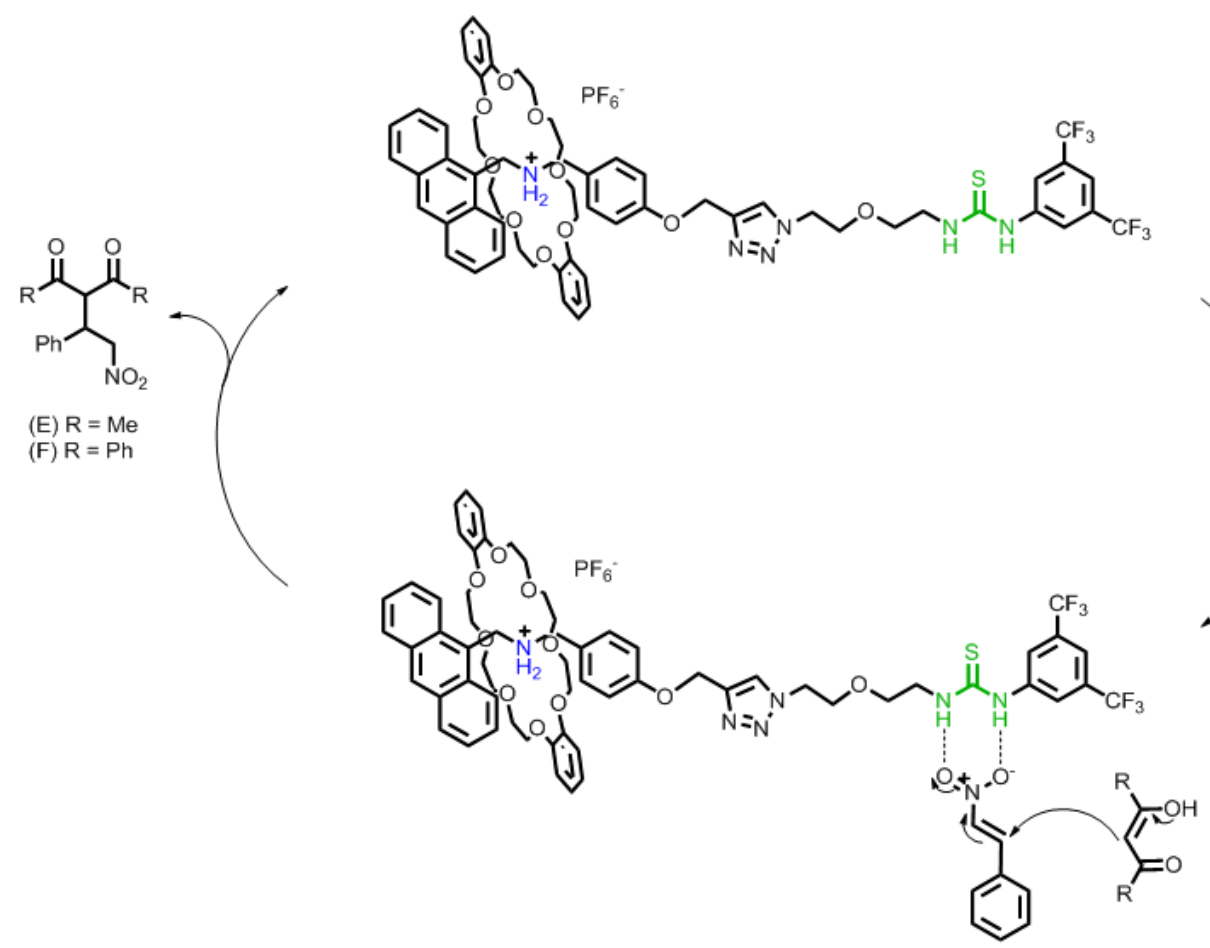

(A) $\mathrm{R}=\mathrm{Me}$

(B) $\mathrm{R}=\mathrm{Ph}$

Scheme S1 Reaction mechanism of Michael addition between acetylacetone (A)/ dibenzoylmethane $(\mathbf{B})$ and trans- $\beta$-nitrostyrene $(\mathbf{C})$.
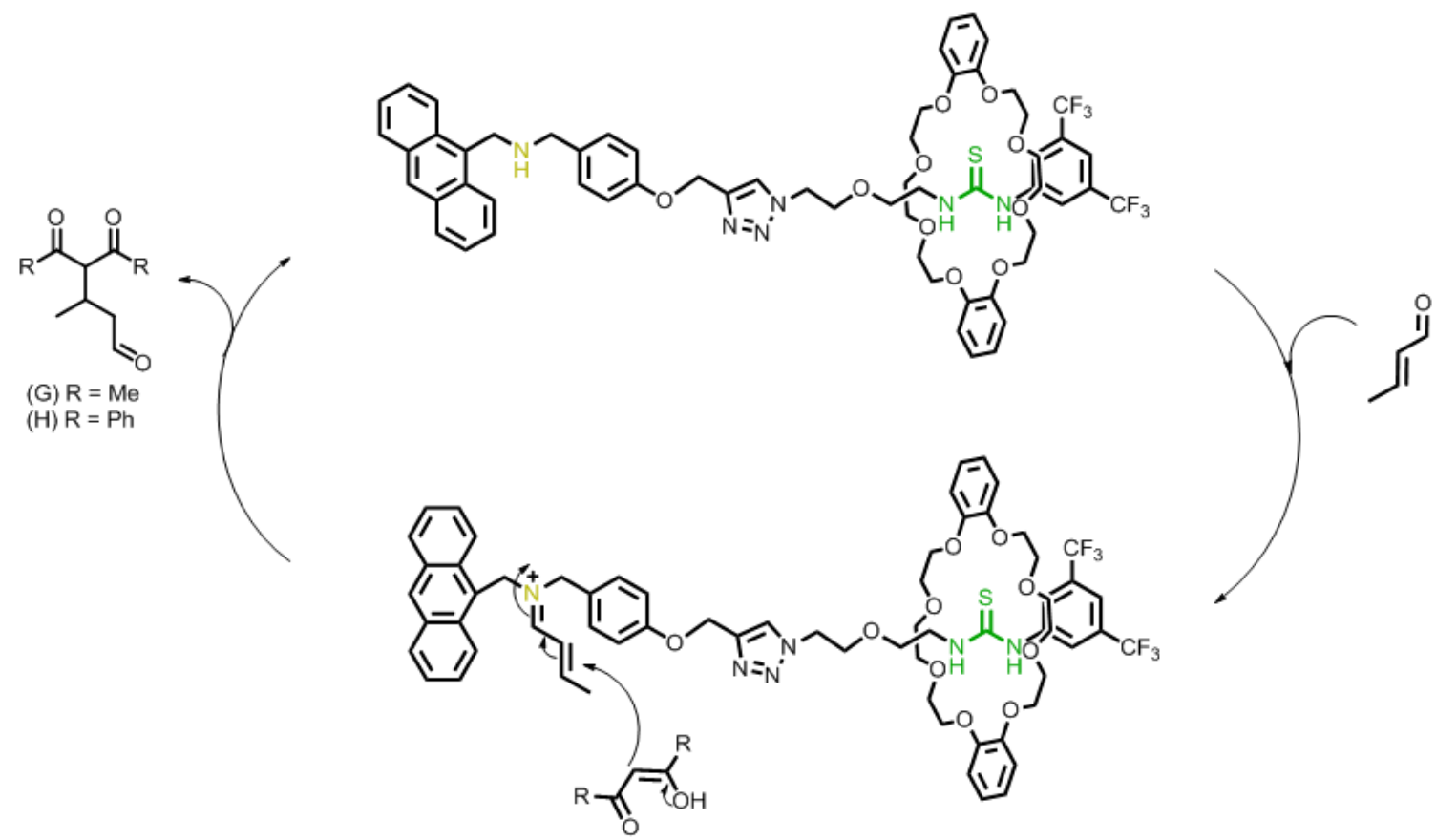<smiles>[R]C(=O)CC([R])=O</smiles>

(A) $\mathrm{R}=\mathrm{Me}$

(B) $\mathrm{R}=\mathrm{Ph}$

Scheme $\mathbf{S} 2$ Reaction mechanism of Michael addition between acetylacetone (A)/ dibenzoylmethane (B) and crotonaldehyde (D).

S19 


\section{Synthesis of F}

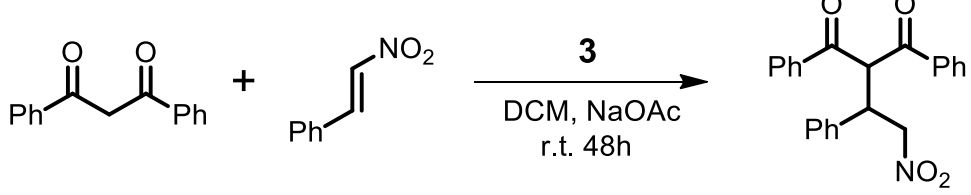

Dibenzoylmethane (B) (450 mg, $2.0 \mathrm{mmol})$ and trans- $\beta$-nitrostyrene (C) (290 mg, 2.0 mmol) were dissolved in $3 \mathrm{~mL}$ DCM, 3 (120 mg, $0.30 \mathrm{mmol})$ and sodium acetate (30 $\mathrm{mg}, 0.4 \mathrm{mmol}$ ) were added. The reaction mixture was stirred at room temperature for 48 hours. After that, the solvent was concentrated under reduced pressure, giving a yellow residue. Diethyl ether was added to the residue, yielding a white precipitate. The precipitate was filtered and washed with diethyl ether twice, yielding $\mathbf{F}$ (520 mg, $70 \%$ ) as a white solid. The ${ }^{1} \mathrm{H}$ NMR was in agreement with previously literature reported data. ${ }^{\mathrm{S} 5}{ }^{1} \mathrm{H}$ NMR $\left(400 \mathrm{MHz}, \mathrm{CDCl}_{3}\right) \delta 7.86(\mathrm{dd}, \mathrm{J}=8.3,1.3 \mathrm{~Hz}, 2 \mathrm{H}), 7.78(\mathrm{dd}$, $\mathrm{J}=8.3,1.3 \mathrm{~Hz}, 2 \mathrm{H}), 7.55(\mathrm{t}, \mathrm{J}=7.4 \mathrm{~Hz}, 1 \mathrm{H}), 7.51(\mathrm{t}, \mathrm{J}=7.4 \mathrm{~Hz}, 1 \mathrm{H}), 7.41-7.35(\mathrm{~m}$, 4H), $7.25-7.15(\mathrm{~m}, 5 \mathrm{H}), 5.84(\mathrm{~d}, \mathrm{~J}=8.0 \mathrm{~Hz}, 1 \mathrm{H}), 5.00(\mathrm{~d}, \mathrm{~J}=6.8 \mathrm{~Hz}, 2 \mathrm{H}), 4.62(\mathrm{q}, \mathrm{J}$ $=7.1 \mathrm{~Hz}, 1 \mathrm{H})$.

\section{Synthesis of $\mathbf{E}$}

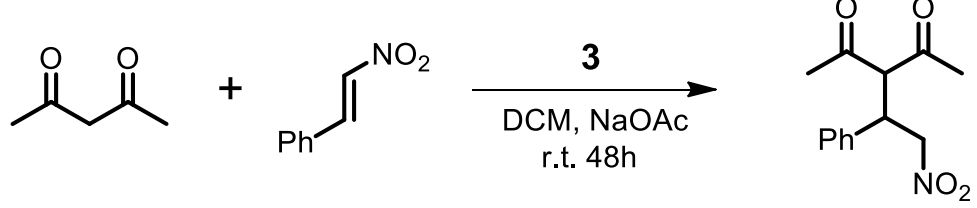

Acetylacetone (A) $(200 \mu \mathrm{L}, 2.0 \mathrm{mmol})$ and trans- $\beta$-nitrostyrene (C) $(290 \mathrm{mg}, 2.0$ mmol) were dissolved in $3 \mathrm{~mL} \mathrm{DCM}, 3$ (120 mg, $0.30 \mathrm{mmol})$ and sodium acetate (30 $\mathrm{mg}, 0.4 \mathrm{mmol}$ ) were added. The reaction mixture was stirred at room temperature for 48 hours. After that, the solvent was concentrated under reduced pressure, giving a yellow residue. Diethyl ether was added to the residue, yielding a pale-yellow precipitate. The precipitate was filtered and washed with diethyl ether twice, yielding F $(370 \mathrm{mg}, 75 \%)$ as a pale-yellow solid. The ${ }^{1} \mathrm{H}$ NMR was in agreement with previously literature reported data. ${ }^{\mathrm{S} 3}{ }^{1} \mathrm{H}$ NMR $\left(400 \mathrm{MHz}, \mathrm{CDCl}_{3}\right) \delta 7.38-7.24(\mathrm{~m}$, $3 \mathrm{H}), 7.22-7.14(\mathrm{~m}, 2 \mathrm{H}), 4.70-4.56(\mathrm{~m}, 2 \mathrm{H}), 4.37$ (d, J = 10.8 Hz, 1H), 4.24 (ddd, J $=10.7,7.7,4.9 \mathrm{~Hz}, 1 \mathrm{H}), 2.30(\mathrm{~s}, 3 \mathrm{H}), 1.94(\mathrm{~s}, 3 \mathrm{H})$. 


\section{Synthesis of $\mathbf{H}$}

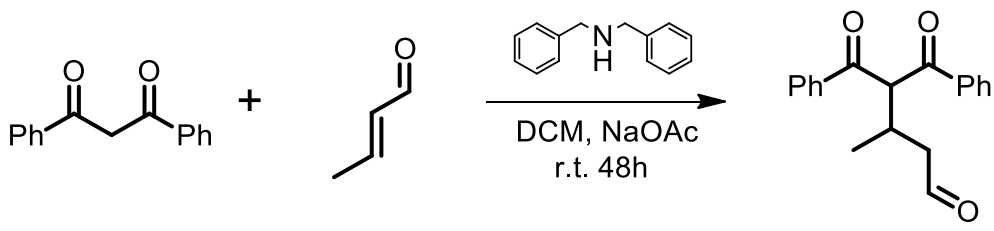

Dibenzoylmethane (B) (450 mg, $2.0 \mathrm{mmol})$ and crotonaldehyde (D) (330 $\mu \mathrm{L}, 4.0$ mmol) were dissolved in $3 \mathrm{~mL} \mathrm{DCM}$, dibenzylamine ( $77 \mu \mathrm{L}, 0.40 \mathrm{mmol})$ and sodium acetate $(30 \mathrm{mg}, 0.40 \mathrm{mmol})$ were added. The reaction mixture was stirred at room temperature for 48 hours. After that, the reaction mixture was extracted with water, the combined organic layers were dried over anhydrous $\mathrm{MgSO}_{4}$ and concentrated under reduced pressure. The residue was purified by column chromatography $\left(\mathrm{SiO}_{2}\right.$; Hex/EtOAc 5:1) affording $\mathbf{H}$ (460 mg, 78\%) as a pale yellow oil. The ${ }^{1} \mathrm{H}$ NMR was in agreement with previously literature reported data. ${ }^{\mathrm{S} 6}{ }^{1} \mathrm{H} \mathrm{NMR}\left(400 \mathrm{MHz}, \mathrm{CDCl}_{3}\right) \delta$ 9.73 (s, 1H), 7.98 (m, 4H), 7.54 (m, 2H), 7.43 (m, 4H), 5.52 (d, J = 7.5 Hz, 1H), 3.19 $(\mathrm{m}, 1 \mathrm{H}), 2.77(\mathrm{dd}, \mathrm{J}=17.9,4.7 \mathrm{~Hz}, 1 \mathrm{H}), 2.55(\mathrm{ddd}, \mathrm{J}=18.0,7.7,1.8 \mathrm{~Hz}, 1 \mathrm{H}) 1.09(\mathrm{~d}$, $\mathrm{J}=6.9 \mathrm{~Hz}, 3 \mathrm{H})$.

\section{Synthesis of G}<smiles>CC(=O)CC(C)=O</smiles><smiles>C/C=C/C=O</smiles>

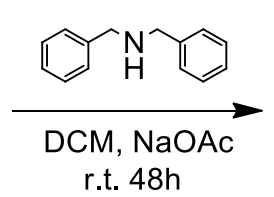<smiles>CC(=O)C(C(C)=O)C(C)C=O</smiles>

Acetylacetone (A) $(200 \mu \mathrm{L}, 2.0 \mathrm{mmol})$ and crotonaldehyde (D) $(330 \mu \mathrm{L}, 4.0 \mathrm{mmol})$ were dissolved in $3 \mathrm{~mL}$ DCM, dibenzylamine ( $77 \mu \mathrm{L}, 0.40 \mathrm{mmol})$ and sodium acetate (30 $\mathrm{mg}, 0.40 \mathrm{mmol}$ ) were added. The reaction mixture was stirred at room temperature for 48 hours. After that, the reaction mixture was extracted with water, the combined organic layers were dried over anhydrous $\mathrm{MgSO}_{4}$ and concentrated under reduced pressure. The residue was purified by column chromatography $\left(\mathrm{SiO}_{2}\right.$; Hex/EtOAc 7:1) affording $\mathbf{G}(230 \mathrm{mg}, 68 \%)$ as a pale yellow oil. The ${ }^{1} \mathrm{H}$ NMR was in agreement with previously literature reported data. ${ }^{\mathrm{S}}{ }^{1} \mathrm{H}$ NMR $\left(400 \mathrm{MHz}, \mathrm{CDCl}_{3}\right) \delta$ $9.68(\mathrm{~s}, 1 \mathrm{H}), 3.66(\mathrm{~d}, \mathrm{~J}=9.2 \mathrm{~Hz}, 1 \mathrm{H}), 2.86(\mathrm{~m}, 1 \mathrm{H}), 2.39(\mathrm{~m}, 1 \mathrm{H}), 2.26(\mathrm{~m}, 1 \mathrm{H}), 2.17$ $(\mathrm{s}, 6 \mathrm{H}), 0.94(\mathrm{~d}, \mathrm{~J}=5.1 \mathrm{~Hz}, 3 \mathrm{H})$. 


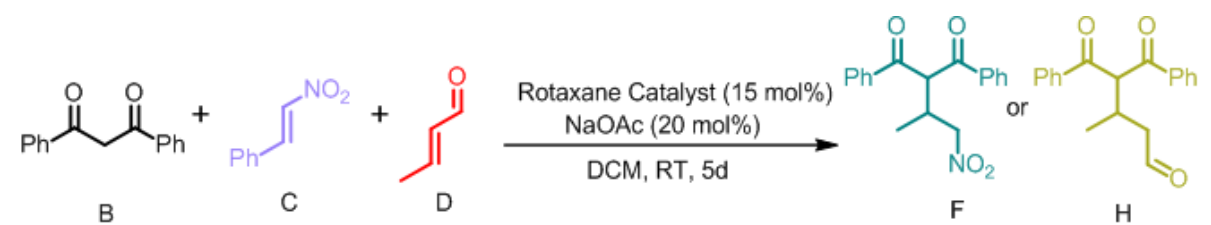

a.)
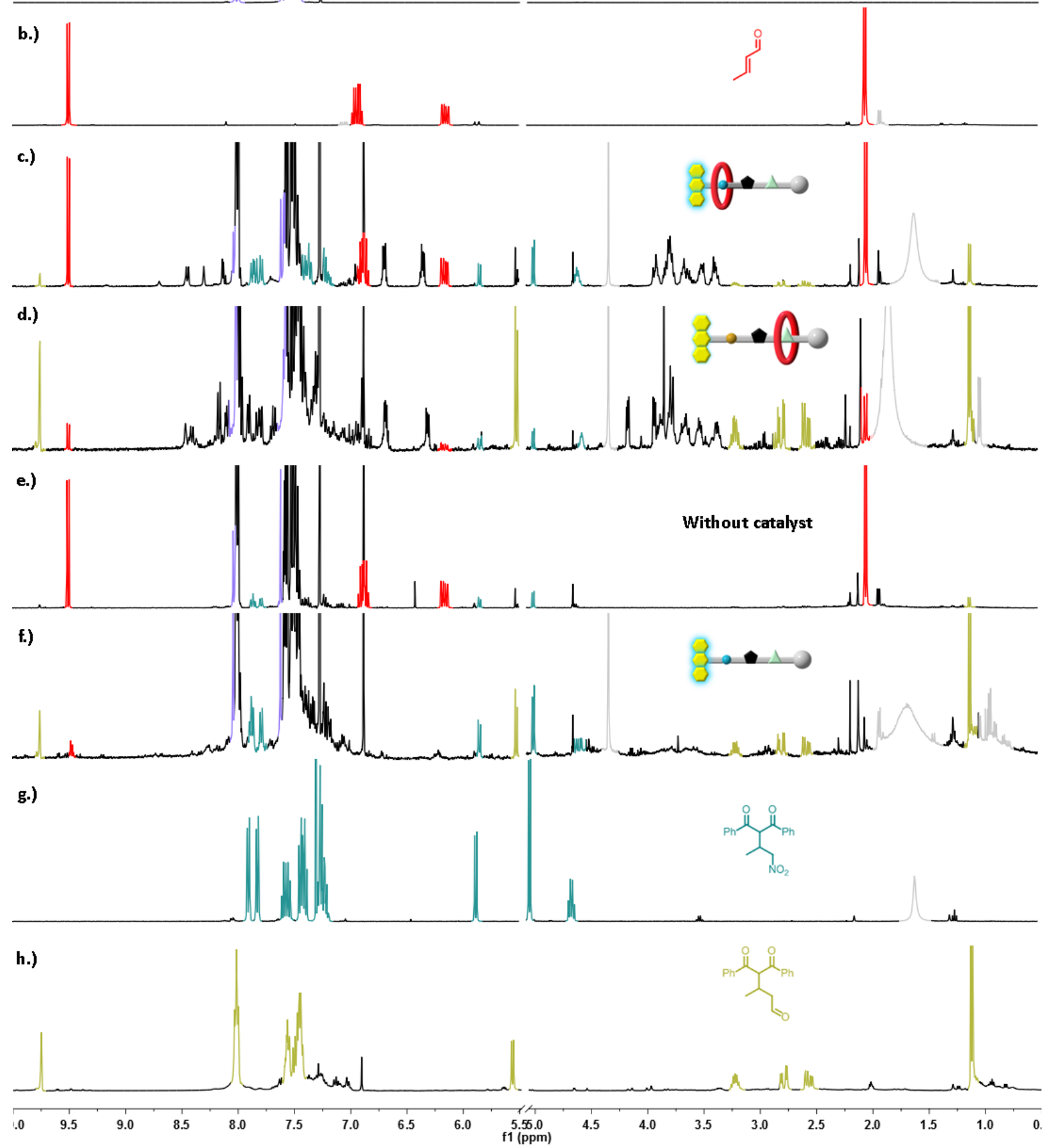

Figure S14 Stack ${ }^{1} \mathrm{H}$ NMR spectrum (400 $\left.\mathrm{MHz}, \mathrm{CDCl}_{3}, 298 \mathrm{~K}\right)$ of: a) trans- $\beta$-nitrostyrene (C); b) crotonaldehyde (D); c) reaction mixture of dibenzoylmethane (B) (2 equiv), $\mathbf{C}$ (1 equiv), $\mathbf{D}$ (2 equiv), $\mathbf{1}-\mathrm{H} \cdot \mathrm{PF}_{6}(15 \mathrm{~mol} \%)$, and 
$\mathrm{NaOAc}$ (20 mol\%), after stirring for 5 days; d) reaction mixture of dibenzoylmethane (B) (2 equiv), C ( 1 equiv), D ( 2 equiv), 1 (15 mol\%), and $\mathrm{NaOAc}(20 \mathrm{~mol} \%)$, after stirring for 5 days.; e) reaction mixture of dibenzoylmethane (B) (2 equiv), $\mathbf{C}$ (1 equiv), $\mathbf{D}$ ( 2 equiv) and $\mathrm{NaOAc}(20 \mathrm{~mol} \%)$ without catalyst, after stirring for 5 days.; f) reaction mixture of dibenzoylmethane (B) (1 equiv), $\mathbf{C}$ (1 equiv), $\mathbf{D}$ (1 equiv), 2- $\mathrm{H} \cdot \mathrm{PF}_{6}(15 \mathrm{~mol} \%)$, and $\mathrm{NaOAc}(20 \mathrm{~mol} \%)$, after stirring for 5 days; g) Product $\mathbf{F}$; h) Product $\mathbf{H}$. The color-coding of the peaks represents the starting materials as well as the products. 


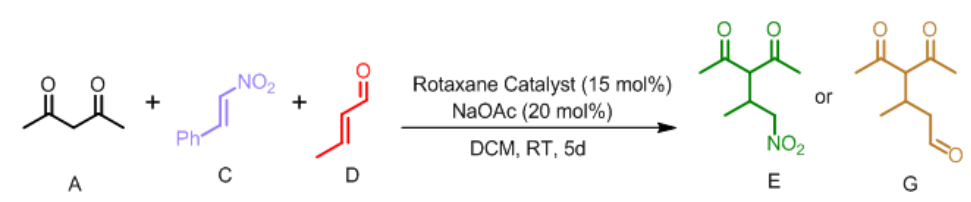

a.)

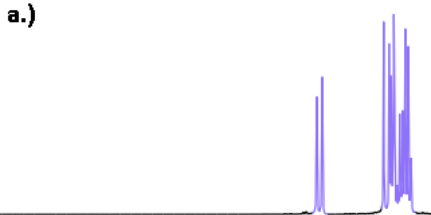

b.)

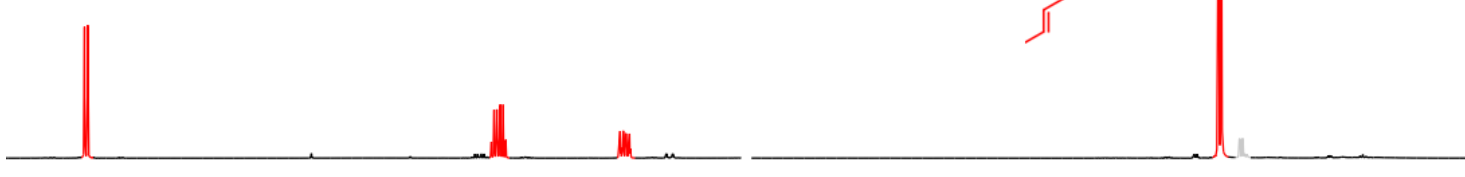

c.)
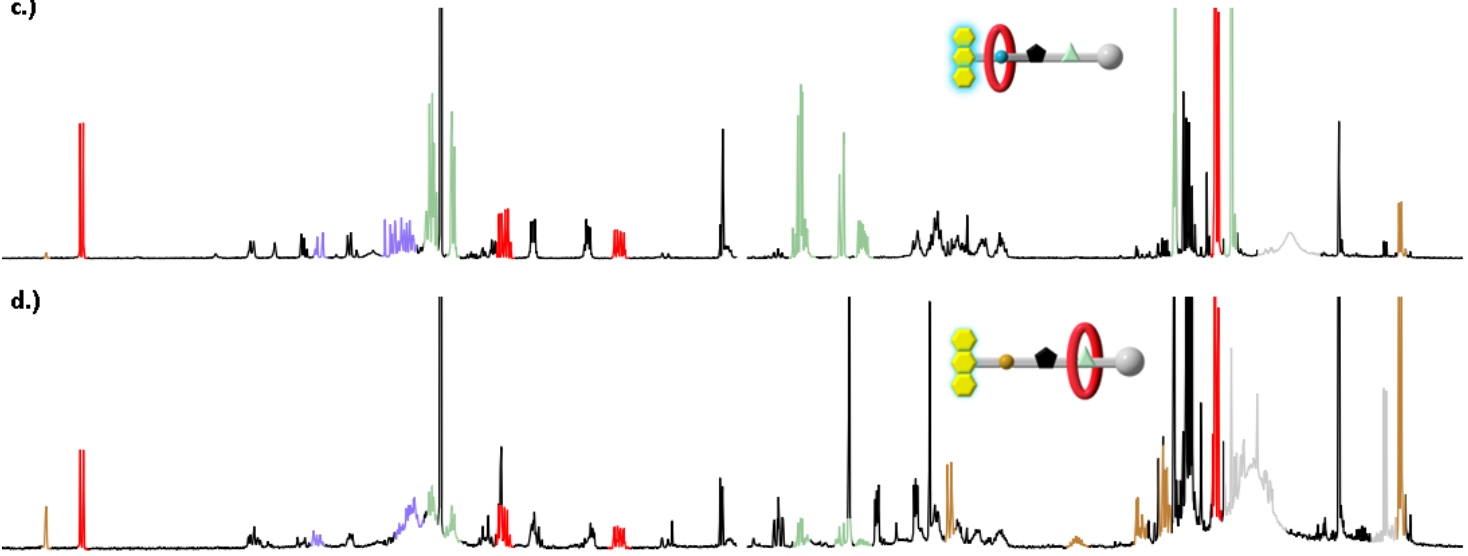

e.)

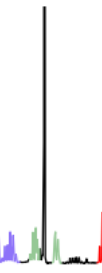

f.)

Without catalys
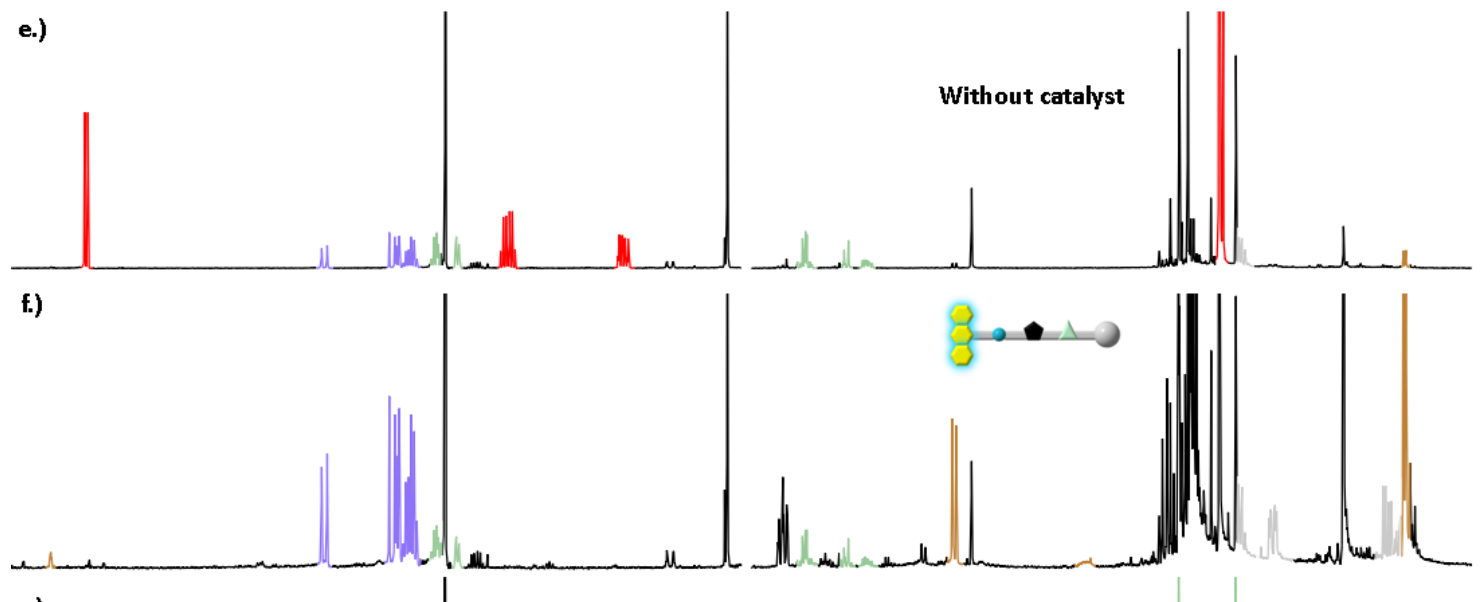

g.)

$\lambda_{\mathrm{NO}_{2}}$

h.)
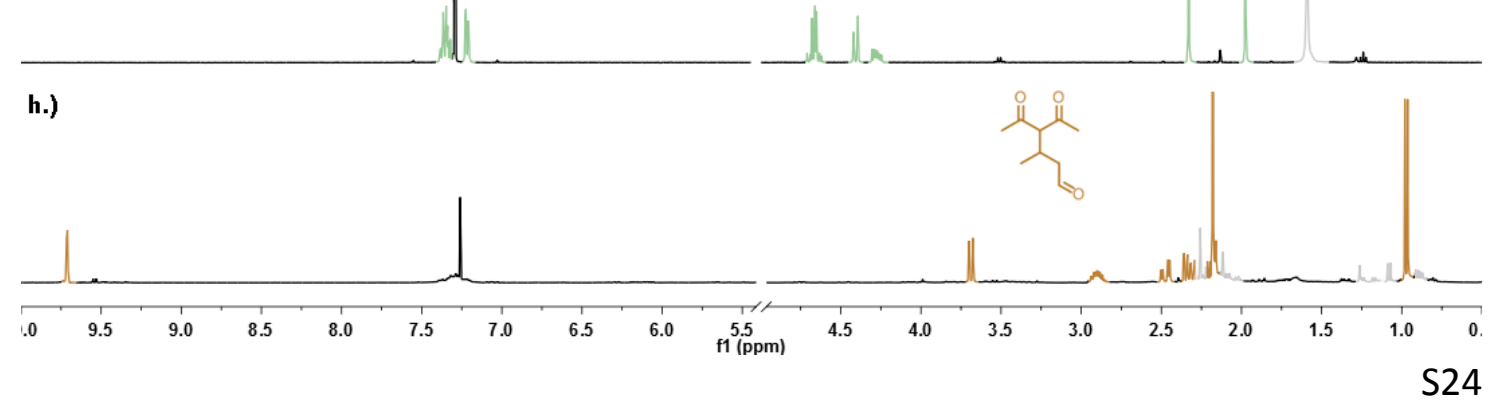
Figure S15 Stack ${ }^{1} \mathrm{H}$ NMR spectrum (400 $\left.\mathrm{MHz}, \mathrm{CDCl}_{3}, 298 \mathrm{~K}\right)$ of: a) trans- $\beta$-nitrostyrene $(\mathbf{C})$; b) crotonaldehyde $(\mathbf{D})$; c) reaction mixture of acetylacetone (A) (2 equiv), $\mathbf{C}$ ( 1 equiv), $\mathbf{D}$ ( 1 equiv), $\mathbf{1}-\mathrm{H} \cdot \mathrm{PF}_{6}(15 \mathrm{~mol} \%)$, and $\mathrm{NaOAc}(20 \mathrm{~mol} \%)$, after stirring for 5 days; d) reaction mixture of acetylacetone (A) (2 equiv), $\mathbf{C}$ (1 equiv), $\mathbf{D}$ ( 1 equiv), $\mathbf{1}(15 \mathrm{~mol} \%)$, and $\mathrm{NaOAc}(20 \mathrm{~mol} \%)$, after stirring for 5 days.; e) reaction mixture of acetylacetone (A) ( 2 equiv), $\mathbf{C}$ ( 1 equiv), $\mathbf{D}$ (1 equiv) and $\mathrm{NaOAc}$ (20 mol\%) without catalyst, after stirring for 5 days.; f) reaction mixture of acetylacetone (A) (1 equiv), $\mathbf{C}$ (1 equiv), $\mathbf{D}$ (1 equiv), $2-\mathrm{H} \cdot \mathrm{PF}_{6}(15 \mathrm{~mol} \%)$, and $\mathrm{NaOAc}(20 \mathrm{~mol} \%)$, after stirring for 5 days; g) Product E; h) Product G. The color-coding of the peaks represents the starting materials as well as the products. 


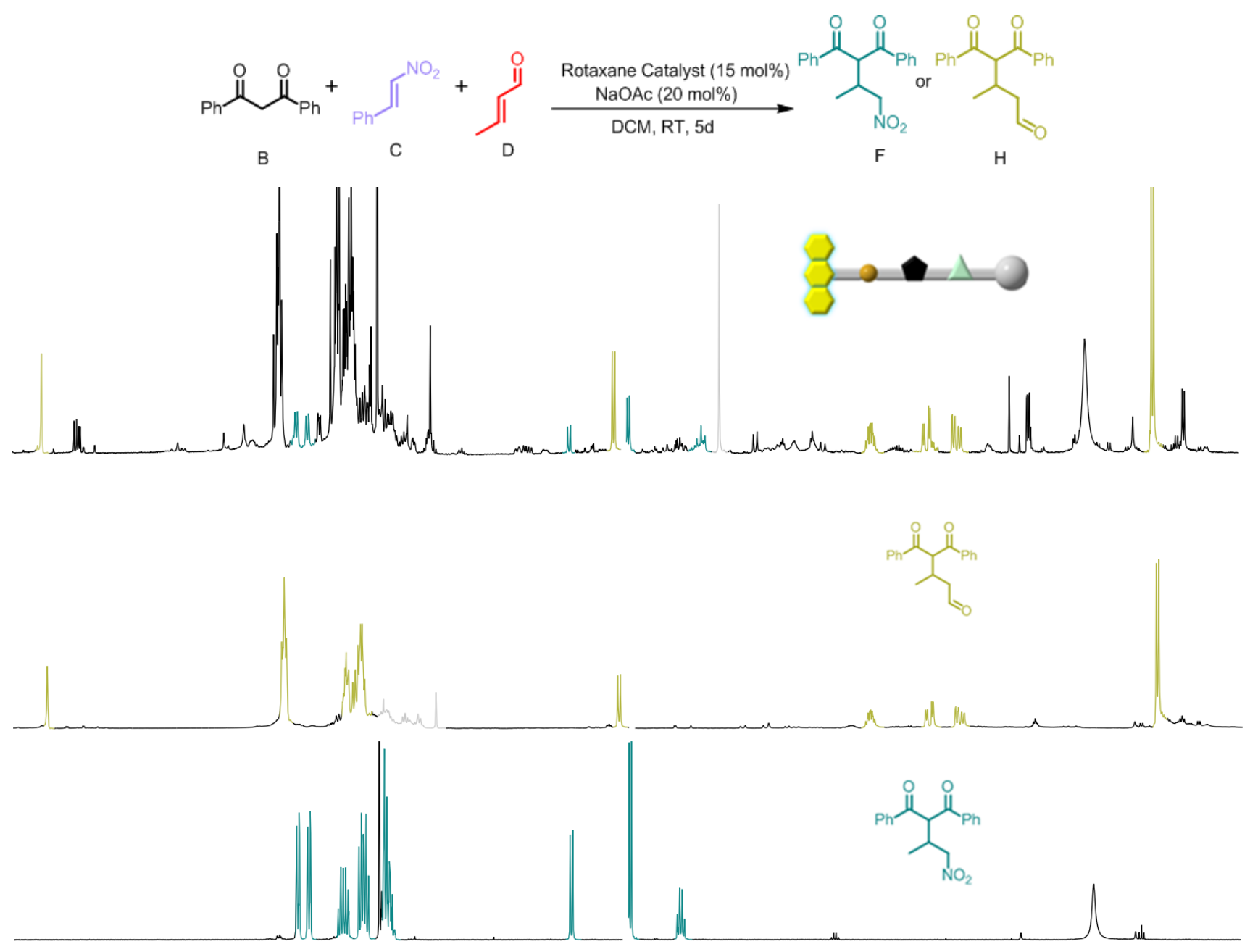

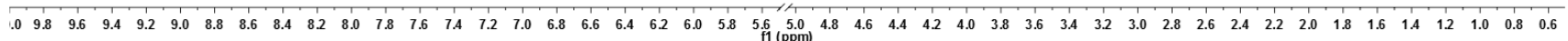

Figure S16 Stack ${ }^{1} \mathrm{H}$ NMR spectrum $\left(400 \mathrm{MHz}, \mathrm{CDCl}_{3}, 298 \mathrm{~K}\right)$ of reaction mixture of dibenzoylmethane (B) (1 equiv), C (1 equiv), D (1 equiv), 2 (15 mol\%), and $\mathrm{NaOAc}$ (20 mol\%), after stirring for 5 days. 

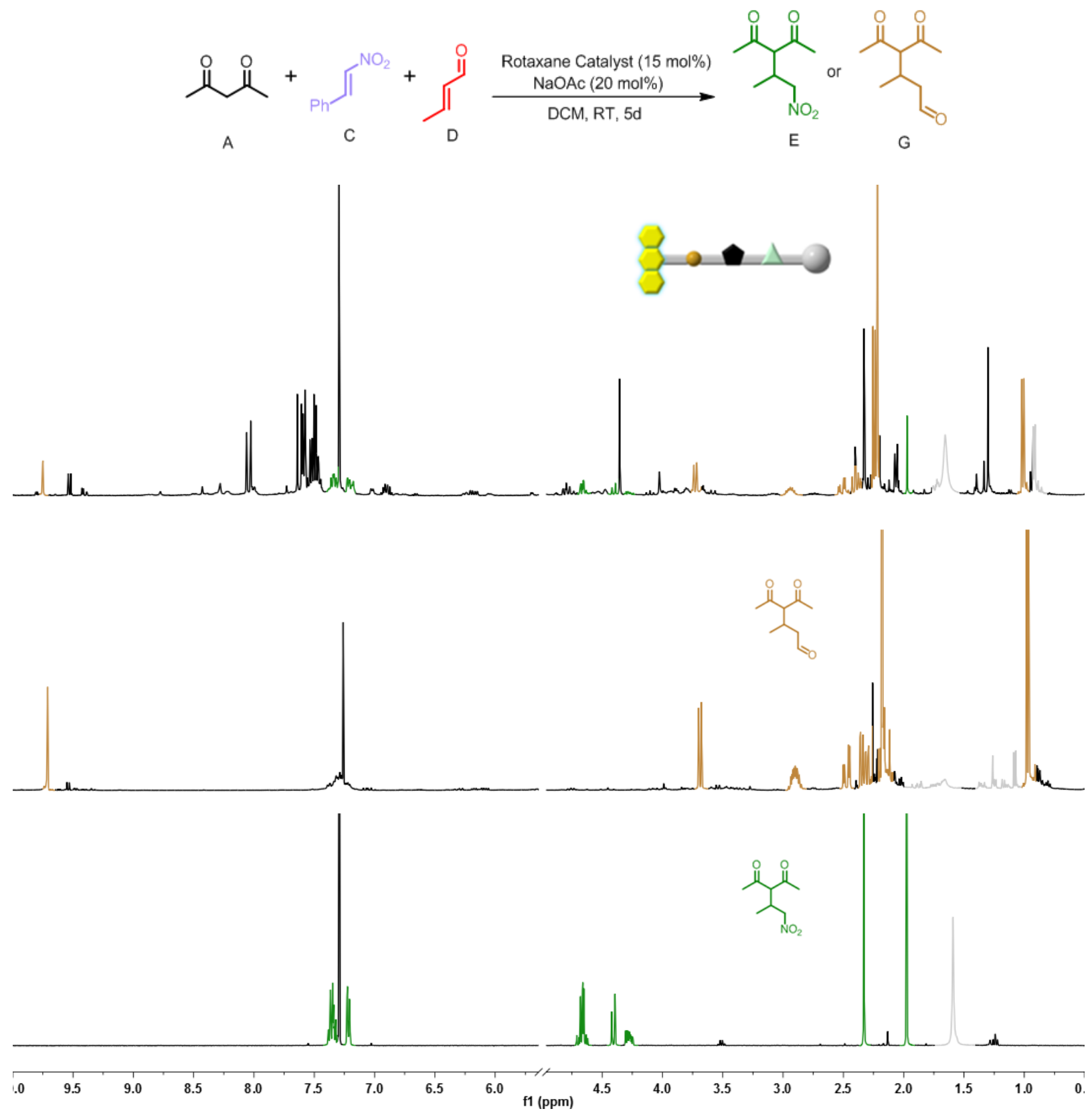

Figure S17 Stack ${ }^{1} \mathrm{H}$ NMR spectrum (400 MHz, $\mathrm{CDCl}_{3}, 298 \mathrm{~K}$ ) of reaction mixture of acetylacetone (A) (1 equiv), $\mathbf{C}$ (1 equiv), $\mathbf{D}$ (1 equiv), 2 (15 mol\%), and $\mathrm{NaOAc}$ (20 mol\%), after stirring for 5 days. 


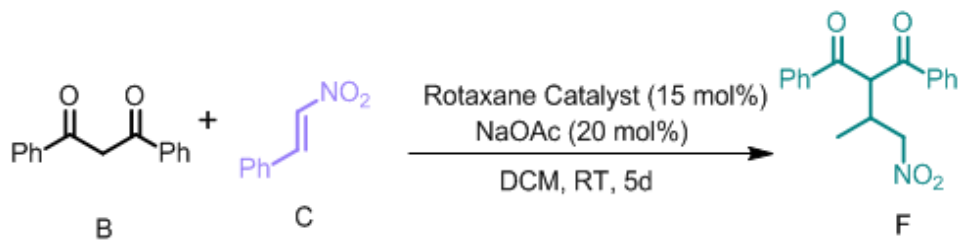

a.)

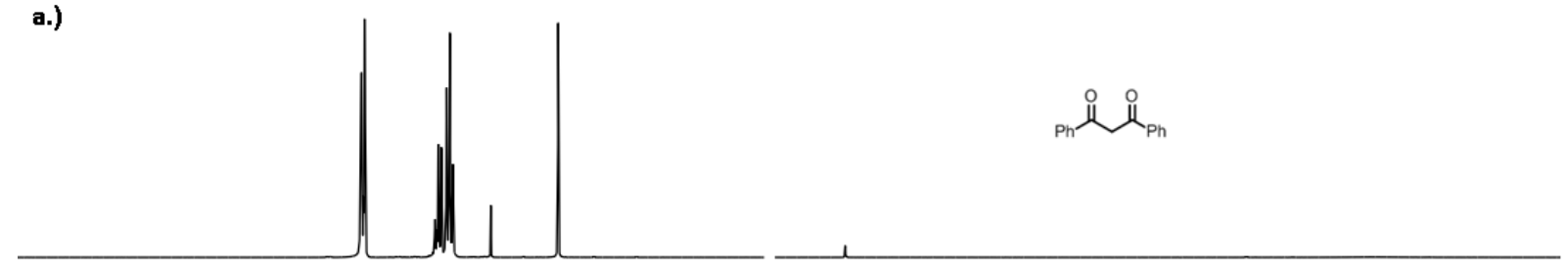

b.)

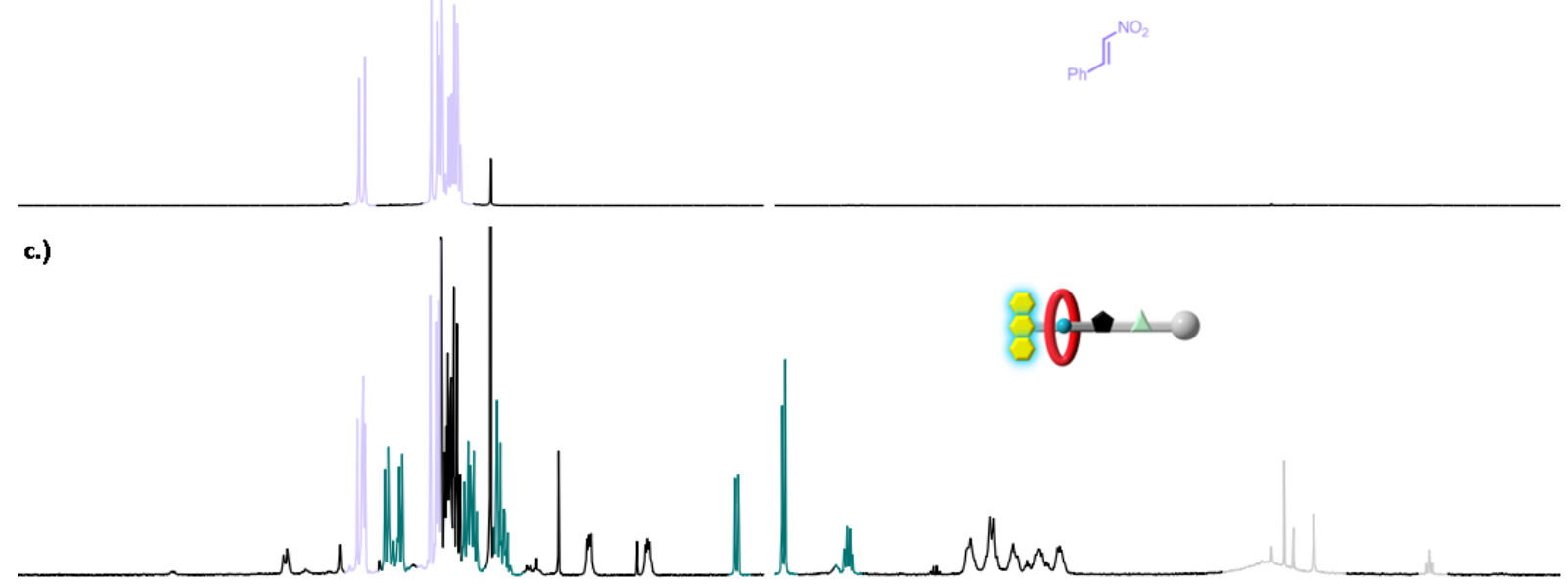

d.)

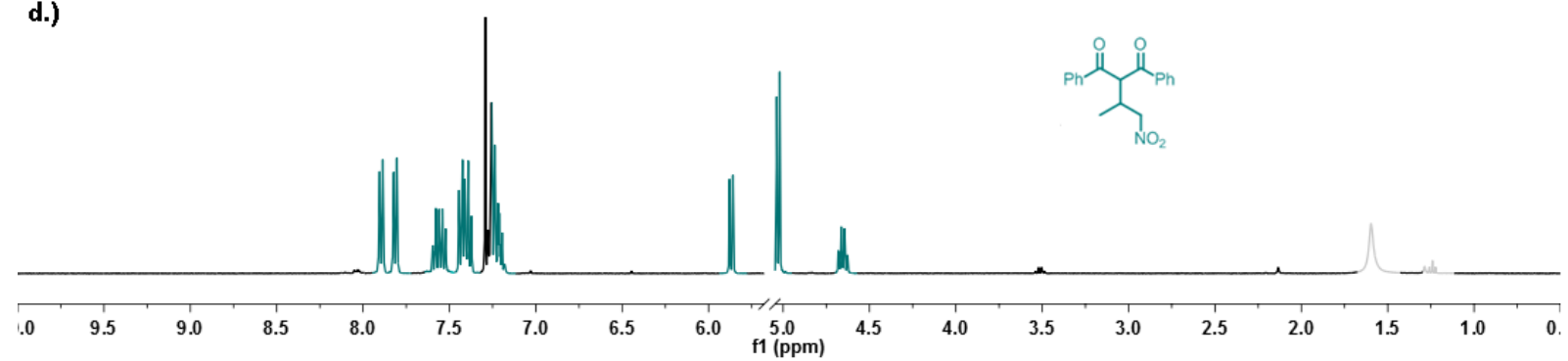

Figure S18 Stack ${ }^{1} \mathrm{H}$ NMR spectrum (400 $\left.\mathrm{MHz}, \mathrm{CDCl}_{3}, 298 \mathrm{~K}\right)$ of: a) dibenzoylmethane $(\mathbf{B})$; b) trans- $\beta$-nitrostyrene $(\mathbf{C})$; c) reaction mixture of $\mathbf{B}$ (1 equiv), C (2 equiv), 1-H·PF 6 (15 mol\%), and NaOAc (20 mol\%), after stirring for 5 days; d) Product F. The color-coding of the peaks represents the starting materials as well as the products. 


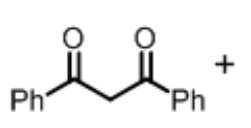

B<smiles>C/C=C/C=O</smiles>

D
Rotaxane Catalyst (15 mol\%) $\mathrm{NaOAc}(20 \mathrm{~mol} \%)$ DCM, RT, 5d

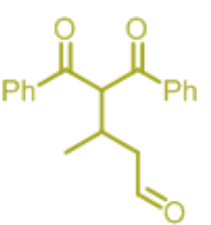

$\mathrm{H}$

a.)

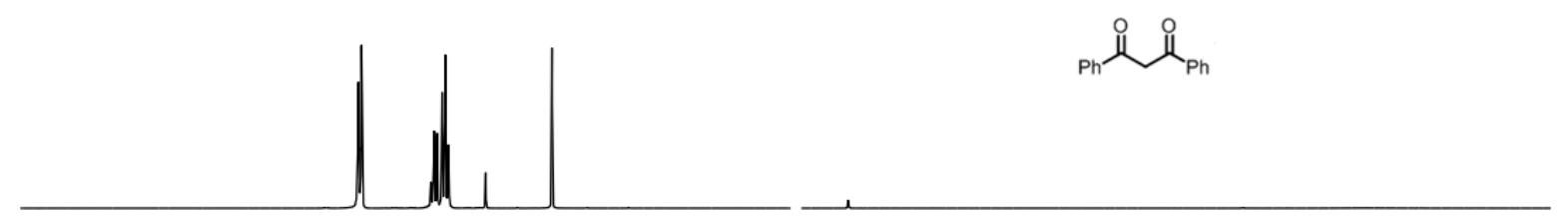

b.)

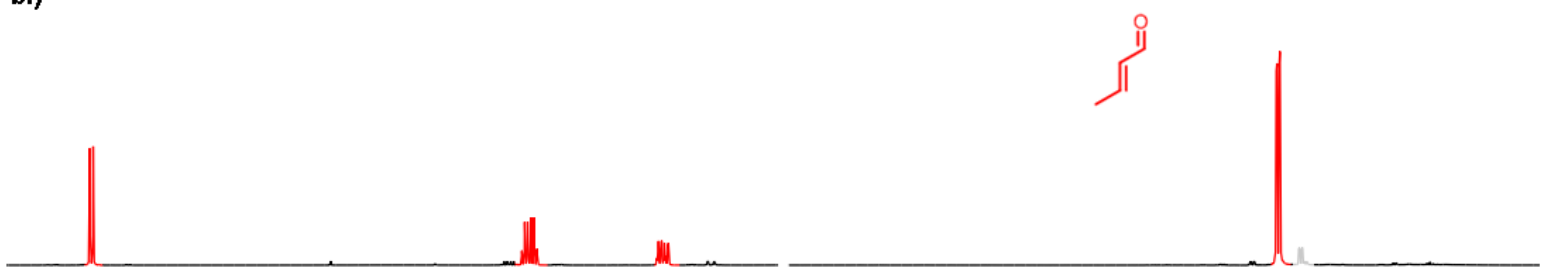

c.)
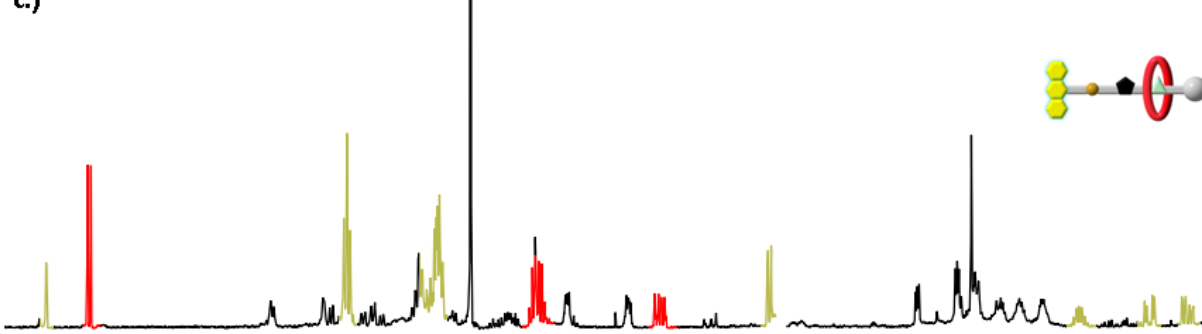

d.)

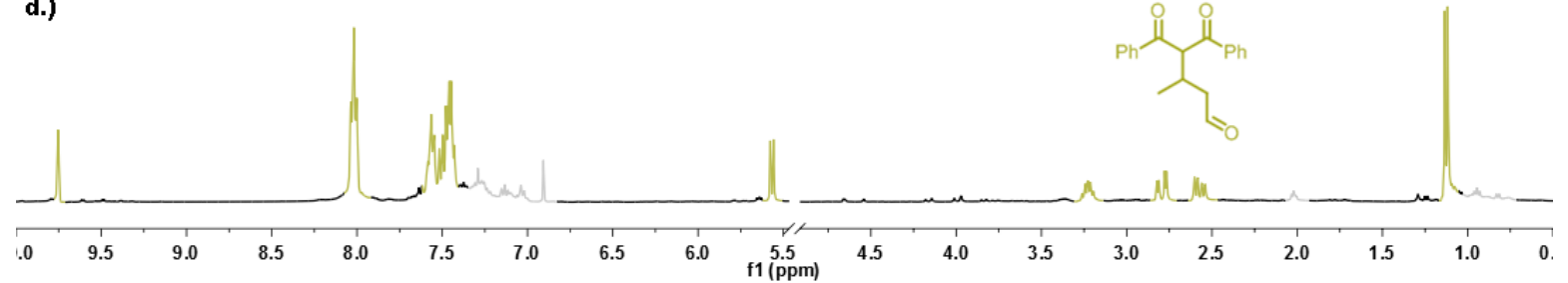

Figure S19 Stack ${ }^{1} \mathrm{H}$ NMR spectrum (400 $\left.\mathrm{MHz}, \mathrm{CDCl}_{3}, 298 \mathrm{~K}\right)$ of: a) dibenzoylmethane (B); b) crotonaldehyde (D); c) reaction mixture of $\mathbf{B}$ (1 equiv), D (2 equiv), $\mathbf{1}(15 \mathrm{~mol} \%$ ), and $\mathrm{NaOAc}$ (20 mol\%), after stirring for 3 days; d) Product $\mathbf{H}$. The color-coding of the peaks represents the starting materials as well as the products. 


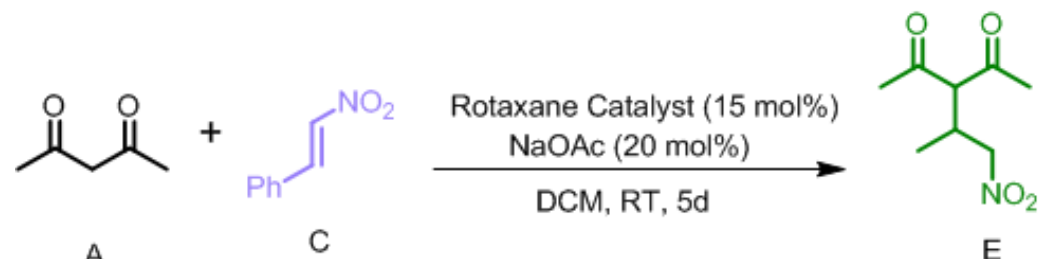

a.)

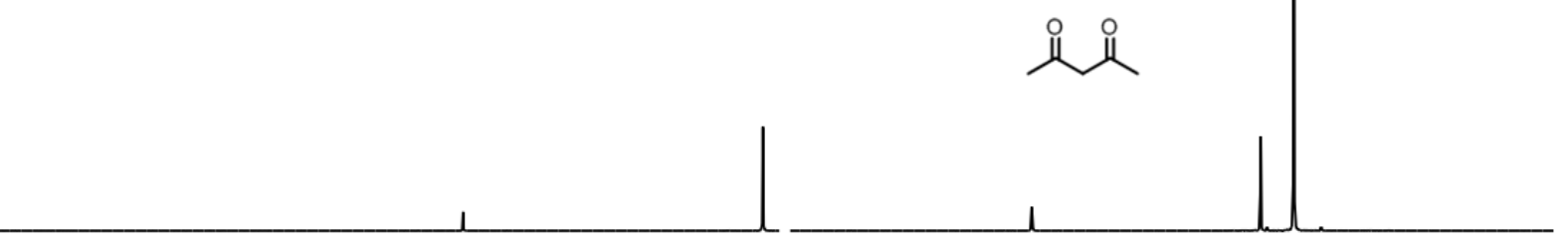

b.)

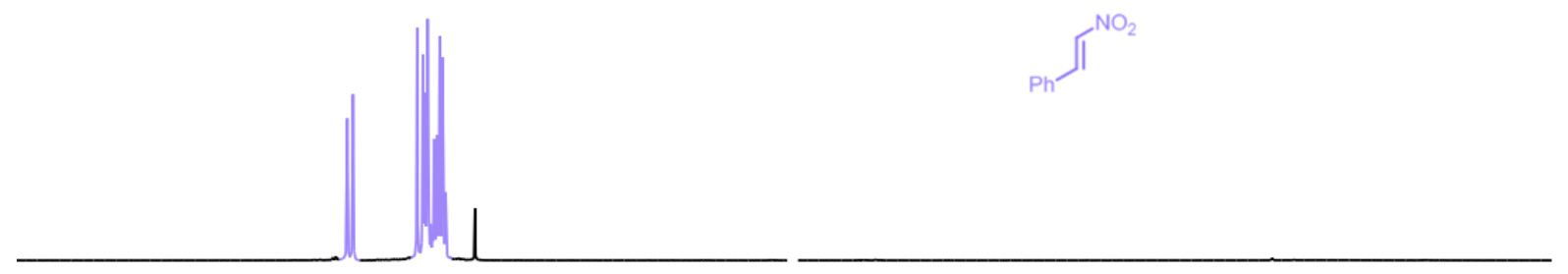

c.)
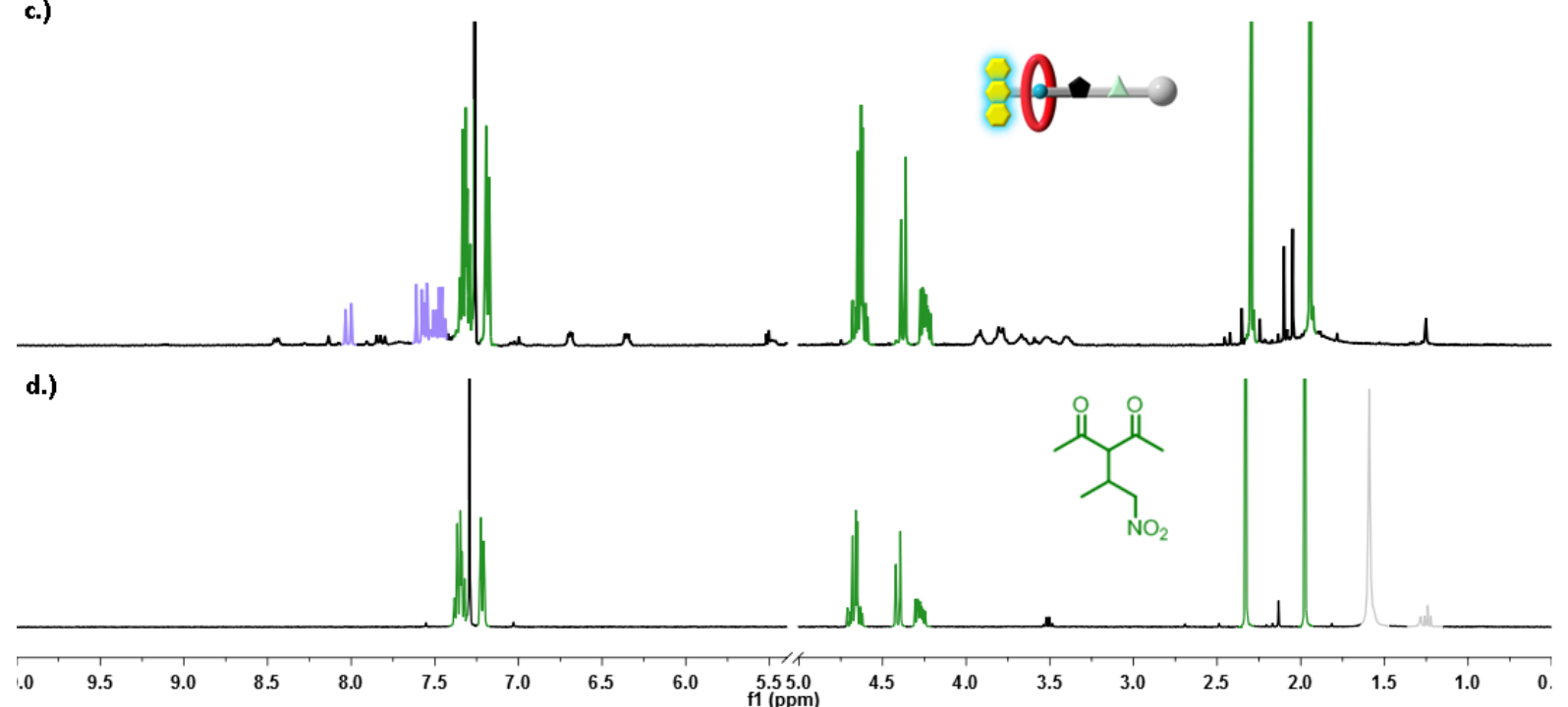

Figure S20 Stack ${ }^{1} \mathrm{H}$ NMR spectrum (400 MHz, $\left.\mathrm{CDCl}_{3}, 298 \mathrm{~K}\right)$ of: a) acetylacetone (A); b) trans- $\beta$-nitrostyrene $(\mathbf{C})$; c) reaction mixture of $\mathbf{A}$ (1 equiv), $\mathbf{C}$ (2 equiv), 1$\mathrm{H} \cdot \mathrm{PF}_{6}(15 \mathrm{~mol} \%)$, and $\mathrm{NaOAc}(20 \mathrm{~mol} \%$ ), after stirring for 3 days; d) Product $\mathbf{E}$. The color-coding of the peaks represents the starting materials as well as the products. 

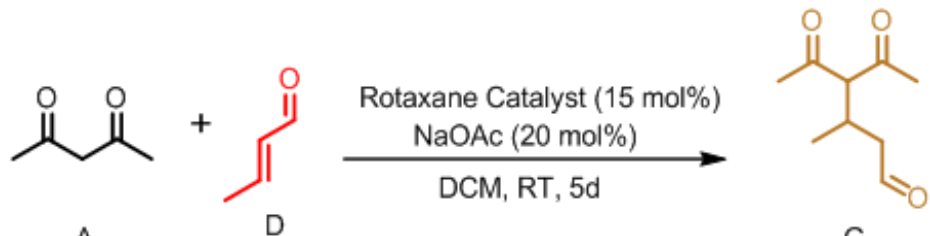

G

a.)

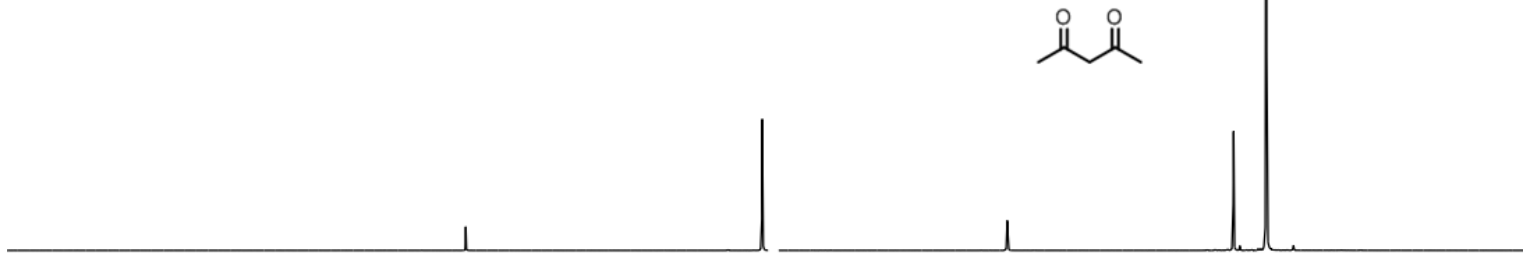

b.)

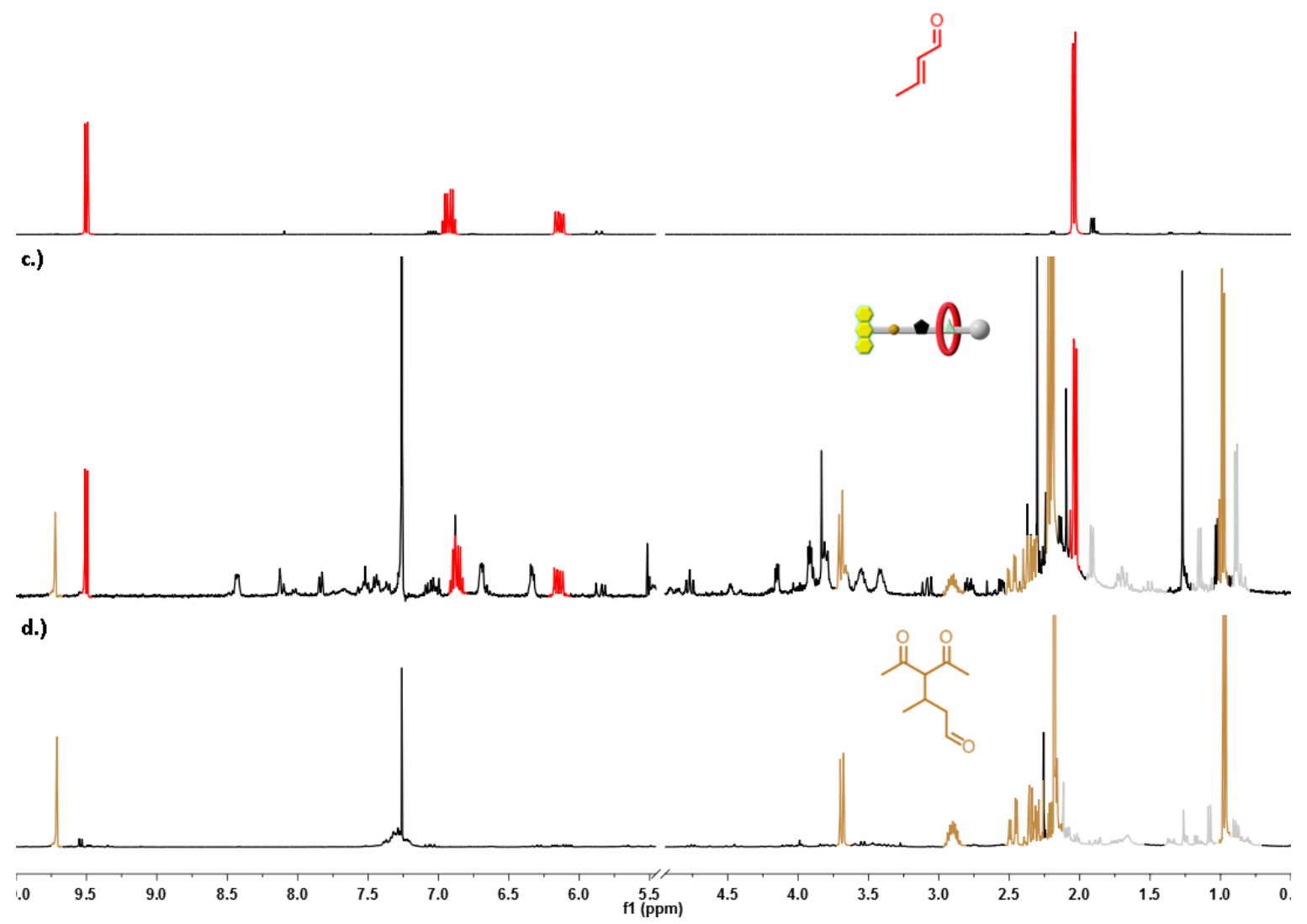

Figure S21 Stack ${ }^{1} \mathrm{H}$ NMR spectrum (400 MHz, $\mathrm{CDCl}_{3}, 298 \mathrm{~K}$ ) of: a) acetylacetone (B); b) crotonaldehyde (D); c) reaction mixture of $\mathbf{B}$ (1 equiv), D (2 equiv), 1 (15 mol\%), and $\mathrm{NaOAc}(20 \mathrm{~mol} \%)$, after stirring for 3 days; d) Product G. The color-coding of the peaks represents the starting materials as well as the products. 

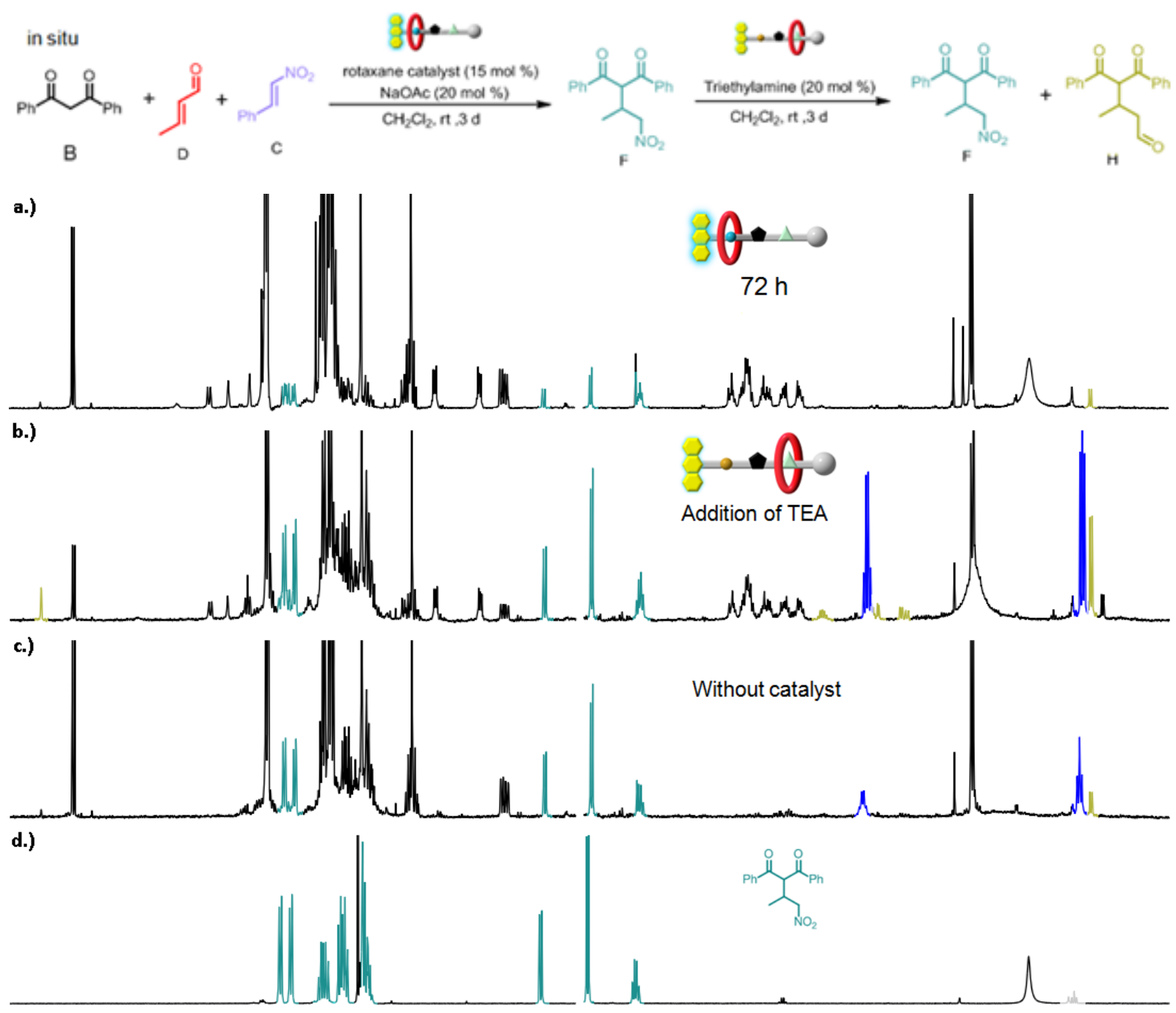

e.)

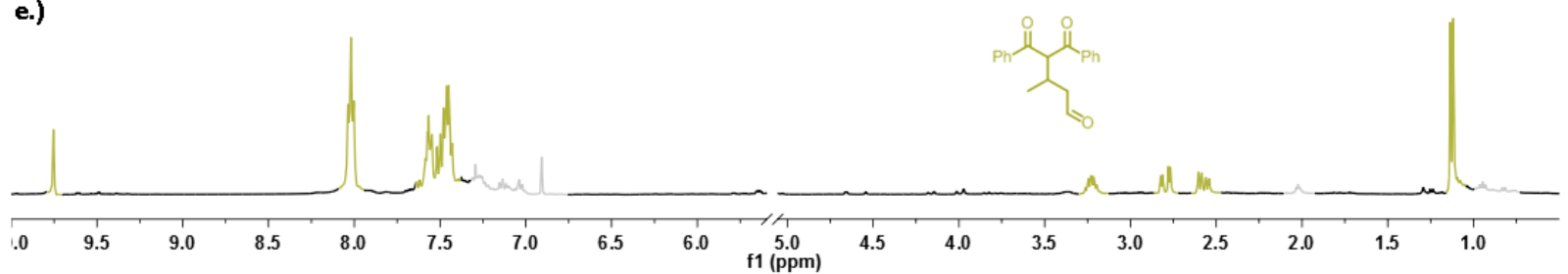

Figure S22 Stack ${ }^{1} \mathrm{H}$ NMR spectrum (400 MHz, $\mathrm{CDCl}_{3}, 298 \mathrm{~K}$ ) of in situ experiment of entry 8: a) reaction mixture of $\mathbf{B}$ ( 2 equiv), $\mathbf{C}$ ( 1 equiv), $\mathbf{D}$ ( 1 equiv), $\mathbf{1}-\mathrm{H} \cdot \mathrm{PF}_{6}(15$ mol\%), and $\mathrm{NaOAc}(20 \mathrm{~mol} \%)$, after stirring for 3 days; b) addition of TEA (20 mol\%) to the reaction mixture of a) stirring for 4 days more.; c) reaction mixture of $\mathbf{B}$ ( 2 equiv), $\mathbf{C}$ ( 1 equiv), $\mathbf{D}$ ( 1 equiv), and $\mathrm{NaOAc}(20 \mathrm{~mol} \%)$ without catalyst after stirring for 3 days, showing no reaction, and addition of TEA (20 mol\%) stirring for 4 days more.; d) Product F.; e) Product $\mathbf{H}$. The color-coding of the peaks represents the starting materials as well as the products. Blue color represents the peaks of TEA. However, at the same time, TEA catalyzes the reaction between $\mathbf{B}$ and $\mathbf{C}$ readily, indicating in this system that, TEA not only acts as a base for switching, but also as a co-catalyst for the reaction between $\mathbf{B}$ and $\mathbf{C}$. 
in situ
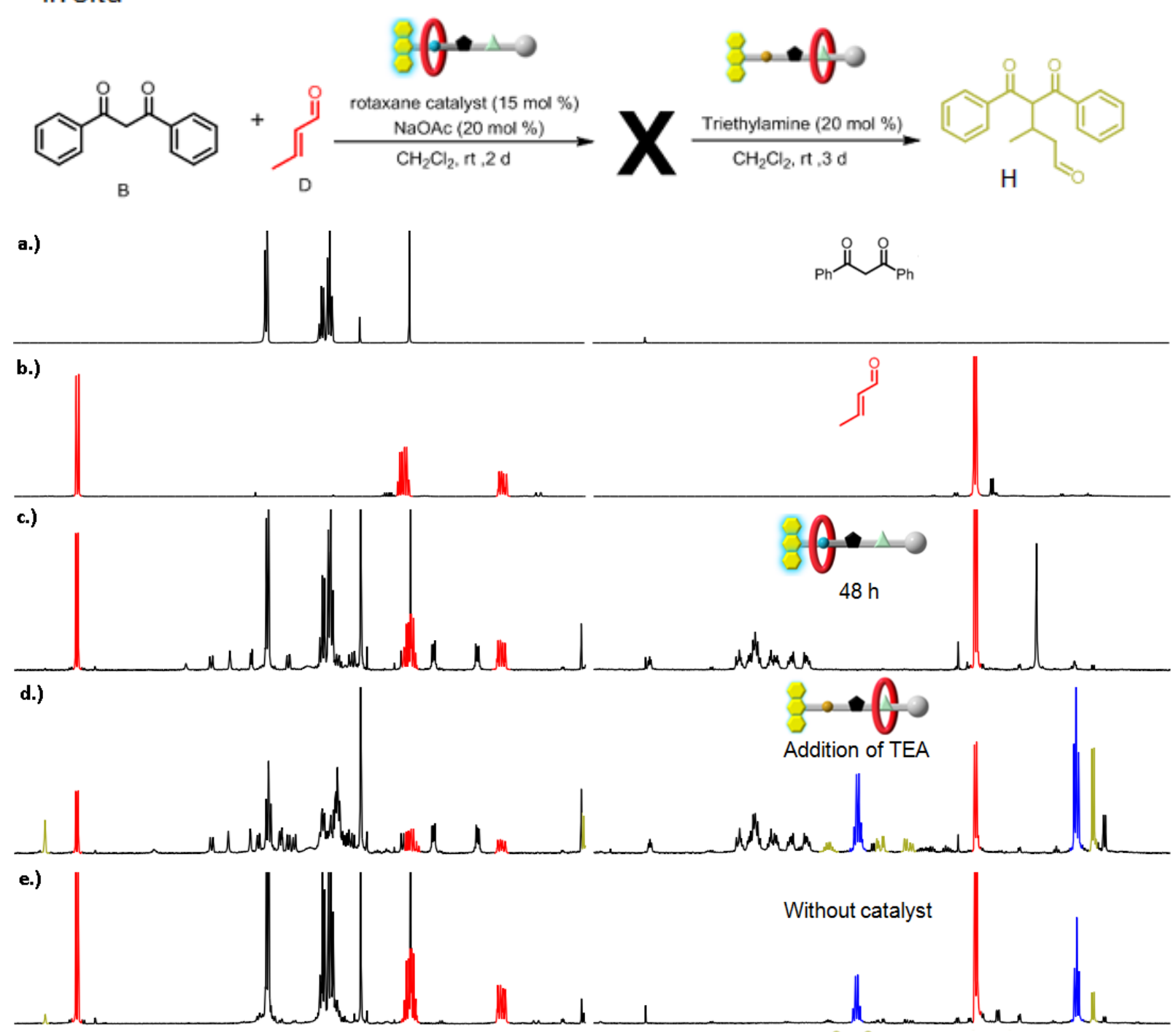

Whand

f.)

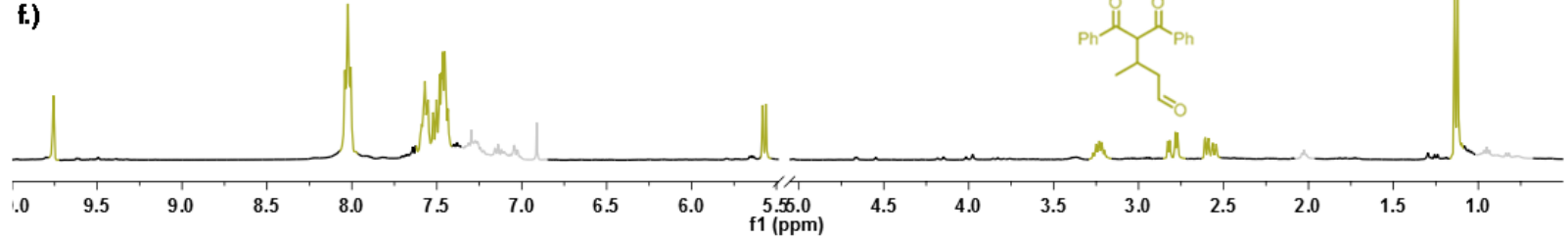

Figure S23 Stack ${ }^{1} \mathrm{H}$ NMR spectrum ( $\left.400 \mathrm{MHz}, \mathrm{CDCl}_{3}, 298 \mathrm{~K}\right)$ of in situ switch on of entry 10: a) dibenzoylmethane (B); b) crotonaldehyde (D); c) reaction mixture of $\mathbf{B}$ (1 equiv), $\mathbf{D}$ (2 equiv), $\mathbf{1}-\mathrm{H} \cdot \mathrm{PF}_{6}(15 \mathrm{~mol} \%)$, and $\mathrm{NaOAc}(20 \mathrm{~mol} \%)$, after stirring for 2 days; d) addition of TEA (20 mol\%) to the reaction mixture of c) stirring for 3 days more.; e) reaction mixture of $\mathbf{B}$ ( 1 equiv), $\mathbf{D}$ (2 equiv), and $\mathrm{NaOAc}(20 \mathrm{~mol} \%)$ without catalyst, after stirring for 2 days, addition of TEA (20 mol\%) stirring for 3 days more; f) Product $\mathbf{H}$. The color-coding of the peaks represents the starting materials as well as the products. Blue color represents the peaks of TEA. 


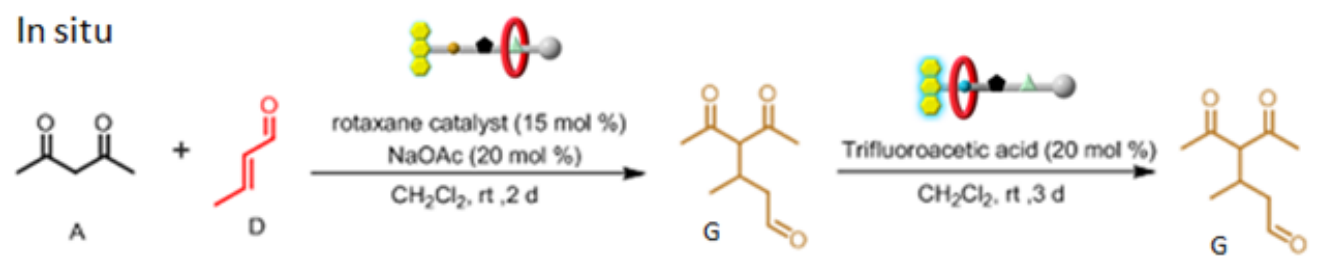

a.)
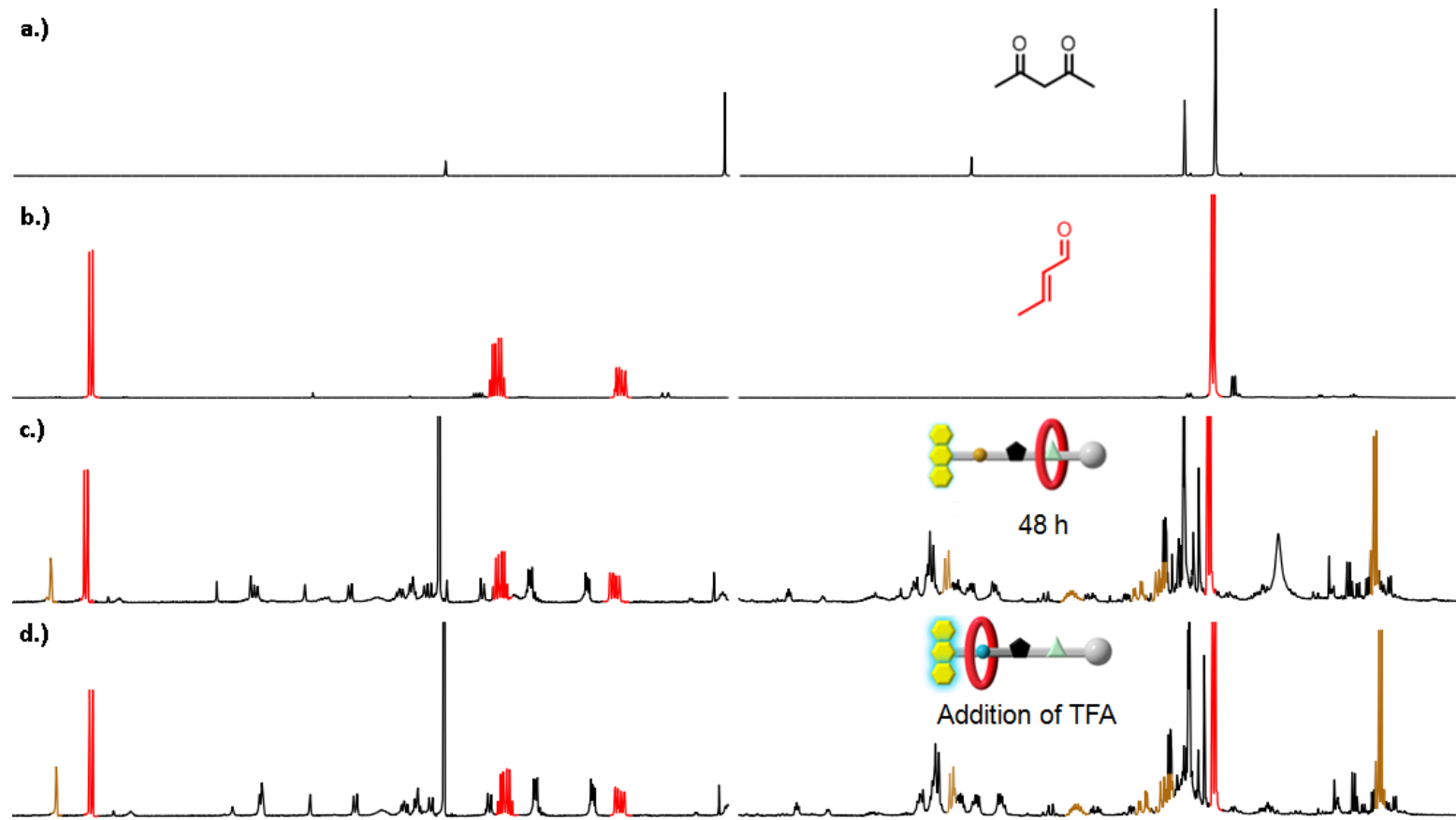

b.)

e.)

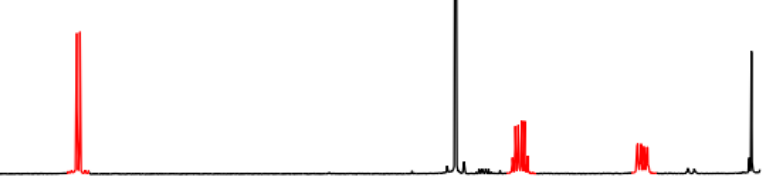

f.)

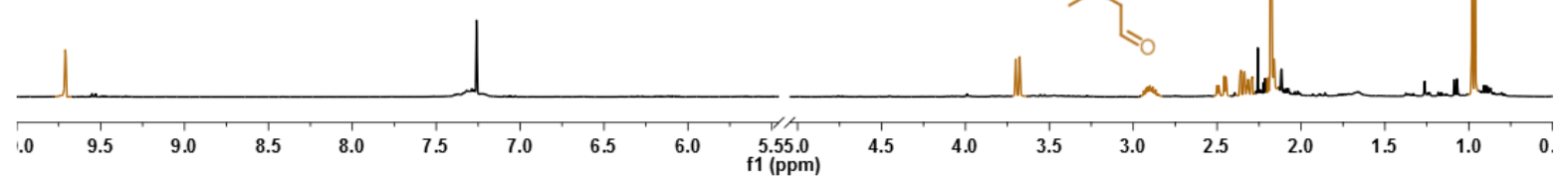

Figure $\boldsymbol{S} 24$ Stack ${ }^{1} \mathrm{H}$ NMR spectrum $\left(400 \mathrm{MHz}, \mathrm{CDCl}_{3}, 298 \mathrm{~K}\right)$ of in situ switch off of entry 12: a) acetylacetone $(\mathbf{A})$; b) crotonaldehyde (D); c) reaction mixture of $\mathbf{A}$ (1 equiv), D (2 equiv), 1 (15 mol\%), and $\mathrm{NaOAc}$ (20 mol\%), after stirring for 2 days; d) addition of TFA ( $20 \mathrm{~mol} \%$ ) to the reaction mixture of c) stirring for 3 days more; e) reaction mixture of $\mathbf{A}$ (1 equiv), $\mathbf{D}$ ( 2 equiv), and $\mathrm{NaOAc}$ (20 mol\%) without catalyst, after stirring for 2 days, addition of TFA (20 mol\%) stirring for 3 days more; $\mathrm{f}$ ) Product G. The color-coding of the peaks represents the starting materials as well as the products. 

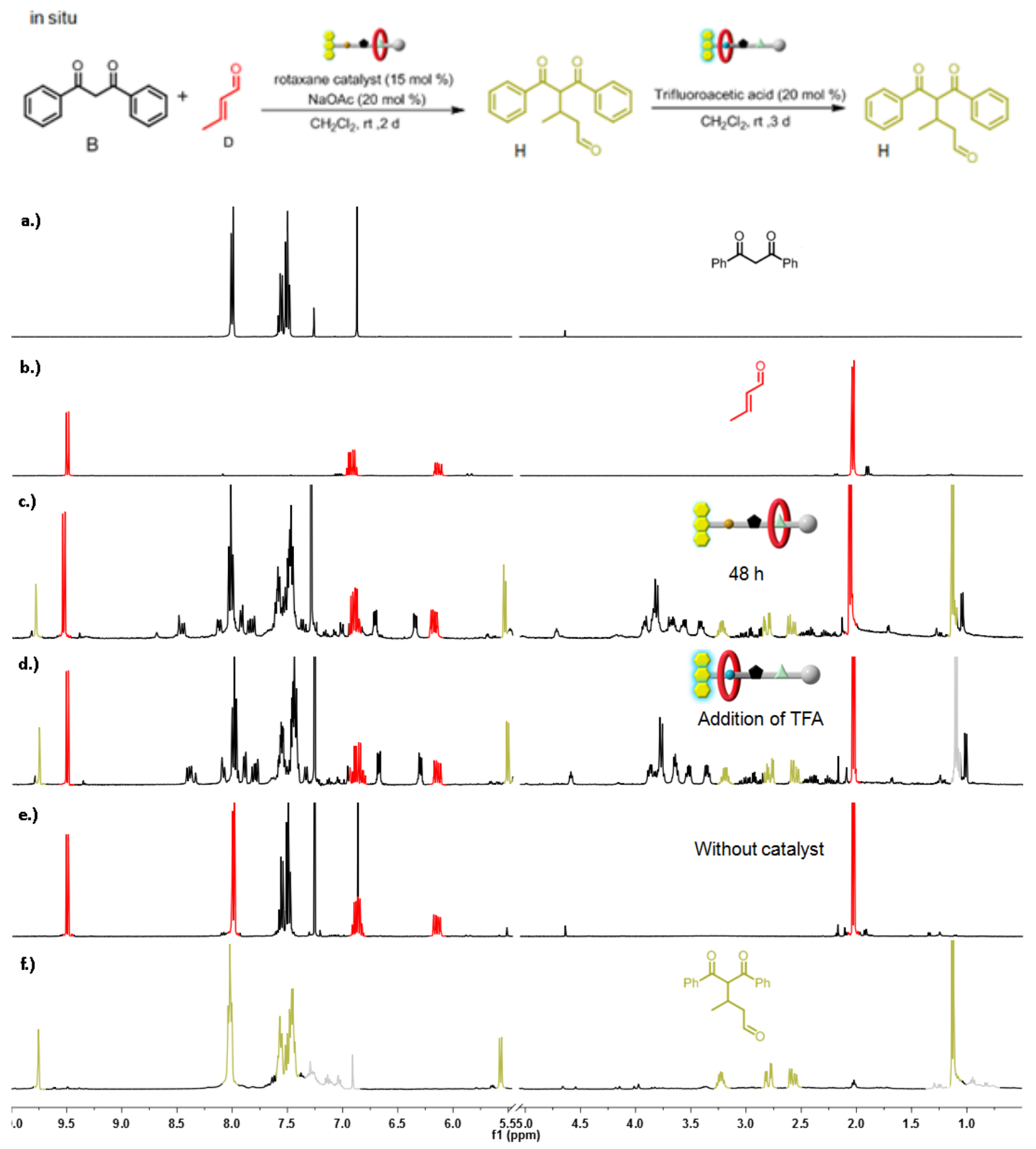

Figure S25 Stack ${ }^{1} \mathrm{H}$ NMR spectrum (400 MHz, $\mathrm{CDCl}_{3}, 298 \mathrm{~K}$ ) of in situ switch off of entry 10: a) dibenzoylmethane (B); b) crotonaldehyde (D); c) reaction mixture of $\mathbf{A}$ (1 equiv), $\mathbf{D}$ (2 equiv), $\mathbf{1}$ (15 mol\%), and $\mathrm{NaOAc}$ (20 mol\%), after stirring for 2 days; d) addition of TFA ( $20 \mathrm{~mol} \%$ ) to the reaction mixture of c) stirring for 3 days more; e) reaction mixture of $\mathbf{A}$ (1 equiv), $\mathbf{D}$ ( 2 equiv), and $\mathrm{NaOAc}$ (20 mol\%) without catalyst, after stirring for 2 days, addition of TFA (20 mol\%) stirring for 3 days more; f) Product $\mathbf{H}$. The color-coding of the peaks represents the starting materials as well as the products. 
Table S1 Summary of in situ experiment of entry 8, 12, 15, 18. TEA: triethylamine; TFA: trifluoroacetic acid.

\begin{tabular}{|c|c|c|c|c|}
\hline Entry & Catalyst & $\begin{array}{c}\text { Switching } \\
\text { agent }\end{array}$ & $\begin{array}{c}\text { Yield before } \\
\text { switching (\%) }\end{array}$ & $\begin{array}{c}\text { Yield after } \\
\text { switching (\%) }\end{array}$ \\
\hline $\mathbf{8}$ & $\mathbf{1}^{-H} \cdot \mathrm{PF}_{6}$ & TEA & $34(\mathbf{F})$ & $80(\mathbf{F}), 41(\mathbf{H})$ \\
\hline Control 8 & - & TEA & - & $78(\mathbf{F})$ \\
\hline $\mathbf{9}$ & $\mathbf{1 - H} \cdot \mathrm{PF}_{6}$ & TEA & - & $72(\mathbf{H})$ \\
\hline Control 9 & - & TEA & - & - \\
\hline $\mathbf{1 2}$ & $\mathbf{1}$ & TFA & $39(\mathbf{G})$ & $39(\mathbf{G})$ \\
\hline Control 12 & - & TFA & - & - \\
\hline $\mathbf{1 0}$ & $\mathbf{1}$ & TFA & $69(\mathbf{H})$ & $70(\mathbf{H})$ \\
\hline Control 10 & - & TFA & - & - \\
\hline
\end{tabular}

In control 8, TEA catalyzes the reaction between $\mathbf{A}$ and $\mathbf{C}$ readily. ${ }^{\mathrm{S} 8}$ 


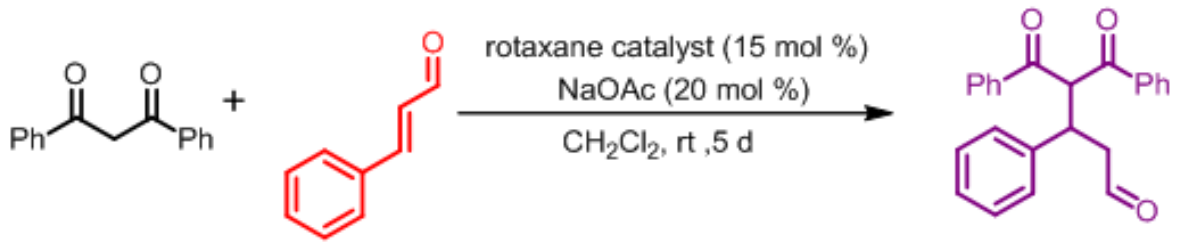

a.)

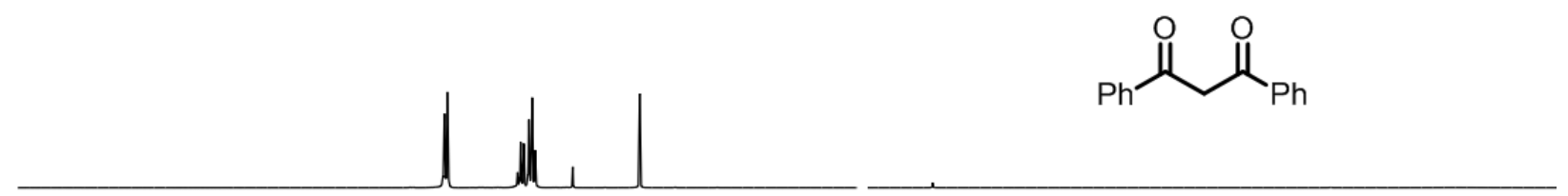

b.)
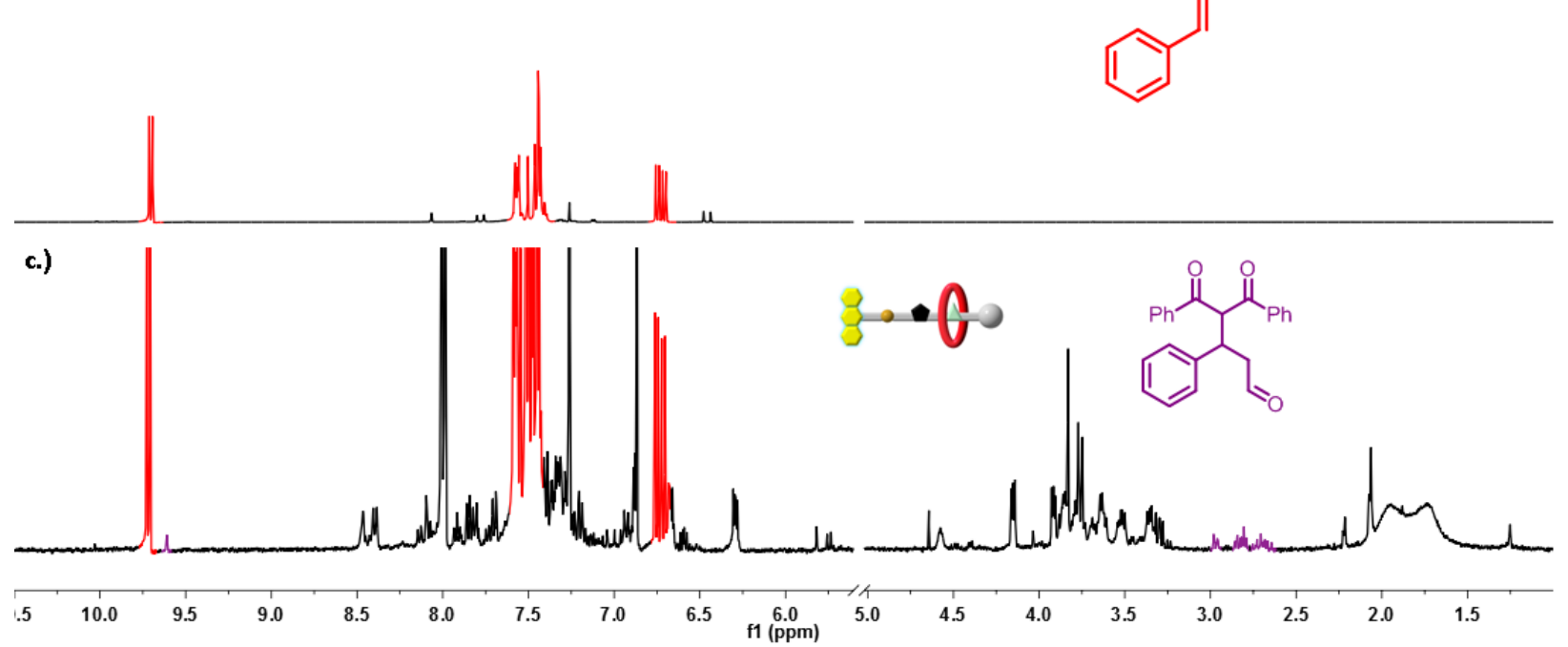

Figure S26 Stack ${ }^{1} \mathrm{H}$ NMR spectrum (400 $\left.\mathrm{MHz}, \mathrm{CDCl}_{3}, 298 \mathrm{~K}\right)$ of: a) dibenzoylmethane; b) trans-cinnamaldehyde; c) reaction mixture of dibenzoylmethane (1 equiv), trans-cinnamaldehyde (2 equiv), 1 (15 mol\%), and $\mathrm{NaOAc}(20 \mathrm{~mol} \%)$, after stirring for 5 days. The color-coding of the peaks represents the starting materials as well as the products. 


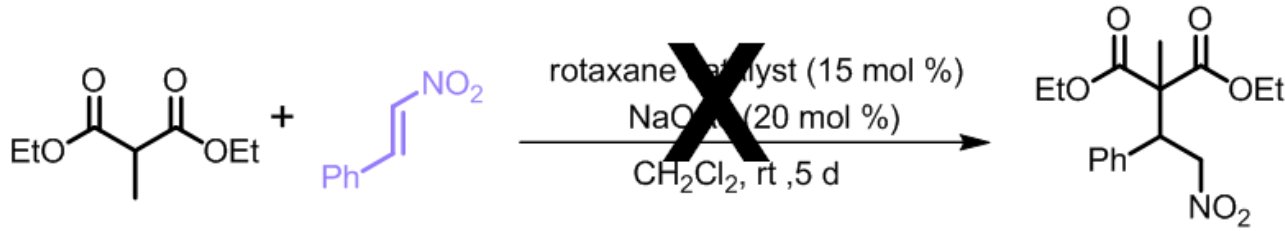

a.)

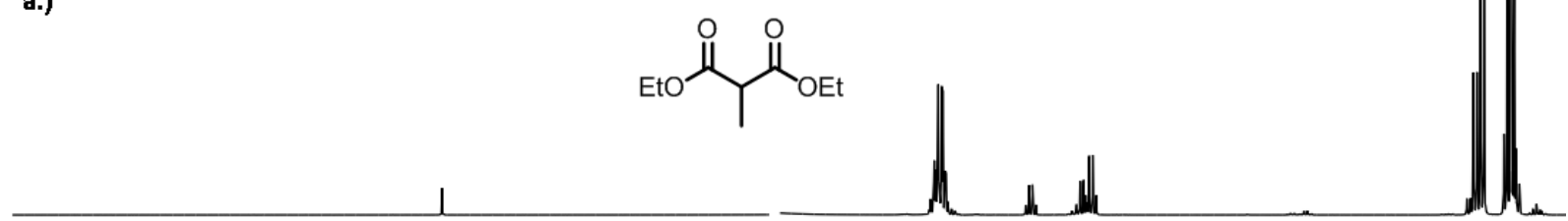

b.)

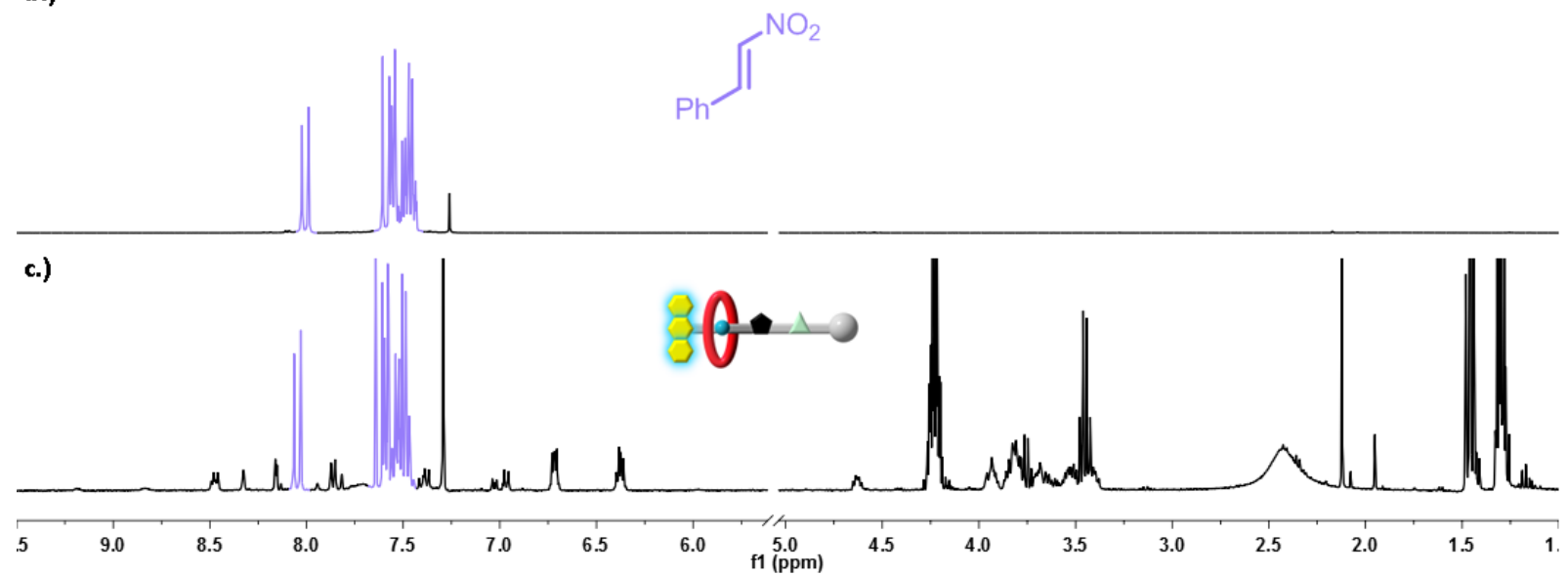

Figure S27 Stack ${ }^{1} \mathrm{H}$ NMR spectrum (400 $\left.\mathrm{MHz}, \mathrm{CDCl}_{3}, 298 \mathrm{~K}\right)$ of: a) diethyl methylmalonate; b) trans- $\beta$-nitrostyrene; c) reaction mixture of diethyl methylmalonate ( 1 equiv), trans- $\beta$-nitrostyrene ( 2 equiv), $\mathbf{1}-\mathrm{H} \cdot \mathrm{PF}_{6}(15 \mathrm{~mol} \%)$, and $\mathrm{NaOAc}(20 \mathrm{~mol} \%)$, after stirring for 5 days. The color-coding of the peaks represents the starting materials. 
<smiles>CCOC(=O)CC(=O)[OH+]c1ccccc1</smiles>

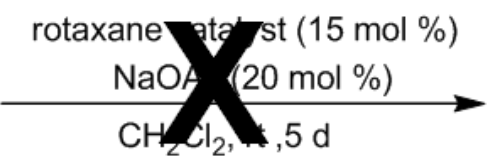<smiles>CCOC(=O)C(C(=O)OCC)C(C[N+](=O)[O-])c1ccccc1</smiles>

a.)<smiles>CCOC(=O)CC(=O)OCC</smiles>

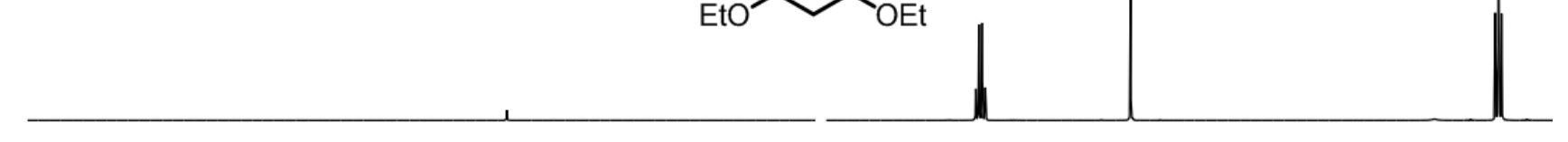

b.)

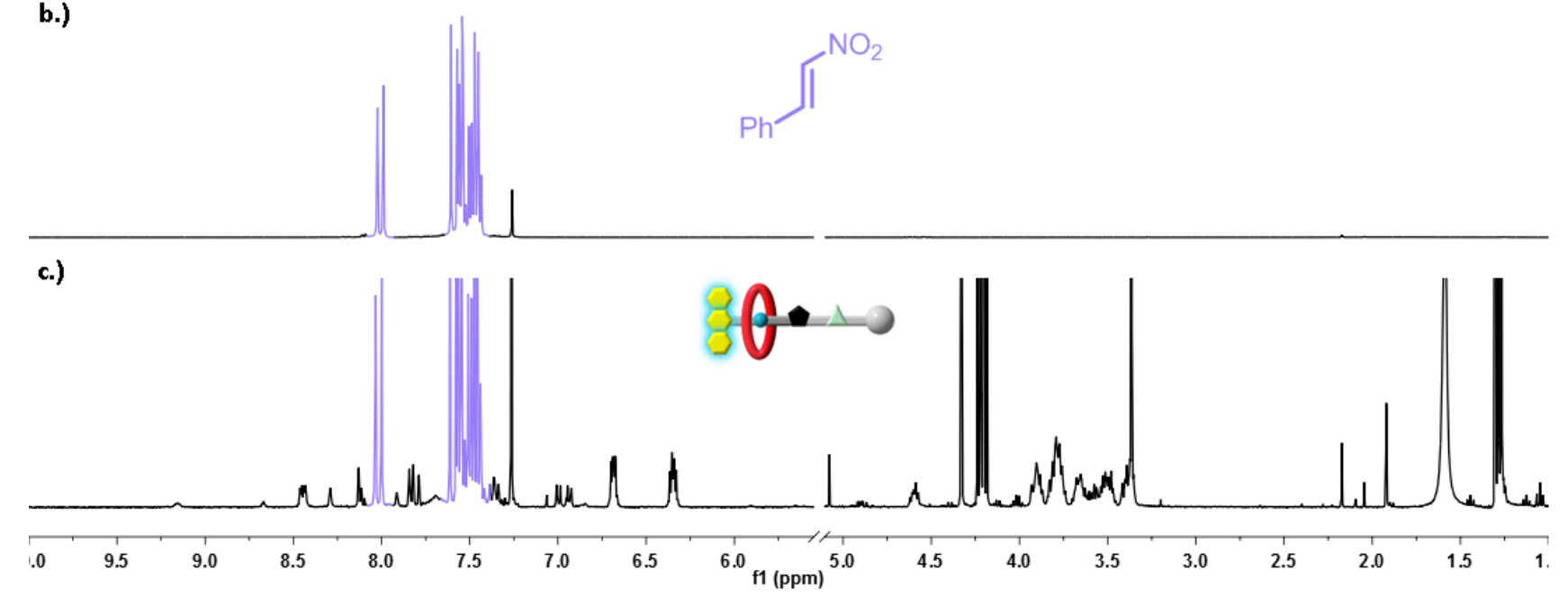

Figure S28 Stack ${ }^{1} \mathrm{H}$ NMR spectrum (400 MHz, $\mathrm{CDCl}_{3}, 298 \mathrm{~K}$ ) of: a) diethylmalonate; b) trans- $\beta$-nitrostyrene; c) reaction mixture of diethylmalonate (1 equiv), trans- $\beta$-nitrostyrene ( 2 equiv), $\mathbf{1}-\mathrm{H} \cdot \mathrm{PF}_{6}(15 \mathrm{~mol} \%)$, and $\mathrm{NaOAc}(20 \mathrm{~mol} \%)$, after stirring for 5 days. The color-coding of the peaks represents the starting materials. 


\section{Kinetics study of selected organocatalysis}

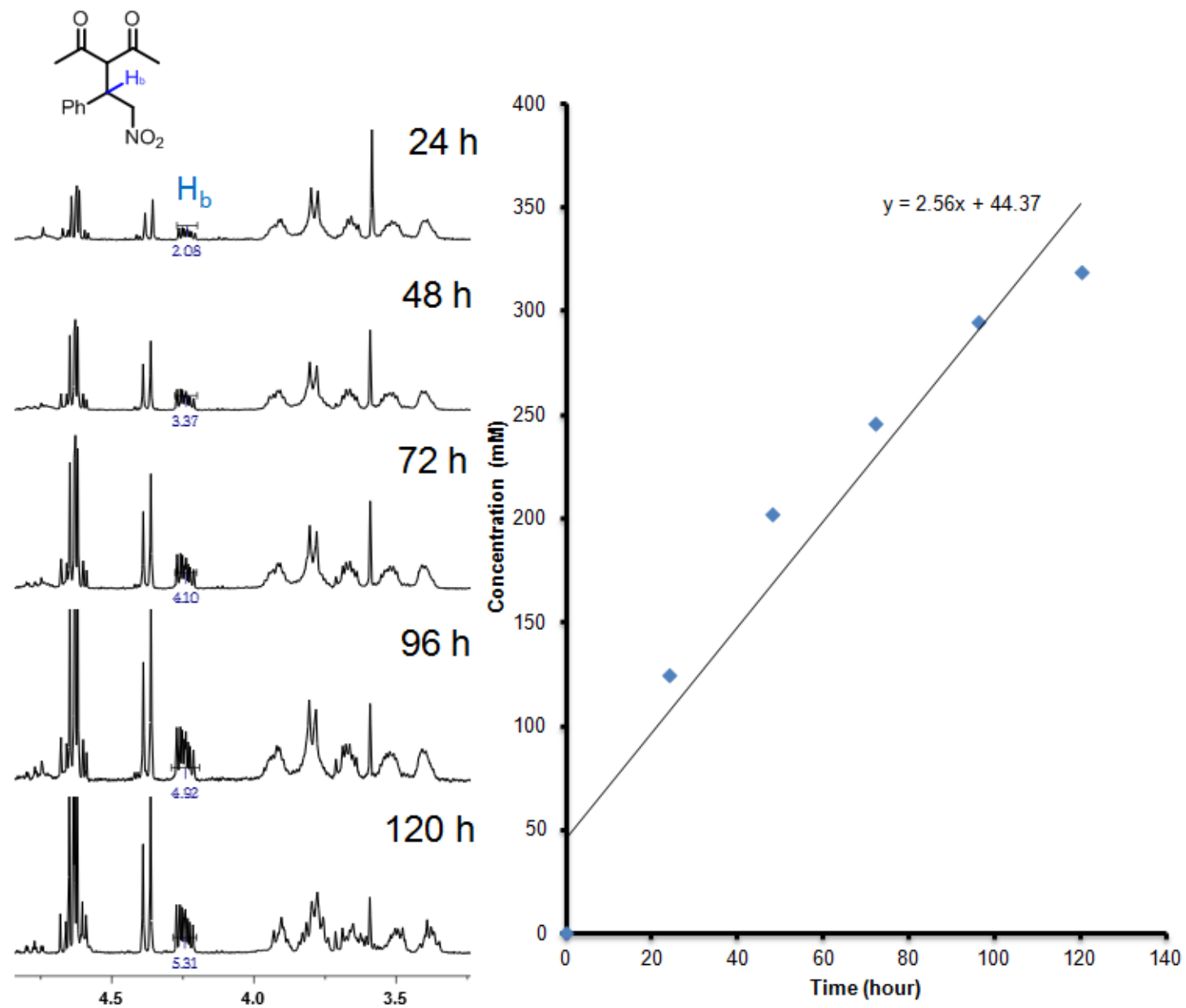

Figure S29 Partial ${ }^{1} \mathrm{H}$ NMR spectrum of entry 1 with respect to time, and the kinetics study of product $\mathbf{E}$. 
<smiles>CC(=O)CC(C)C(C(=O)c1ccccc1)C(=O)c1ccccc1</smiles>
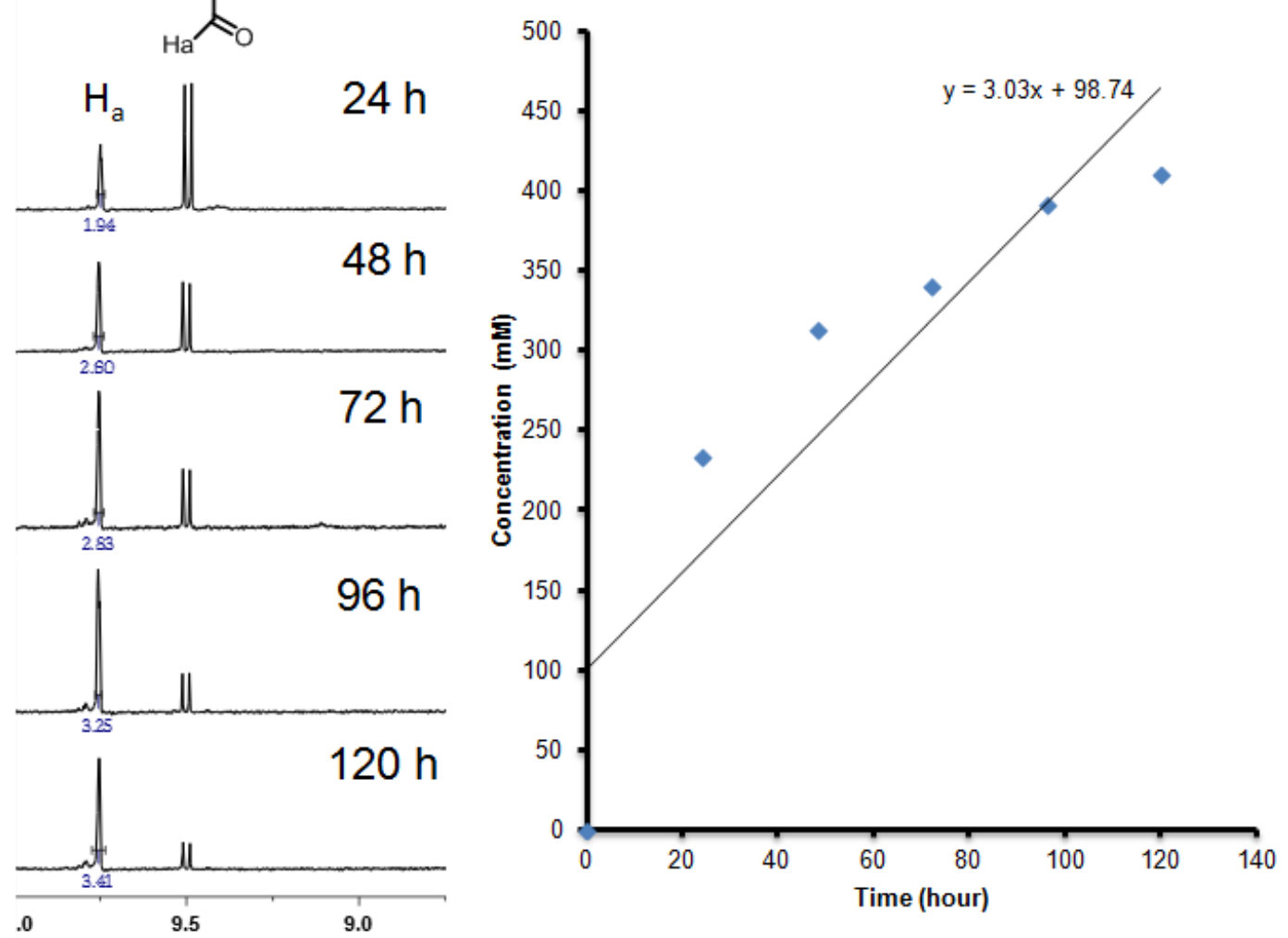

Figure S30 Partial ${ }^{1} \mathrm{H}$ NMR spectrum of entry 6 with respect to time, and the kinetics study of product $\mathbf{H}$.
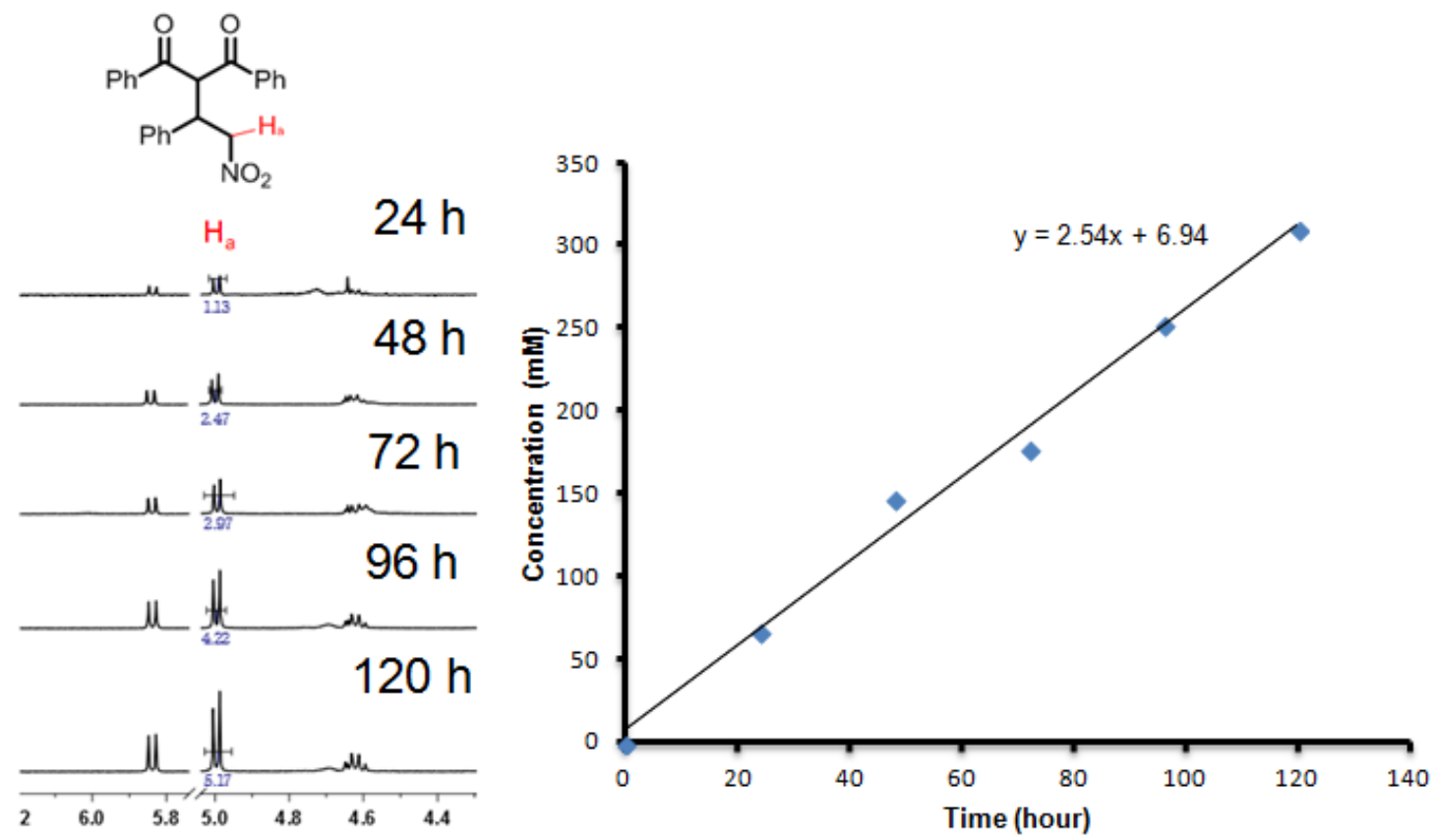

Figure S31 Partial ${ }^{1} \mathrm{H}$ NMR spectrum of entry 9 with respect to time, and the kinetics study of product $\mathbf{F}$. 

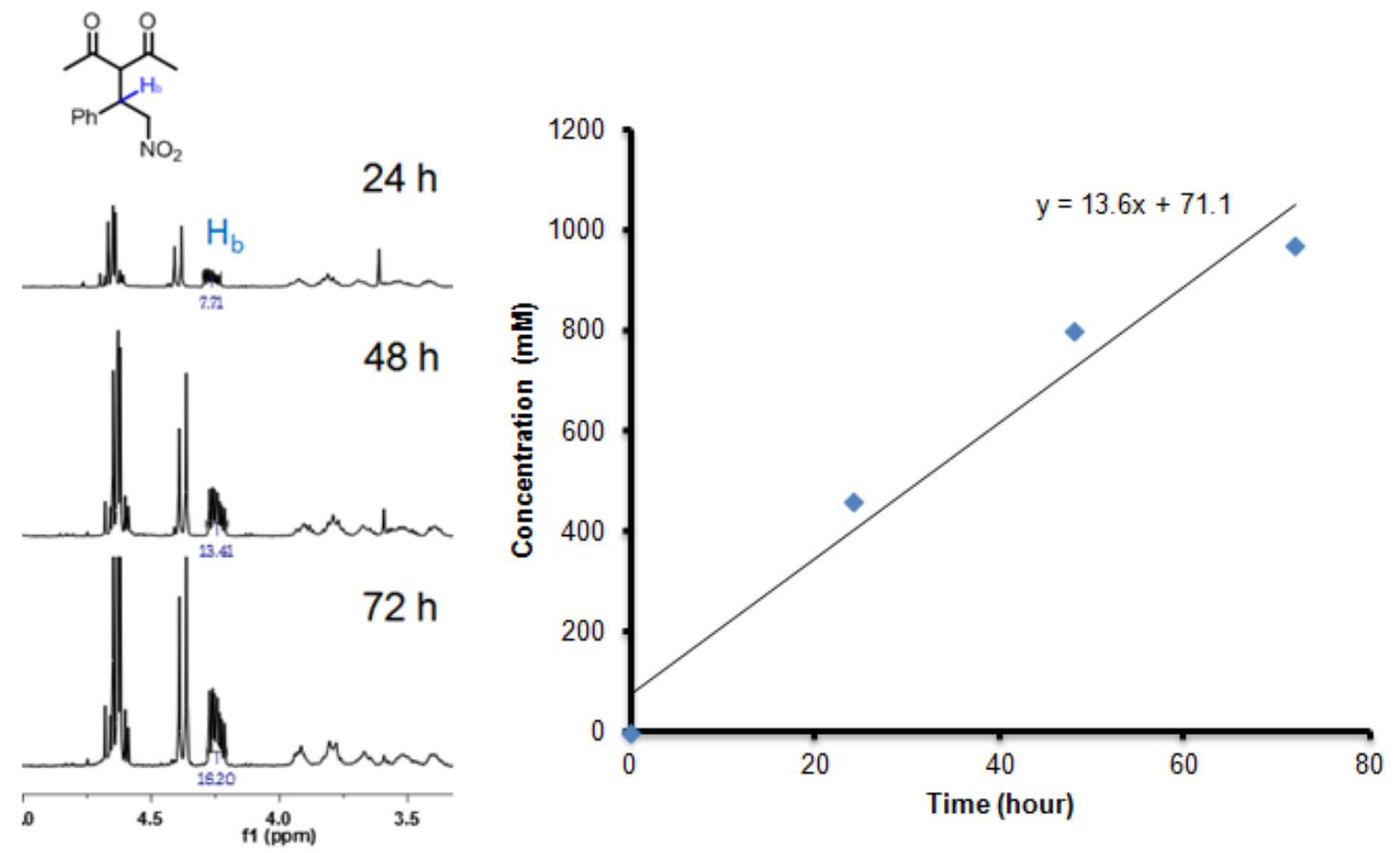

Figure S32 Partial ${ }^{1} \mathrm{H}$ NMR spectrum of entry 11 with respect to time, and the kinetics study of product $\mathbf{E}$.
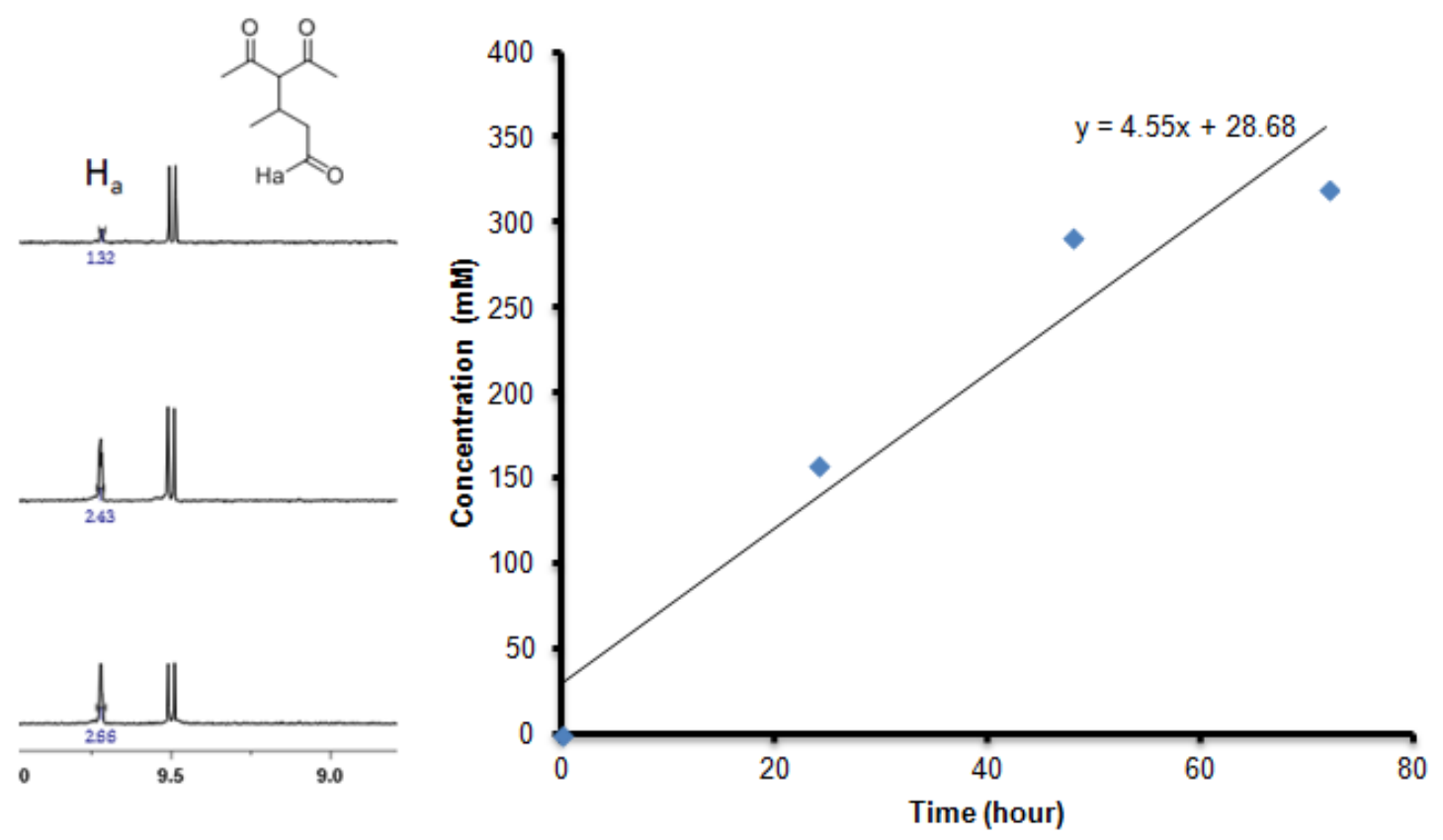

Figure S33 Partial ${ }^{1} \mathrm{H}$ NMR spectrum of entry 12 with respect to time, and the kinetics study of product $\mathbf{G}$. 
NMR Spectra of selected compounds

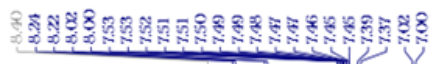

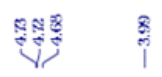

$\sqrt[3]{\sqrt[3]{3}}$

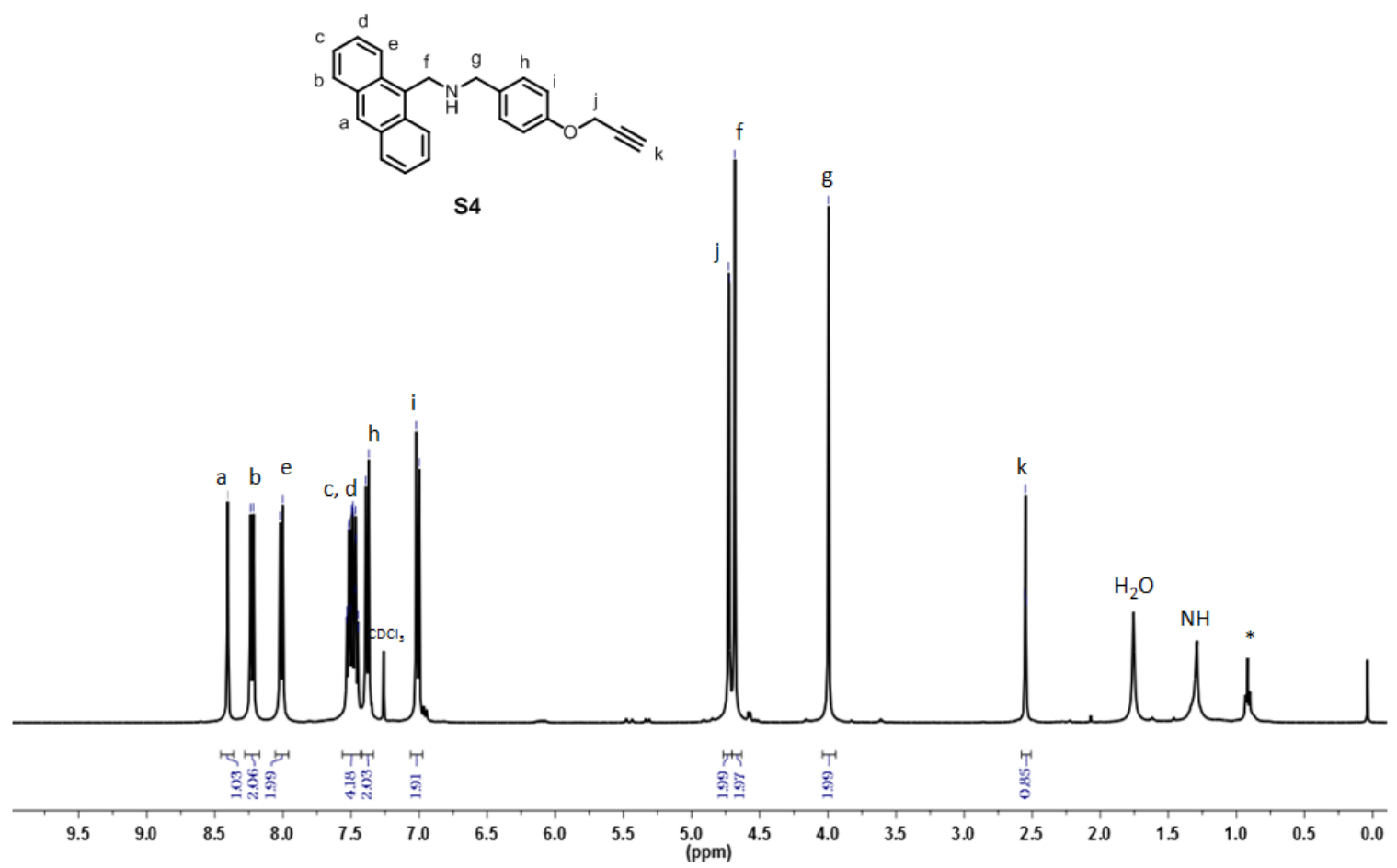

Figure $\mathbf{S 3 4}{ }^{1} \mathrm{H}$ NMR spectrum of ( $\left.400 \mathrm{MHz}, \mathrm{CDCl}_{3}\right) \mathbf{S 4}$ (Asterisk: solvent residual signal).

高

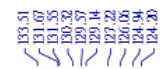

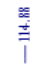

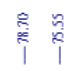

呙

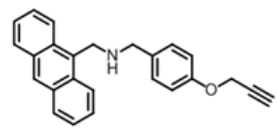

SH
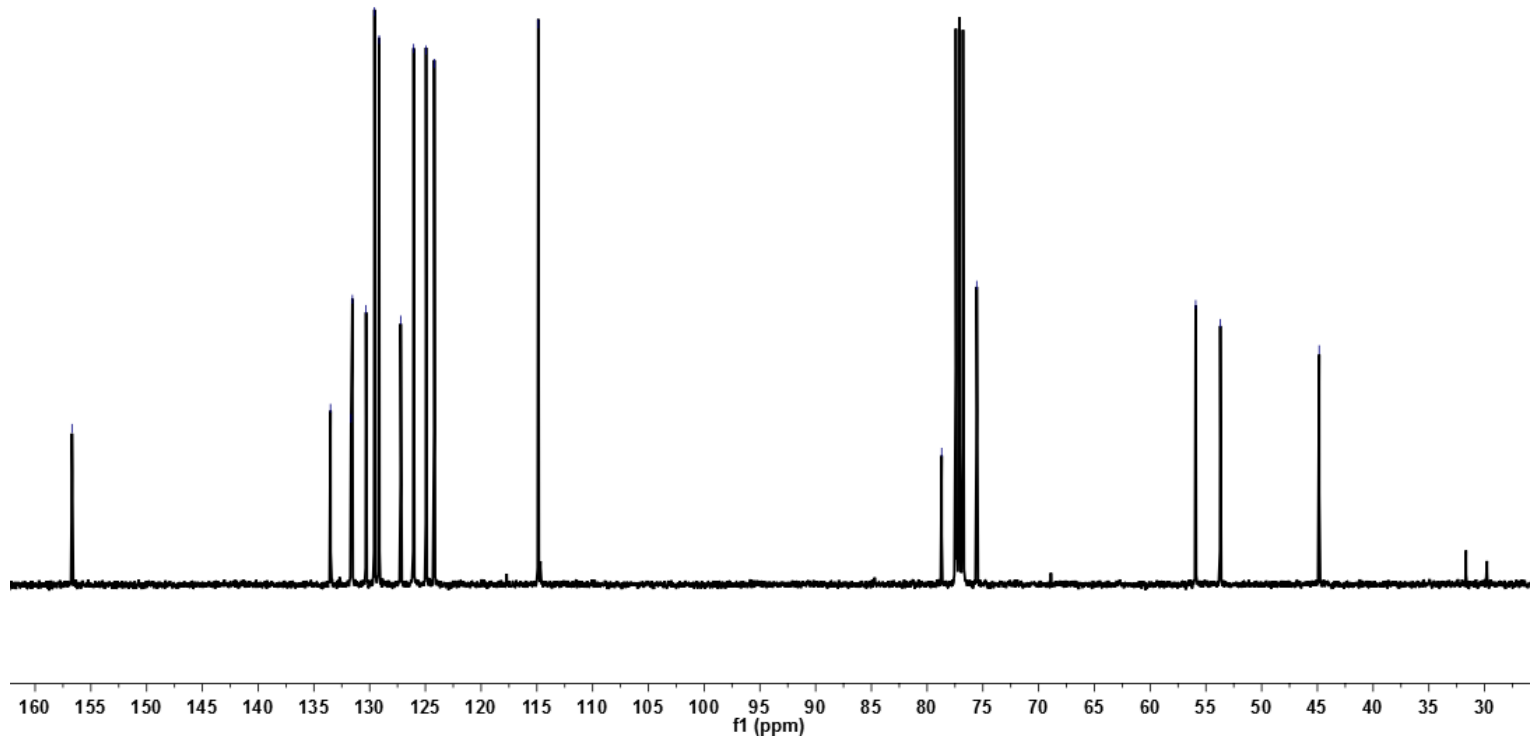

Figure $\mathbf{S 3 5}{ }^{13} \mathrm{C}$ NMR spectrum of (101 MHz, $\left.\mathrm{CDCl}_{3}\right) \mathbf{S 4}$.

S43 


$$
\text { f }
$$
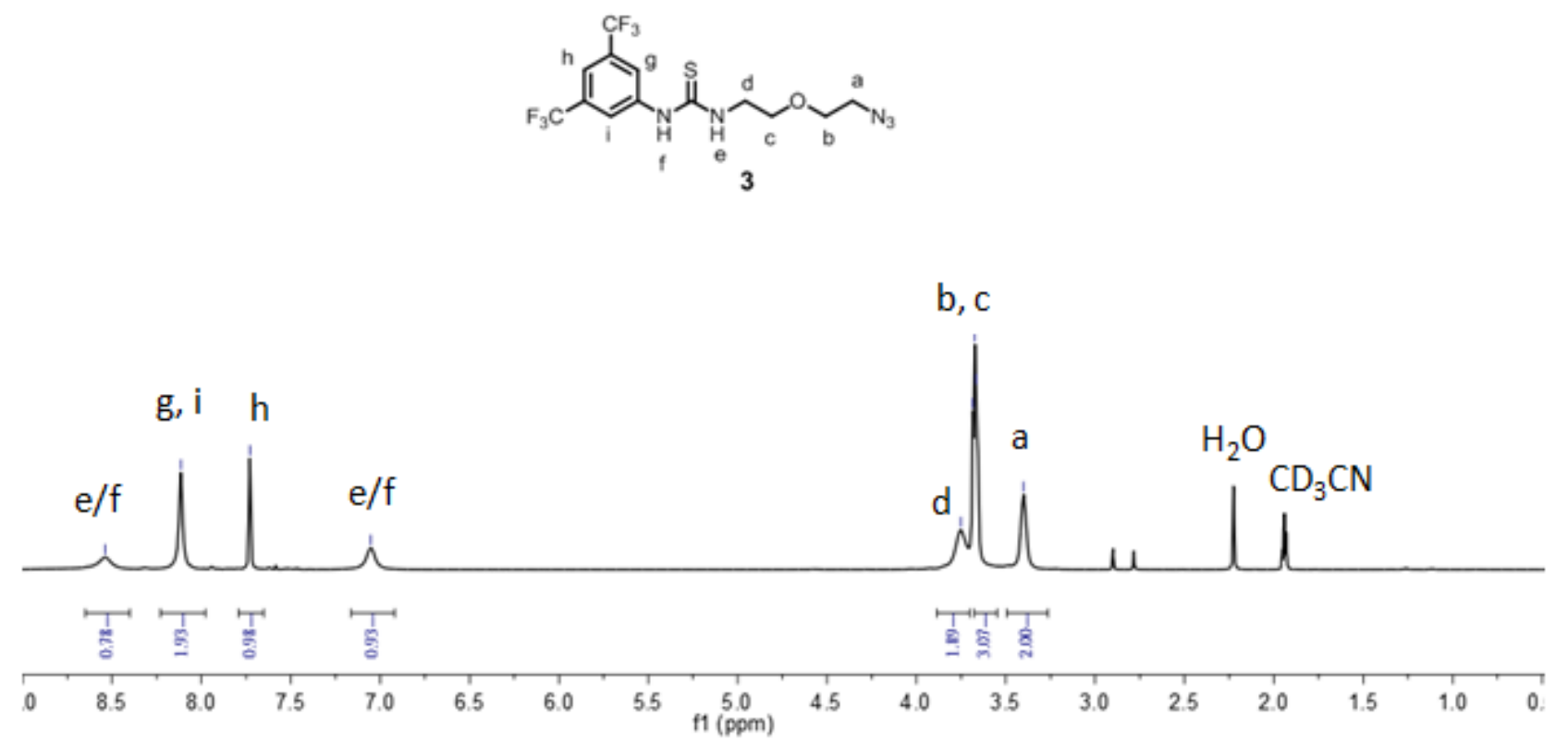

Figure S36 ${ }^{1} \mathrm{H}$ NMR spectrum of (400 MHz, CD $\left.{ }_{3} \mathrm{CN}\right) 3$.

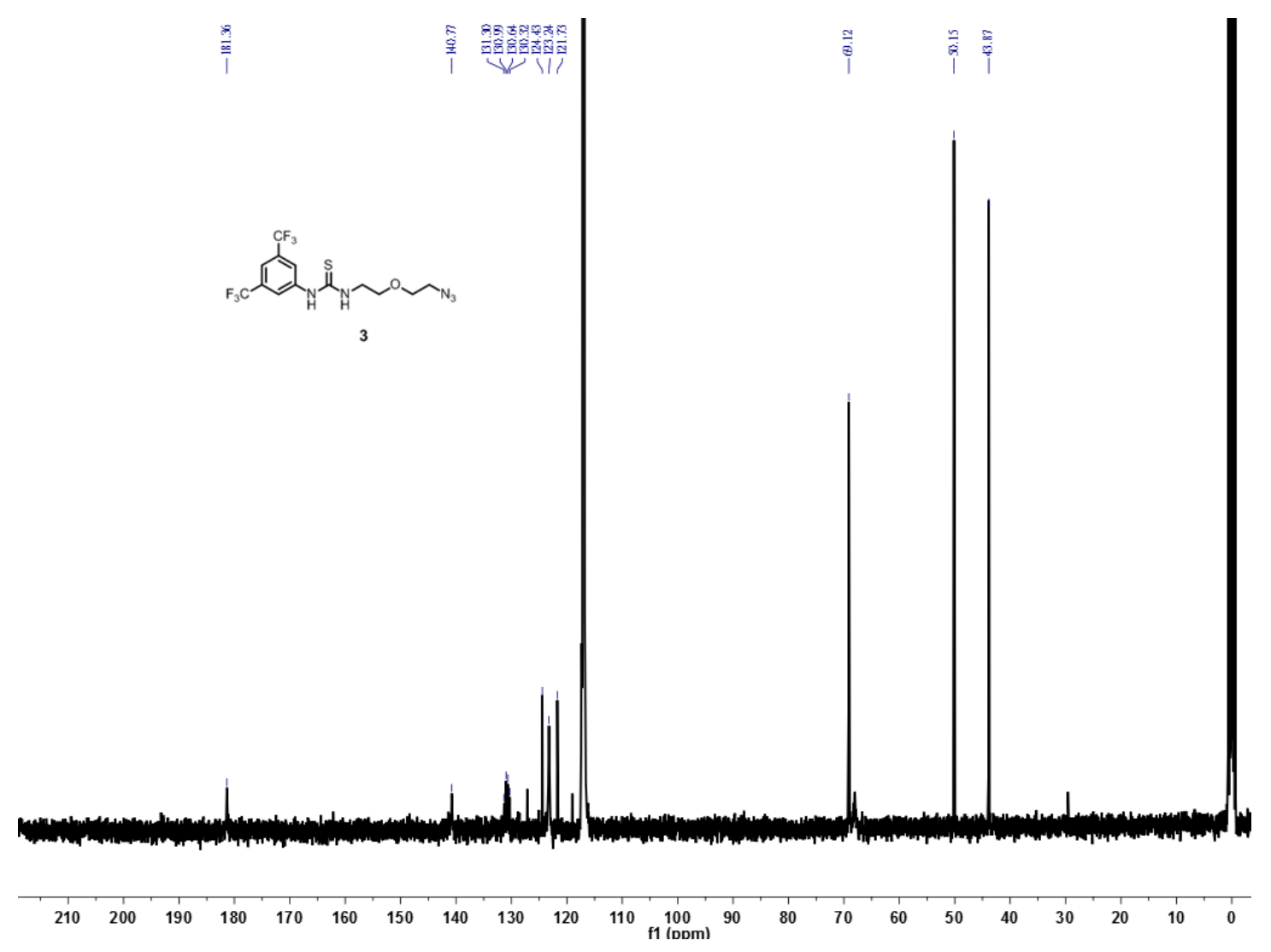

Figure $S 37^{13} \mathrm{C}$ NMR spectrum of $\left(101 \mathrm{MHz}, \mathrm{CD}_{3} \mathrm{CN}\right) 3$. 

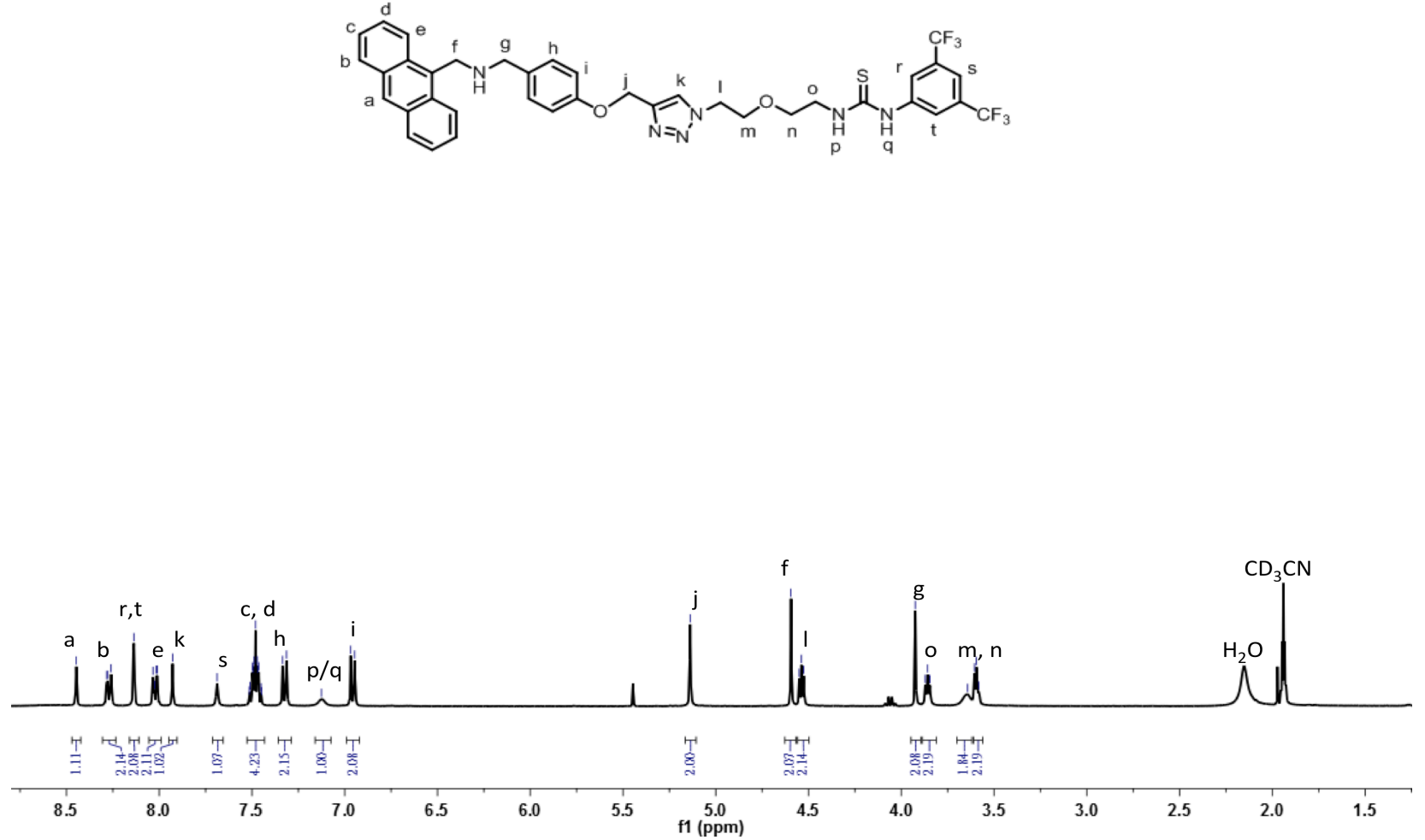

Figure $\boldsymbol{S 3 8}{ }^{1} \mathrm{H}$ NMR spectrum of (400 MHz, CD $\left.{ }_{3} \mathrm{CN}\right) 2$.

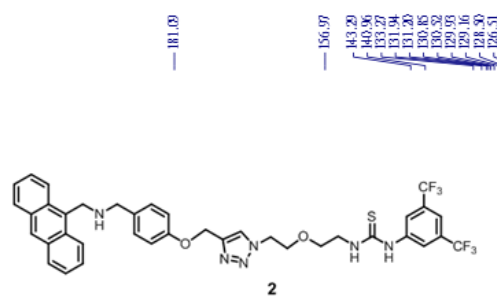

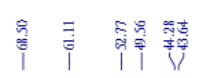

$\begin{array}{llllllllllll}110 & 200 & 190 & 180 & 170 & 160 & 150 & 140 & 130 & 120 & 110 & \begin{array}{c}100 \\ \mathrm{f} 1(\mathrm{ppm})\end{array}\end{array}$

Figure S39 ${ }^{13} \mathrm{C}$ NMR spectrum of $\left(101 \mathrm{MHz}, \mathrm{CD}_{3} \mathrm{CN}\right) 2$. 

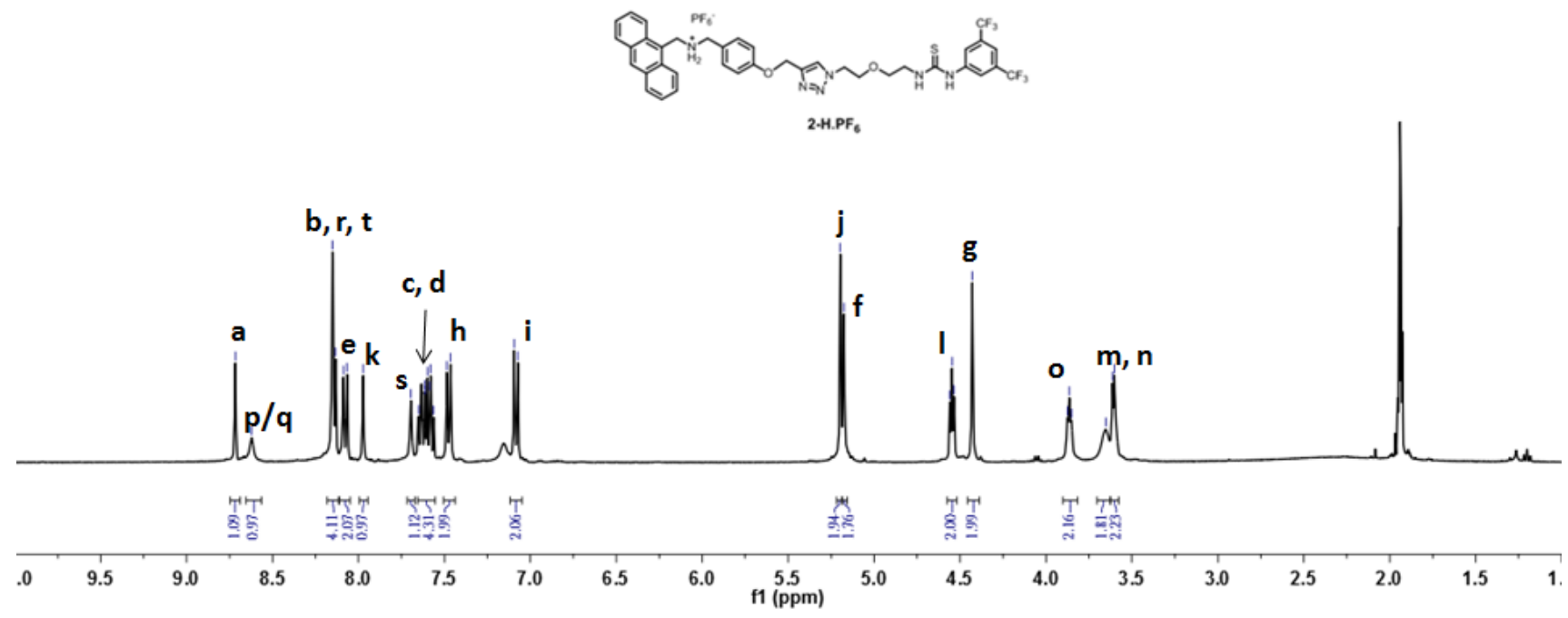

Figure $\boldsymbol{S 4 0}{ }^{1} \mathrm{H}$ NMR spectrum of $\left(400 \mathrm{MHz}, \mathrm{CD}_{3} \mathrm{CN}\right) \mathbf{2}-\mathrm{H} \cdot \mathrm{PF}_{6}$. 


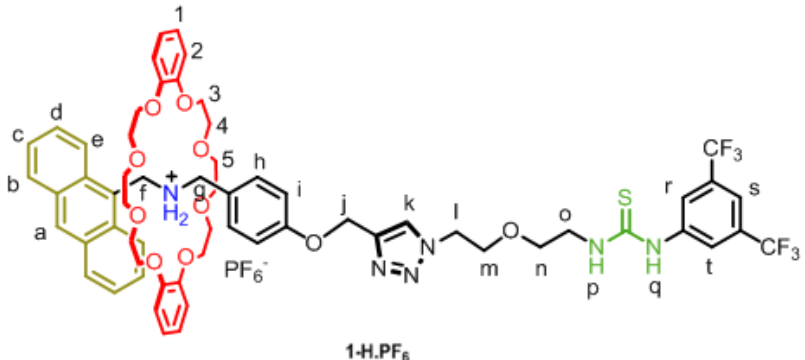

1.H.PF

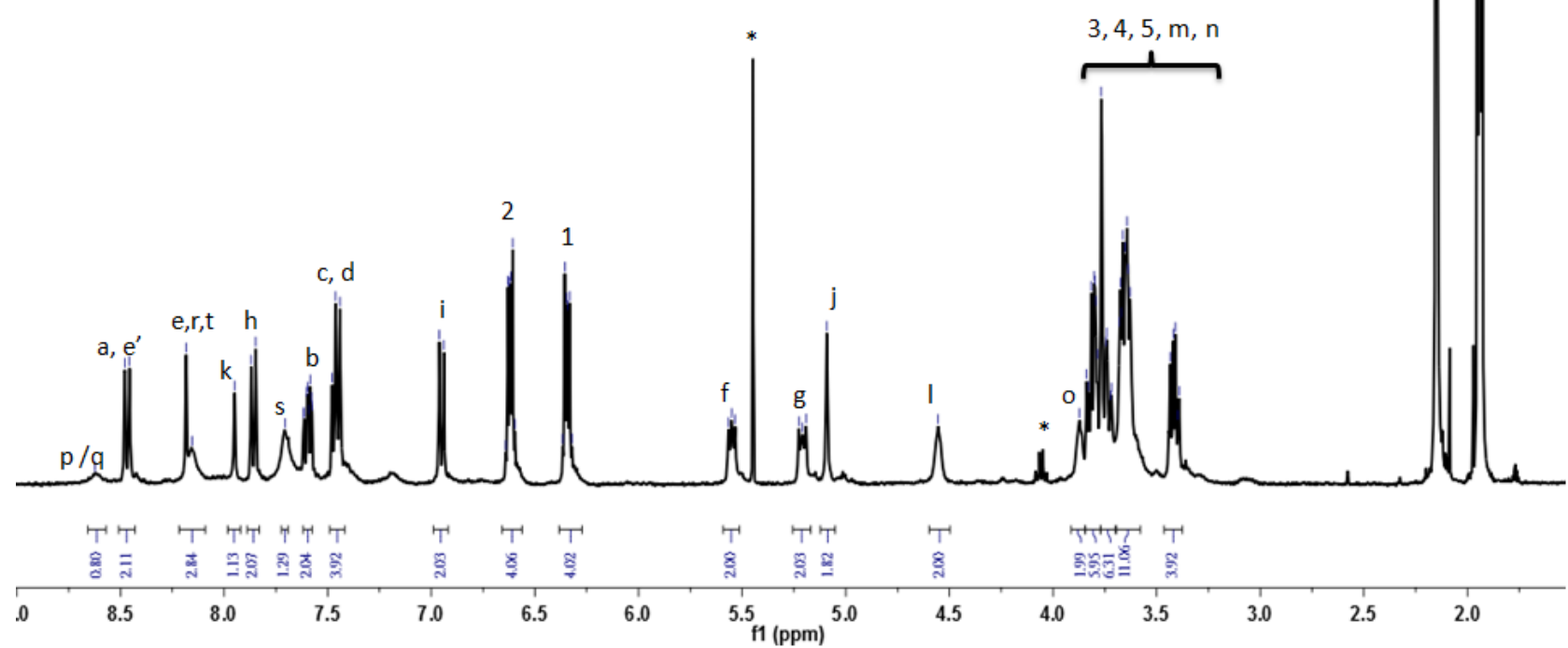

Figure $41{ }^{1} \mathrm{H}$ NMR spectrum of $\left(400 \mathrm{MHz}, \mathrm{CD}_{3} \mathrm{CN}\right) \mathbf{1 - H} \cdot \mathrm{PF}_{6}$ (Asterisk: solvent residual signal)

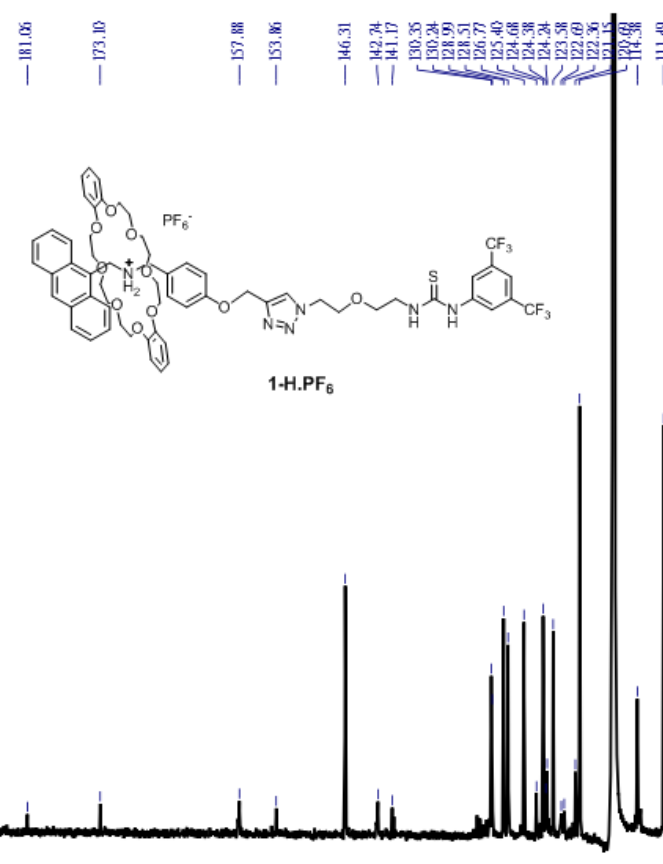

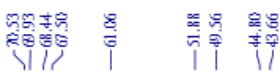

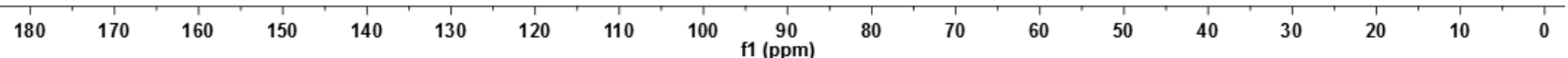

Figure $\mathbf{S 4 2}{ }^{13} \mathrm{C}$ NMR spectrum of $\left(101 \mathrm{MHz}, \mathrm{CD}_{3} \mathrm{CN}\right) \mathbf{1 - H} \cdot \mathrm{PF}_{6}$. 

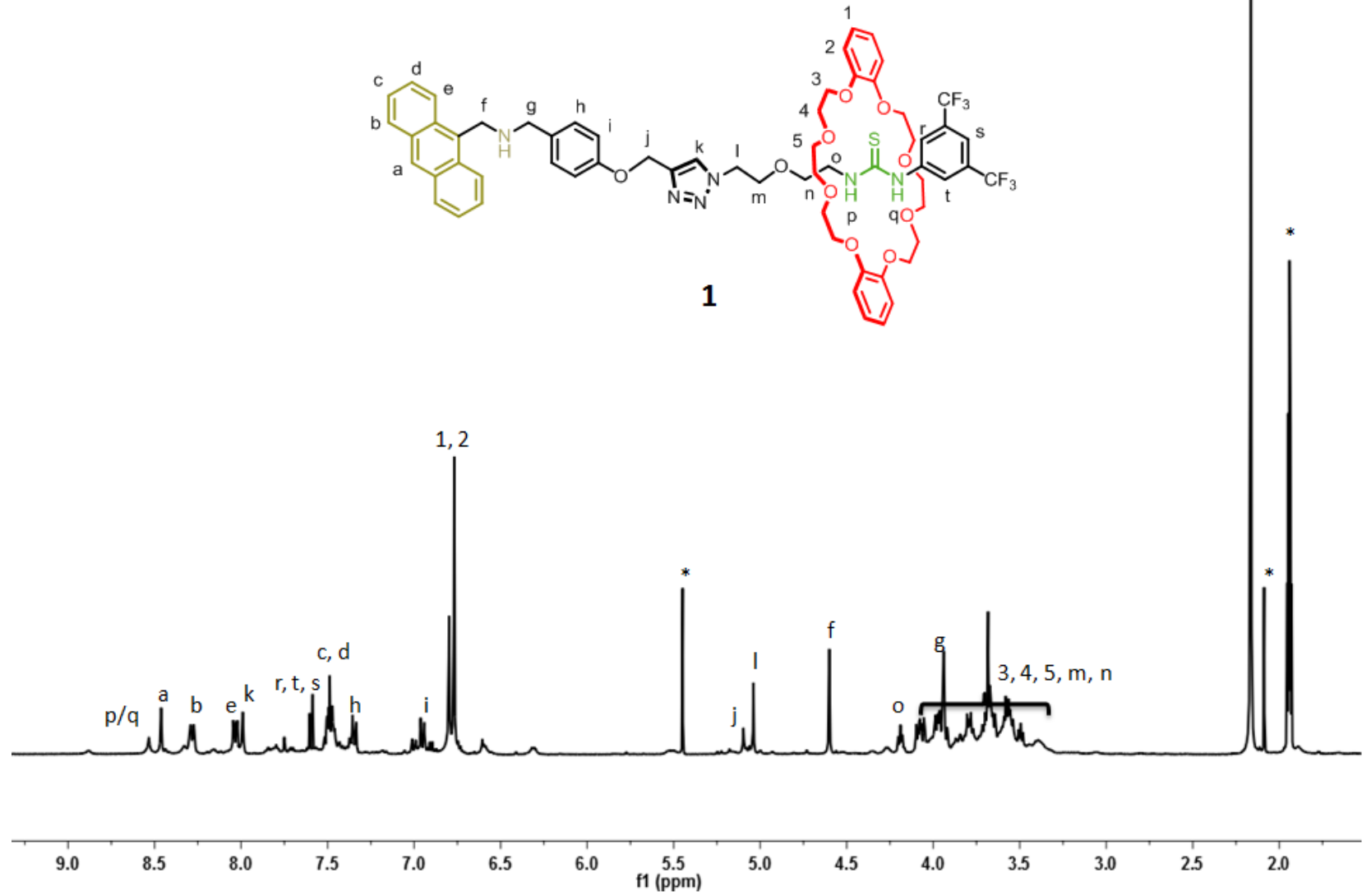

Figure $\boldsymbol{S 4 3}{ }^{1} \mathrm{H}$ NMR spectrum of $\left(400 \mathrm{MHz}, \mathrm{CD}_{3} \mathrm{CN}\right) \mathbf{1}$ (Asterisk: solvent residual signal). 


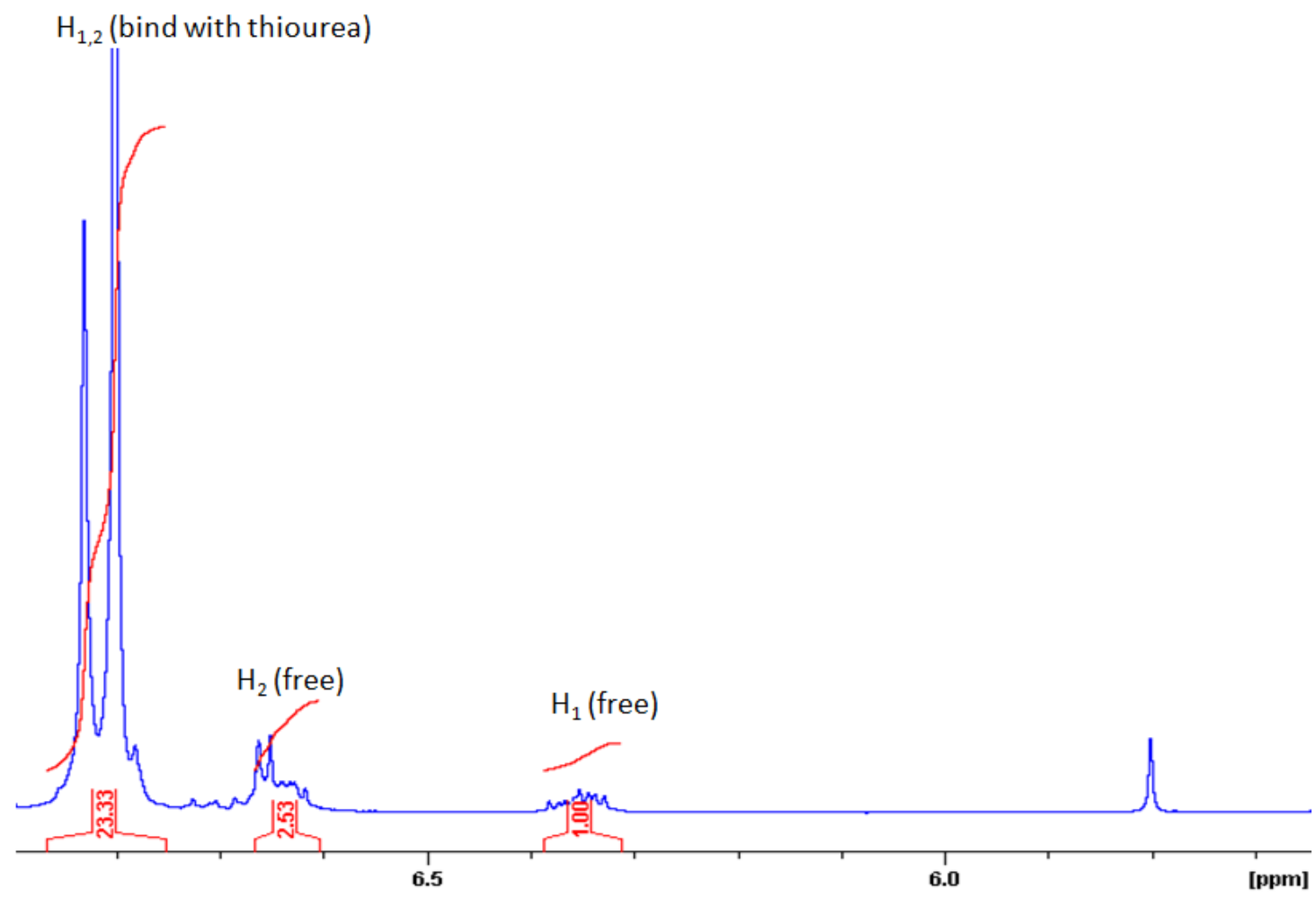

Figure S44 Partial enlarged ${ }^{1} \mathrm{H}$ NMR spectrum of $1\left(\mathrm{CD}_{3} \mathrm{CN}, 20 \mathrm{mM}\right)$ for binding constant determination. The binding constant $K_{a}$ was calculated from the integration ratio of $\mathrm{H}_{1}$ and $\mathrm{H}_{2}$ (bound and free) of DB24C8's aryl proton binding with thiourea, whereas $K_{a}=5029 \mathrm{M}^{-1}$. 
Mass Spectra of selected compounds

HONG KONG BAPTIST UNIVERSITY, DEPARTMENT OF CHEMISTRY (MALDI-TOF)
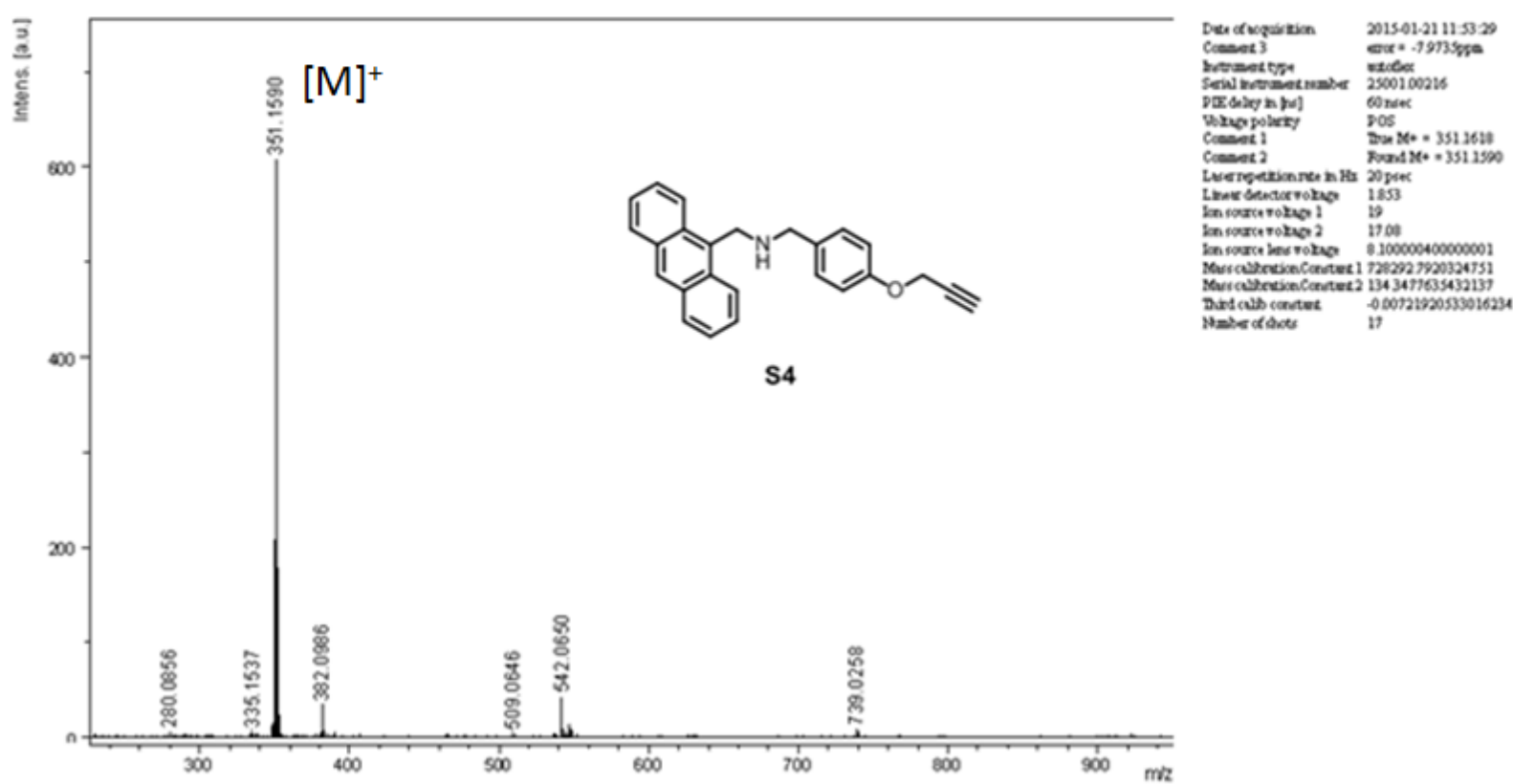

Figure S45 HRMS (MALDI-TOF) of S4.

\section{HONG KONG BAPTIST UNIVERSITY, DEPARTMENT OF CHEMISTRY (MALDI-TOF)}
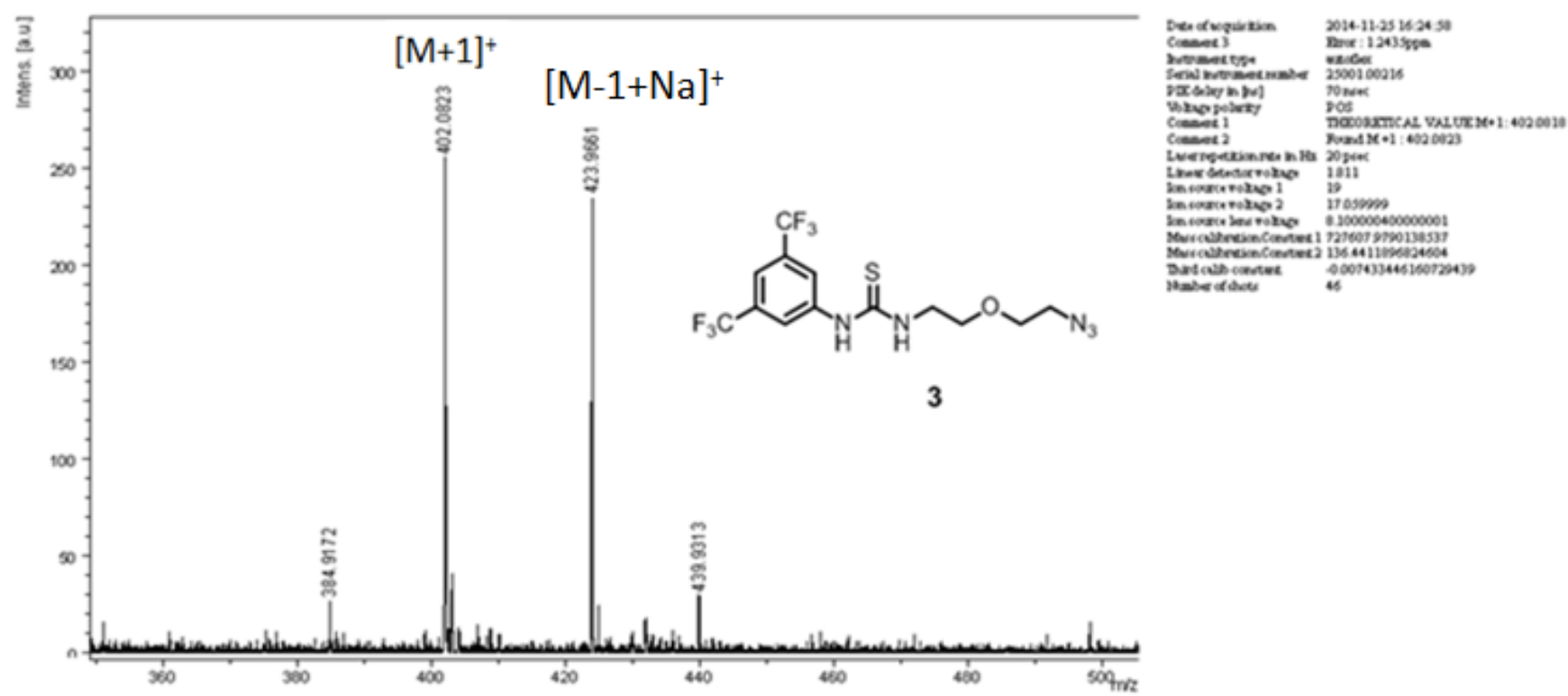

Figure S46 HRMS (MALDI-TOF) of 3. 


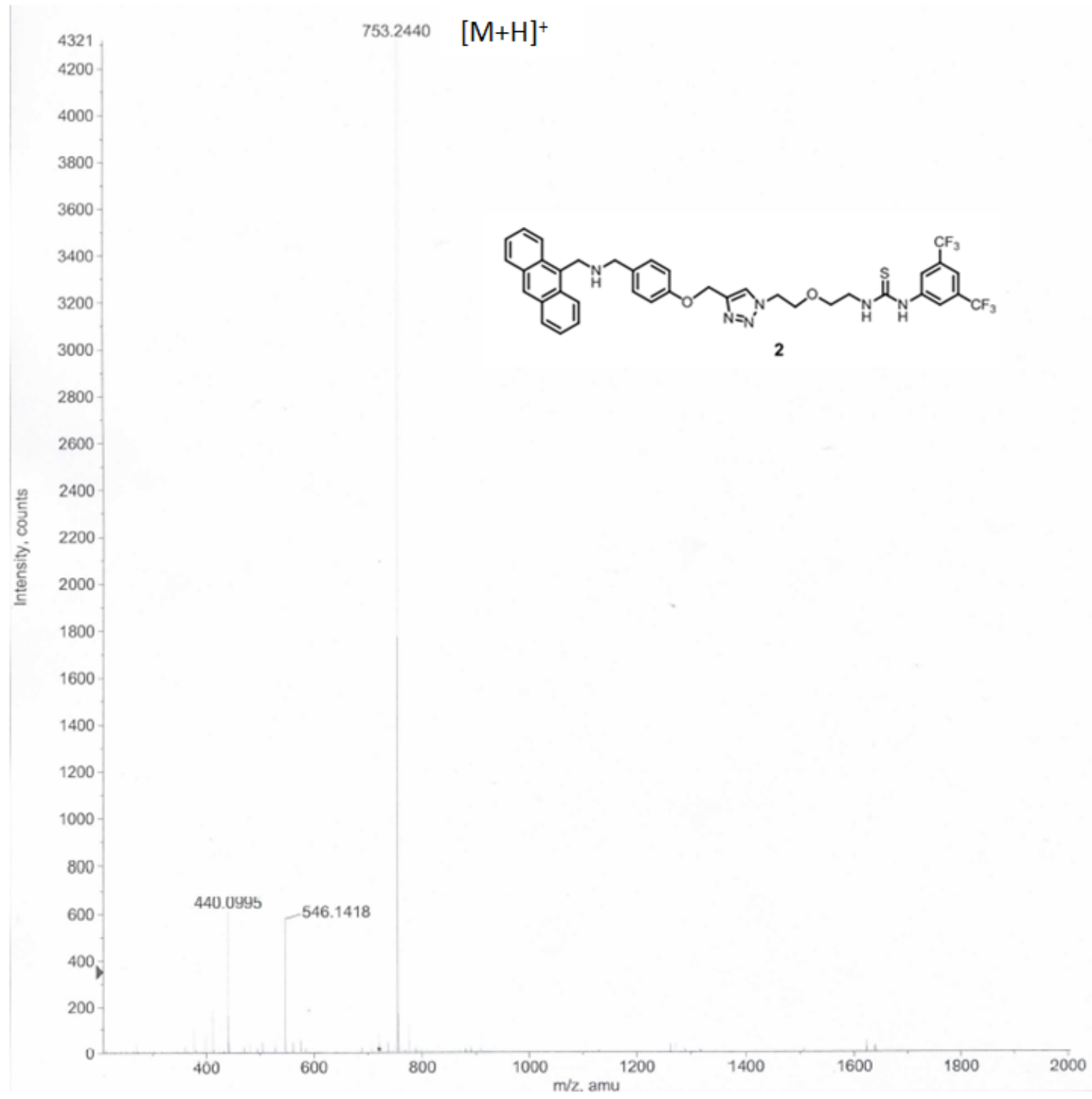

Figure S47 HRMS (ESI) of 2.

S51 


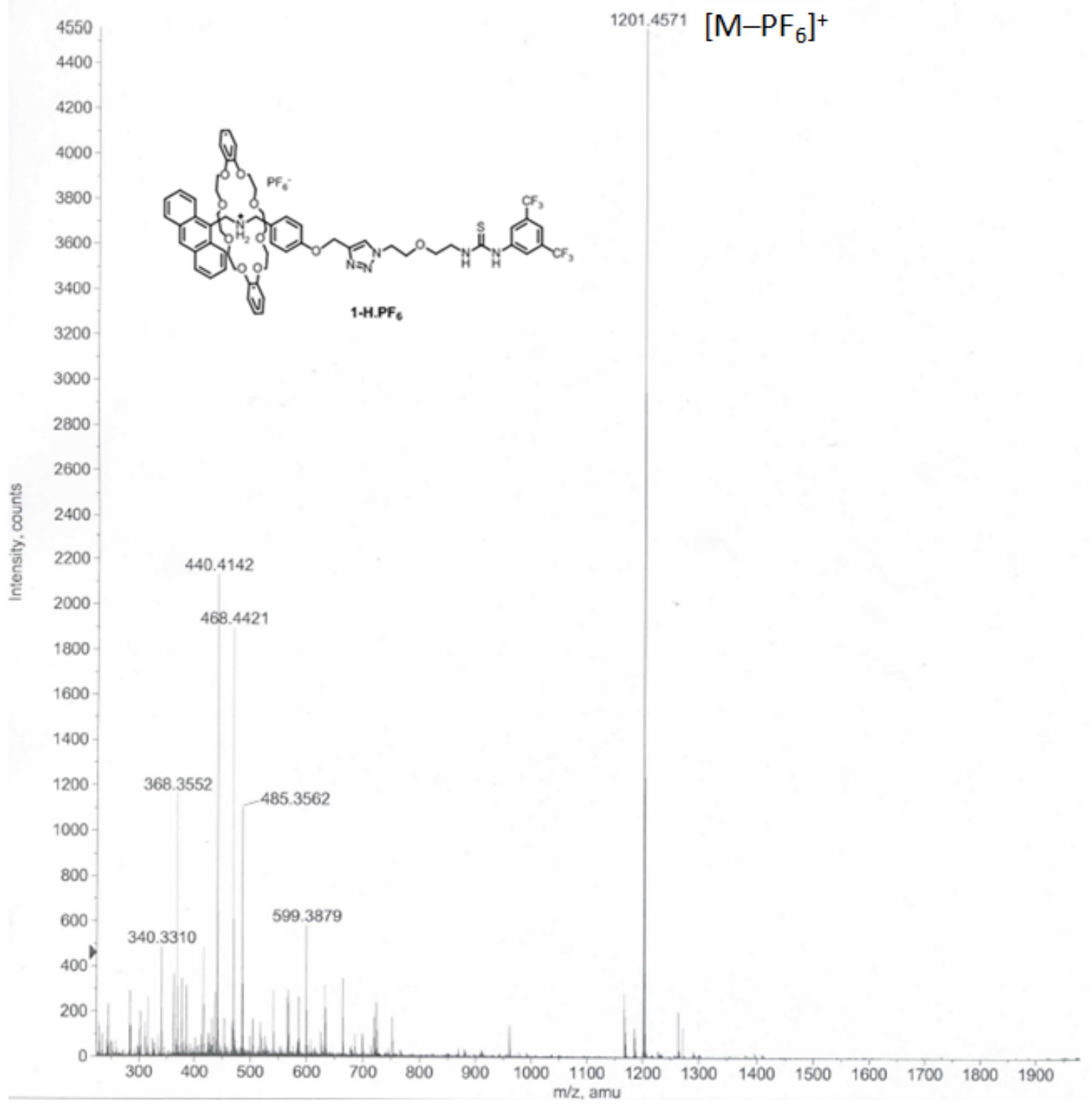

Figure $\boldsymbol{S 4 8} \mathrm{HRMS}(\mathrm{ESI})$ of $\mathbf{1}-\mathrm{H} \cdot \mathrm{PF}_{6}$. 


\section{Notes and References}

S1. Z. J. Zhang, H. Y. Zhang, H. Wang, Y. Liu, Angew. Chem. Int. Ed. 2011, 46, 10834-10838.

S2. A. R. Bogdan, N. L. Davies, K. James, Org. Biomol. Chem. 2011, 9, 7727-7733.

S3. F. F. Naciuk, D. Z. Vargas, R. M. D. Caroline, C. C. Moro, D. Russowsky, New J. Chem. 2015, 39, 1643-1653.

S4. S. P. Lathrop, T. Rovis, J. Am. Chem. Soc. 2009 131, 13628-13630.

S5. J. Beswick, V. Blanco, G. D. Bo, D. A. Leigh, U. Lewandowska, B. Lewandowski, V. Marcos, J. Am. Chem. Soc. 2014, 136, 15775-15780.

S6. J. Beswick, V. Blanco, G. D. Bo, D. A. Leigh, U. Lewandowska, B. Lewandowski, K. Mishiro, Chem. Sci. 2015, 6, 140-143.

S7. S. Garaudée, S. Silvi, M. Venturi, A. Credi, A. H. Flood and J. F. Stoddart, ChemPhysChem, 2005, 6, 2145-2152.

S8. K. Gönczi, V. Kudar, Z. Jászay, P. Bombicz, F. Faigl, J. Madarász, Thermochimica Acta, 2014, 580, 46-52. 